\title{
Advances in fatty acids nutrition in dairy cows: from gut to cells and effects on performance
}

\author{
Massimo Bionaz $^{1^{*}}$ (D), Einar Vargas-Bello-Pérez ${ }^{2}$ and Sebastiano Busato ${ }^{1}$
}

\begin{abstract}
High producing dairy cows generally receive in the diet up to $5-6 \%$ of fat. This is a relatively low amount of fat in the diet compared to diets in monogastrics; however, dietary fat is important for dairy cows as demonstrated by the benefits of supplementing cows with various fatty acids (FA). Several FA are highly bioactive, especially by affecting the transcriptome; thus, they have nutrigenomic effects. In the present review, we provide an up-to-date understanding of the utilization of FA by dairy cows including the main processes affecting FA in the rumen, molecular aspects of the absorption of FA by the gut, synthesis, secretion, and utilization of chylomicrons; uptake and metabolism of FA by peripheral tissues, with a main emphasis on the liver, and main transcription factors regulated by FA. Most of the advances in FA utilization by rumen microorganisms and intestinal absorption of FA in dairy cows were made before the end of the last century with little information generated afterwards. However, large advances on the molecular aspects of intestinal absorption and cellular uptake of FA were made on monogastric species in the last 20 years. We provide a model of FA utilization in dairy cows by using information generated in monogastrics and enriching it with data produced in dairy cows. We also reviewed the latest studies on the effects of dietary FA on milk yield, milk fatty acid composition, reproduction, and health in dairy cows. The reviewed data revealed a complex picture with the FA being active in each step of the way, starting from influencing rumen microbiota, regulating intestinal absorption, and affecting cellular uptake and utilization by peripheral tissues, making prediction on in vivo nutrigenomic effects of FA challenging.
\end{abstract}

Keywords: Absorption, Dairy cow, Dietary fatty acids, Intestine, Liver, Metabolism, Performance, Transcription factors, Transport

\section{Introduction}

Important advances in the understanding of overall lipid digestion, absorption, and metabolism in dairy cows has been made between 1950 to 1990; afterwards, due to technological advances, a larger emphasis was placed on determining the molecular aspects of those processed. Furthermore, before the 1990's, the effect fatty acids (FA) on transcription of genes was virtually unknown.

\footnotetext{
*Correspondence: massimo.bionaz@oregonstate.edu

'Department of Animal and Rangeland Sciences, Oregon State University, Corvallis, OR 97331, USA

Full list of author information is available at the end of the article
}

Discovery of transcription factors (TF) that sense the presence of lipids, especially FA, and the advances in the understanding of biological effects of FA in many pathways and functions in cells, have provided a great window into the biological roles of FA. Borrowing methods and knowledge obtained from monogastric species, especially model organisms, advances were made on our knowledge on the molecular processes related to the metabolism and biological functions of lipid molecules in dairy cows.

Different from monogastric species, ruminants generally receive a low amount of lipids into the diet. It is 
common practice in nutrition of dairy cows to provide no more than $6 \%$ of lipids (>90\% FA) in the diet, with around 3\% coming from the forages and grains, and the rest added as supplemental fat. Different than monogastrics where dietary FA arrive to the intestine with no modifications, the presence of the rumen with the high microbial activity, substantially modify FA, especially unsaturated FA (UFA); thus, the need of supplementing dairy cows rumen-protected FA. A recent review about the historical prospect and importance of feeding fat to dairy cows, especially rumen-protected FA, is available elsewhere [1]. The supplementation of fat has positive effects on the performance of dairy cows, as observed with UFA (if rumen protected) [2] and saturated FA (SFA), especially C16:0 and C18:0 [3]. The observed positive effects of supplementing rumen-protected fat to dairy cows goes beyond the increased level of energy in the diet; however, this additional effect remains largely unexplained and can be considered a "black box" in molecular nutrition and physiology of dairy cows.

Nutrigenomics is a relatively new branch of science in dairy cows with the underline hypothesis that feedstuffs contain compounds that directly affect transcription of genes via binding of specific TF [4]. In this contest, few are the TF that can be modulated by FA [4]. Among those, the peroxisome-proliferator-activate receptors (PPAR) and Sterol regulatory element-binding protein (SREBP) have been studied extensively in ruminants, as previously reviewed $[4,5]$. Besides TF also free fatty acid receptors are emerging as important player in the transcriptomic response to FA. Nutrigenomics is thus of importance in dairy cows when considering the observed beneficial effects of dietary FA. The possibility of finely modulating specific TF by dietary FA hold a great promise in improving animal health and performance, but also improving milk quality $[4,6,7]$.

The application of nutrigenomic approaches by supplementing dairy cows with FA requires understanding at molecular level of all the processes of FA in dairy cows once ingested, from the digestion, absorption, and transport in circulation to cellular uptake and effects in peripheral tissues. Here we attempt to provide an up-todate review of all those aspects with the intent to contribute to shine some light into the nutrigenomic use of dietary FA in dairy cows and their effects on the biology of dairy cows. Furthermore, we cover the latest effects of supplementing FA on performance and health of dairy cows.

\section{Fate of dietary lipids in the rumen}

Excellent comprehensive reviews about the digestion, absorption and transport of lipids in ruminant animals were provided more than 20 years ago by Noble [8], Jenkins [9], and Harfoot and Hazlewood [10]. More recent reviews have covered lipid metabolism in the rumen [11, 12] and very little advances have been made since the publications of those reviews.

From the point of view of nutrition of ruminants, it is important to highlight that forages contain around $2 \%$ lipids, mostly in the form of galactosyldiglycerides and phospholipids, with minor amount of tri- and diglycerides. The most abundant FA present in forages are C18:3 (60-70\%) and C18:2 ( 20\%). Triglycerides (TAG) are instead the most abundant form of lipids when seedderived products are fed to dairy cows [13]. Lipids in the rumen, when released via mastication and microbiota activity, undergo two major processes: lipolysis and biohydrogenation [12].

\section{Lipolysis}

The lipolysis of esterified FA in the rumen is performed by lipases released by rumen bacteria, mainly Anaerovibrio lipolytica $[10,12,13]$ that break down mostly TAG, and Butyrivibrio spp. responsible for hydrolysis of phospho- and galacto-lipids, but also by lipases present in fresh plant materials. Those lipases remain active for up to $5 \mathrm{~h}$ in the rumen [13]. A characterization of the lipases present in bacteria using a combination of a genomic approach and expression of recombinant proteins identified three lipases in Anaerovibrio lipolyticus with high activity toward MCFA, particularly C8:0, C10:0, and C12:0 [14]. Interestingly, the relative abundance of those bacteria increases early post-partum when the diet is enriched with large amount of fat, such as cottonseed and rumen inert fat [15]. In addition, galactosidases and phospholipases from the plants participate to the release of FA and the use of FA to produce energy by rumen microbes is minimal, manly by protozoa [9].

\section{Biohydrogenation}

The FA released by lipolysis are rapidly and almost completely hydrogenated by the action of bacteria isomerases followed by the activity of reductases [9]. The attachment of FA to food particles in the rumen increases biohydrogenation, while bacteria adherent to particles tend to accumulate more UFA and protect them from biohydrogenation [10]. More than $60 \%$ of free FA are adsorbed onto the surface of the feed particles present in the rumen [9]. Protozoa in the rumen play a role in accumulation of dietary FA as lipid droplets in their cells. Protozoa appears also to accumulate and provide between $30 \%$ and $40 \%$ of ruminal outflow of biohydrogenation intermediates, such as conjugated linoleic acids (CLA) and vaccenic acid [13].

As reviewed by others [10-12], there are several types of bacteria that can induce biohydrogenation of UFA in the rumen. The biohydrogenation of UFA requires the presence of a free carboxyl group. Due to the pathway 
involved in biohydrogenation, the main CLA escaping the rumen are cis-9, trans-11 and trans-9, trans-11 while trans-11 is the most abundant from C18:1, but many more positional and geometric isomers of CLA outflow the rumen and are present in milk of dairy cows [11, 16]. A very recent study demonstrated that PUFA esterified to more complex lipids, such as phospholipids and cholesterol esters proportionally abundant in forages, are less prone to biohydrogenation compared to PUFA esterified to TAG, abundant in seeds and derived oil [17]. Findings from that study can have important implication in feeding dairy cows to increase enrichment of PUFA in milk.

The large biohydrogenation of UFA in the rumen is the major impediment to enrich cattle products with UFA, especially poly-unsaturated FA (PUFA) [13]. Several techniques have been developed to protect FA from rumen biohydrogenation, including encapsulating FA in a matrix of protein treated with formaldehyde, production of calcium soap, heat treatment, or conversion of FA to fatty acyl amide $[1,9]$. The protection of FA from rumen microbiota is however only partial [18].

\section{Lipids leaving the rumen}

Around 20\% of lipids leaving the rumen are of microbial origin (or an estimated $15 \mathrm{~g} / \mathrm{kg}$ of organic matter in animals not receiving lipid supplement [9]), mainly bacteria and protozoa. Of those, around $70 \%$ are neutral lipids produced by microorganisms partly via de novo synthesis using acetate and glucose to produce even-chain FA, mostly C18:0 and C16:0 at a ratio of 2:1, and propionate for the synthesis of odd-chain FA, such as C13:0, C15:0, and C17:0 [9] with minor amounts of rumen biohydrogenation intermediates [10].

\section{Volatile fatty acids and their contribution to lipid metabolism in dairy cows}

Forty years ago it was very well-established that rumen microbes produce volatile fatty acids (VFA) that are chiefly absorbed by the epithelium of the rumen and of the omasum ( $>70 \%$ of all the produced VFA) [8]. Among VFA, acetate (60-70\% of all VFA) and the butyrate-derived $\beta$-hydroxybutyrate (BHBA) are the main precursors for de novo synthesis of FA in peripheral tissues, with a minor role of propionate for the synthesis of odd-chain FA [19]. Acetate has been estimated to contribute between $70 \%$ and $80 \%$ of acetyl-groups for lipogenesis in adipose tissue, $15-30 \%$ in intramuscular depots [20], and it is the major precursor for de novo FA synthesis in mammary gland $[21,22]$. The rumen is the major locus for the synthesis of circulating BHBA both from the absorbed butyric acid (10-15\% of all VFA; approx. half of absorbed butyric acid is converted to BHBA) and medium-chain FA (MCFA) [9]. The MCFA and long-chain FA (LCFA) are absorbed at negligible amount (estimated to be $<4 \%$ ) by the pre-stomachs and abomasum where they are used for production of BHBA by the rumen and omasum epithelium, especially the MCFA. More recently, it was discovered that specific proton-linked monocarboxylate transporters (MCT or SLC16A) are responsible for the transport of short-chain fatty acids (SCFA), with the MCT1, MCT2, and MCT4 likely playing a major role in forestomach absorption of SCFA [23, 24]. However, according to Graham and collaborators [25], the absorption of SCFA by the rumen epithelium is mainly driven by a non-saturable $\mathrm{Na}^{+} / \mathrm{H}^{+}$ antiporter (SLC9A) at the apical part of the epithelial cells. The $\mathrm{Na}^{+} / \mathrm{H}^{+}$exchangers allow the flow of SCFA from the lumen to the cytosol by exchanging $\mathrm{Na}$ with protonated SCFA. The MCT are instead responsible for the translocation of SCFA (or their metabolites, mainly BHBA) from the epithelial cells to the capillaries [24]. Despite the need of saturable transporters, the absorption of SCFA is highly associated with the magnitude of rumen epithelial blood flow. Additional, SCFA can be transported by the sodium-coupled monocarboxylatetransporter 1 (SMCT1/SLC5A8) [26], which appears to transport butyrate and it is highly expressed in the rumen epithelium, but its expression is reduced in vivo by the increase concentration of butyrate [27].

\section{Effects of fatty acids on microbiota of the rumen}

Around $20 \%$ of de novo synthesized FA by bacteria are monounsaturated FA. The de novo FA synthesis of bacteria as well as overall bacterial fermentation are however reduced when FA are increased in the diet, especially by fat supplementation. Jenkins reported that $10 \%$ of fat added into the diet can reduce the fermentation by $>50 \%$, especially if UFA are supplemented [9]. The inhibition of fermentation appears to be due to a coating effect of FA to feed particles but also to a toxic effect of FA by disrupting bacteria membranes [9].

The negative effects of UFA on rumen microbiota have been known for more than five decades. Use of advanced microbiota analysis revealed a strong effect of dietary FA on microbiota composition, as recently reviewed $[13,28]$. PUFA appears to be more toxic to bacteria compared to less unsaturated counterparts [12, 13]. The effect is quite substantial on the overall microbiota composition and activity, as recently demonstrated in goats where supplementation of PUFA-rich linseed substantially reduced the microbiota biodiversity [29]. Considering the negative effect of UFA on bacteria, it has been proposed that biohydrogenation is the main process whereby bacteria reduce the toxicity of those types of FA [13, 28].

Saturated FA can be somewhat toxic to rumen bacteria. Palmitic and stearic acid have been shown to be 
toxic but only to Prevotella ruminicola (propionate producer) and some strains of Butyrivibrio fibrisolvens (acetate and butyrate producers) when added to purified bacterial culture, but the toxicity is less than oleic acid [28]. Among SFA, lauric acid (C12:0) appears to be the most bioactive on rumen microbiota. Early studies using supplementation of C12:0 observed an inhibitory effect on protozoa [28], which should improve ruminal efficiency (especially $\mathrm{N}$ utilization) and milk production. The same finding was confirmed by more recent studies $[30,31]$. The latter studies however concluded that, despite there was a reduction of protozoa, addition of up to $540 \mathrm{~g} / \mathrm{d}$ of lauric acid was not enough to improve ruminal efficiency. Lauric acid has antimicrobial properties when fed to broilers or pigs [32,33]. The effect of lauric acid on rumen bacteria is less known. Recent studies revealed an inhibitory effect of C12:0 and myristic acid (C14:0) on rumen methanogenesis [34-36]. The MCFA have also important effects in reducing rumen biohydrogenation, especially capric acid (C10:0) [13].

\section{Fate of FA in the intestine}

There is a fundamental difference in the digestive system between monogastrics and ruminants. In monogastrics, the duodenum receives intermittent large boluses containing mostly TAG, and the neutralization of each bolus is very rapid. In ruminants the amount of digesta coming from the abomasum is homogenous and is constituted of fine particles, but the quantity of continuous acid material is massive $(200-1200 \mathrm{~mL} / \mathrm{h})$ [8]. Thus, the digesta in the duodenum of ruminant is not fully neutralized, but remains acidic until reaching the end of the jejunum (pH of 3 in duodenum and upper jejunum and 6 in distal jejunum) $[8,37]$. In ruminants, the large majority of lipids flowing through the small intestine are free FA that form micelles or are attached to food particulates $[8,37]$. In ruminants the pancreatic lipase is less important than the bile [8], considering that the latter helps dissociate the micelles of FA and also helps dissociate the FA intimately associated with dietary particulates. In normal dietary conditions, i.e., with not added esterified fatty acids, the amount of TAG coming from the abomasum is very low in ruminants and, thus, the importance of lipases is minimal [8], which is contrary to monogastrics [38].

\section{Absorption of FA by enterocytes}

In monogastric the concentration of free FA in solution in the intestinal lumen is relatively high, in the order of $\mu \mathrm{mol} / \mathrm{L}$, mostly as consequence of the high activity of the lipases [39]. Due to the low concentration of lipids in the diet of ruminants, the low activity of lipases, and the large amount of bile forming micelles, it is likely that the concentration of free FA in solution of the intestinal lumen is lower compared to monogastric animals.

Fatty acids reach the outer membrane of the enterocytes mainly incorporated in micelles. The latter allow overcoming the unstirred water layer close to the surface of the enterocytes.

The low $\mathrm{pH}$ in the small intestine has important implications for the absorption of FA. Low $\mathrm{pH}$ can negatively affect the aggregation of micelles [40] decreasing their solubility and digestibility but also increases the dissociation of micelles containing FA and the hydrogenation of FA, increasing their absorption [41]. Low pH inhibits the activity of pancreatic lipase in the upper part of the intestine, so the release of FA from TAG by this enzyme happens only after reaching a higher $\mathrm{pH}$ in the middle of the jejunum [37]. In ruminants, taurine is the predominant component of the bile, and at low $\mathrm{pH}$, it is partially ionized favoring solubilization and formation of micelles $[8,38,42]$.

The combination of a large amount of bile and the lower $\mathrm{pH}$ likely induces a high release of free FA from the micelles into the unstirred water layer close to the enterocytes. This might explains the high FA absorption efficiency in ruminants compared to monogastrics, particularly for SFA [8]. The efficiency of absorption of FA in ruminant goes from $75 \%$ for SFA to $80-90 \%$ for PUFA [43, 44]. The efficiency of FA absorption is negatively affected by the level of C18:0 flowing into the duodenum [44] and by the level of dietary fat, with a reduction from $95 \%$ to $78 \%$ of FA absorption when dietary lipids increase from $1 \%$ to $8 \%$ [37]. In monogastric animals the absorption of FA in the jejunum is lower than ruminants, especially for the SFA (17\% for C18:0, $50 \%$ for $\mathrm{C} 16: 0, \mathrm{C} 18: 1$ and $\mathrm{C} 18: 2$, and $65 \%$ for $\mathrm{C} 14: 0)$, as quantified in rats [45]. Higher values were observed in humans, where $>95 \%$ absorption was reported for FA present in fish oil besides eicosapentaenoic and docosahexaenoic acids (DHA) that had an absorption of $<70 \%$ [46]. As for other species, in human SFA are absorbed with lower proportion compared to UFA [47]. Thus, despite the lower amount of FA in the diet of dairy cows, the supplementation of FA, if adequately rumen protected, can be highly effective.

A physical barrier for the FA to be absorbed by enterocytes is the mucus covering the enterocytes $[42,48]$. The main constituent of mucus are the various mucins. In the intestine mucin 1 plays a major role and appears to be essential for absorption of cholesterol but not FA in mice [49]. In dairy cows mucin 1 and mucin 20 are expressed through the whole GI tract, but their expression is higher in the small intestine [50]. There are no data on the role of mucin on lipid absorption on bovine.

Once the FA reach the outer membrane of the enterocytes, it is absorbed by both diffusion and active 
transport (see more details on "Cellular fate of fatty acids" section). The relative importance of each of those transport systems in the intestine absorption of FA is still debated. There are authors indicating diffusion being quantitatively more important [39] while others indicate the active transport via specific translocases proteins playing a major role by docking the luminal FA to the membrane of enterocytes that are then passively diffused and are re-docked on the inner side of the plasma membrane [42]. In monogastrics, the argument for the passive diffusion during absorption of intestinal FA is based on the large concentration in solution of free FA in the intestinal lumen. Due to the low amount of lipids in the diet and the high amount of SFA, which have lower solubility compared to UFA [8], the concentration of free FA in the intestinal lumen is very likely low in ruminants, indicating the active transport being more important.

\section{Molecules involved in intestinal FA absorption}

There are no studies in ruminants about molecular absorption of FA from the intestine and most of the information available are from studies conducted in monogastrics, chiefly using murine model, with some studies also carried out in pigs (e.g., [51, 52]). Several proteins drive the active absorption of FA in the enterocytes: fatty acid translocase CD36, scavenger receptor B1 (SR-B1), membraneassociated fatty acid binding protein (FABPpm), and the various fatty acid transport proteins (FATP) [39, 42, 53]. Transcript abundance of those molecules in jejunum, liver, and mammary tissue of lactating cows is available in Fig. 1. A model summarizing the various steps in FA absorption by the enterocytes is available in Fig. 2 .

Intestinal cell line models for bovine have been established from the duodenum [55] or other intestinal sections [56] but have not been used to study absorption of FA. Furthermore, FA are known to be bioactive in bovine cells by affecting the transcriptome [4]. However, studies on the transcriptomic effect of FA on intestinal epithelial cells of ruminants are scant. The only data available are from a study performed on goat intestinal jejunum cells where SCFA induced the transcription of genes related to immune response and SCFA absorption [57].

\section{Main mechanisms of transport of fatty acids across cytoplasmic membrane}

From a biochemical perspective, the plasma membrane is composed of a two leaflets of lipids, interleaved by structural, membrane-embedded proteins, and peripheral proteins [58]. A large degree of dynamism is present between its main structural components; individual phospholipids in the plasma membrane rotate very rapidly along their axis, and can diffuse laterally at a considerable rate, switching position with a neighboring lipid within $\sim 100$ nanoseconds
[59]. In stark contrast with this, transbilateral diffusion (from one leaflet to the other) occurs quite slowly and is dependent on the type of lipid in consideration, particularly the polarity of the headgroup. Lipids with a simple hydroxyl headgroup, such as ceramide, cholesterol, and diacylglycerol, have a high rate of spontaneous transbilayer diffusion [60]; in general, the movement of a lipid's polar headgroup through the hydrophobic inner space of the plasma membrane is highly energetically unfavorable, and as such, benefits from being facilitated by membrane proteins.

Cross-membrane permeation is achieved in a threestep process [61]: 1) FA move from the aqueous phase to the surface of the plasma membrane; 2) FA "flip-flop", moving from one half of the bilayer to the other; 3 ) FA move from the bilayer into the aqueous phase. This process is limited by the rate of desorption, or release of FA into the cytosol (step 3 underlined above), as rates of desorption of most FA were found to be slower than those of adsorption to the membrane (step 1) and flipflop (step 2) [62]. Proteins associated with transmembrane transport of FA are thus classified as flippases (if they mediate movements from the extracellular phase towards the cytosolic face of the membrane), floppases (if the movement is in the opposite direction) and scramblases (which can transport in either directions but, unlike the other two, are ATP-independent) [59].

While the biochemistry of lipid transporters is subject of much ongoing research and discussion, and details about specific flippases and floppases are beyond the scope of this review, some of the most well-known proteins that operate in this process are type 4 subfamily (P4) of the P-type ATPases. Those translocate aminophospholipids and cardiolipin from the exoplasmic to the cytosolic leaflet; and ATP-binding cassette (ABC) transporters, which transport phospholipids and sphingolipids outwards. ATP-dependent transporters have been reviewed in depth elsewhere [63].

Controversy exists on the importance of flip-flop on the rate of FA passage through the plasma membrane. Flip-flop is largely dependent on the specific physicochemical properties of each FA, which determines the energy barrier for passage through the plasma membrane: a considerable portion of membrane FA are protonated at physiological $\mathrm{pH}$, and would have low energy barrier for transmembrane crossing, compared to fatty acid anions [64]. This has been demonstrated through in vitro models, where protonated FA rapidly diffuse across the plasma membrane, by initial desorption from albumin and subsequent flip-flop through the leaflets [65]. Some dependence on the physiological conditions of the organism seems to be at play: pathophysiological conditions have been reported to increase the LCFA:albumin ratio to over 3.0. When said ratios are observed, the concentration of FA unbound to albumin increases, 
tipping the scale towards transmembrane diffusion; at lower ratios, protein-mediated transport becomes crucial [66]. Translocation across the plasma membrane likely requires a FA translocator in actual biological contexts [61].

\section{Fatty acid translocase CD36}

The CD36 appears to be the most important FA translocator $[67,68]$. A membrane-embedded protein, CD36 is expressed in a variety of cells and tissues [69], and its extracellular domain presents strong binding affinity to a wide range of FA, and even oxidized LDL [70]. Still, the mechanism by which CD36 affects FA uptake is unclear [66], but its activity may also reduce FA "flop", by maintaining intracellular FA concentrations, thus increasing overall intracellular utilization [71]. In general, however, it is evident that CD36 plays an important role in the overall fate of FA and their concentration within a cell, its activity being tightly regulated by its translocation from endosomes to the plasma membrane (which renders it active) and gene transcription in response to insulin levels, as proposed by Glatz and Luiken [67].

Regulation of CD36 occurs at a transcriptional and translational level, and is mediated chiefly by the transcription factors CCAAT/enhancer-binding protein $\alpha$ (C/EBP $\alpha)$ [68] and PPAR [69]. Fatty acids are strong regulators of the transcription of CD36 in various bovine cell lines [72, 73], likely via PPAR [5, 73]. Based on the above data, it is likely that transcription of CD36 is regulated by the availability of FA in the intestine likely augmenting the absorption of FA when those are increased into the diet [1]. Absorption of macronutrients increases from pregnancy to lactation as observed for amino acids [74]; however, data comparing intestinal FA absorption during the dry or lactating period in dairy cows are not available. Interestingly, in both monogastric and ruminant animals increasing fat in the diet boosts the absorption of FA by the intestine $[37,75,76]$. Thus, it is possible that the increased FA absorption is driven by changes in the expression of main proteins involved in this process, chiefly CD36.

The translocase CD36 appears to be the most important for intestinal FA absorption, at the least in the proximal segment of the small intestine, as demonstrated in intestinal cells isolated from CD36 null mice where FA uptake was reduced by $50 \%$ while cholesterol uptake was reduced by $60 \%$ compared to wild-type cells [77]. The same mice have defective FA intestinal absorption, TAG synthesis in enterocytes, and intestinal lipoprotein metabolism as observed in vivo $[78,79]$. Besides FA absorption, CD36 also plays additional functions in the intestine, including a role in controlling the intestinal immune reaction, the microflora, and the FA-induced release of cholecystokinin and secretin by enteroendocrine cells $[39,51,80]$.
Although specific studies on CD36 in the intestine of dairy cows are not available, recent RNAseq data became available via the repository NCBI GEO on whole transcriptome of jejunum, liver, and mammary tissue of lactating dairy cows [54]. Those data revealed that the transcription of CD36 in dairy cows is $\sim 10$-fold more abundant in jejunum than liver (Fig. 1), supporting an important role of this translocase in the jejunum.

\section{Scavenger receptor $B 1$}

The SR-B1 (coded by SCARB1 gene) was originally demonstrated to be expressed in enterocytes in rat where it participates in cholesterol absorption [81]. It appears to play also a role in intestinal absorption of FA or even TAG, as demonstrated in mice over-expressing Scarb1 and tracing absorption of $\left[{ }^{3} \mathrm{H}\right]$-triolein [82]. It has been also proposed that SR-B1 might be implicated in the endocytosis of lipids by the enterocytes [82] although this still need be proven. Furthermore, SR-B1 is also involved, together with CD36, in absorption of lipophilic vitamins [83].

The SR-B1 has received little attention among researchers in dairy cows and, to our knowledge, none on its role in lipid absorption by the intestine. The SR-B1 has been associated with marbling in beef animals [84], with dominant follicle formation and luteinization [85, 86], and with the content of carotene in milk [87]. Its expression is induced by somatotropin in liver [88] and by gonadotropin release hormones in the granulosa cells [86]. The increased expression of SCARB1 by growth hormone is of interest, considering the increased concentration of this hormone early post-partum [89]. In support of its role in bovine intestine, its mRNA is relatively abundant in jejunum and at level similar to the liver in lactating dairy cows (Fig. 1).

\section{Membrane-associated fatty acid binding protein}

The FABPpm is a membrane-bound protein present in the mitochondria and plasma membrane that is structurally identical and coded by the aspartate aminotransferase 2 gene (GOT2) [42]. FABPpm plays important roles in the import of FA in intestine, muscle, and liver [90, 91] by working in concert with CD36 $[42,91,92]$. However, little information was generated on this protein in monogastric and none exists for ruminants. In dairy cows the transcription of GOT2 in intestine is abundant (Fig. 1). Interestingly, in rat overexpression of FABPpm in vivo increased transport and oxidation of FA and formation of phospholipids in sarcolemma but did not increase formation of TAG [91]. A role for this protein in FA absorption appears to be not fully proven [93]. 

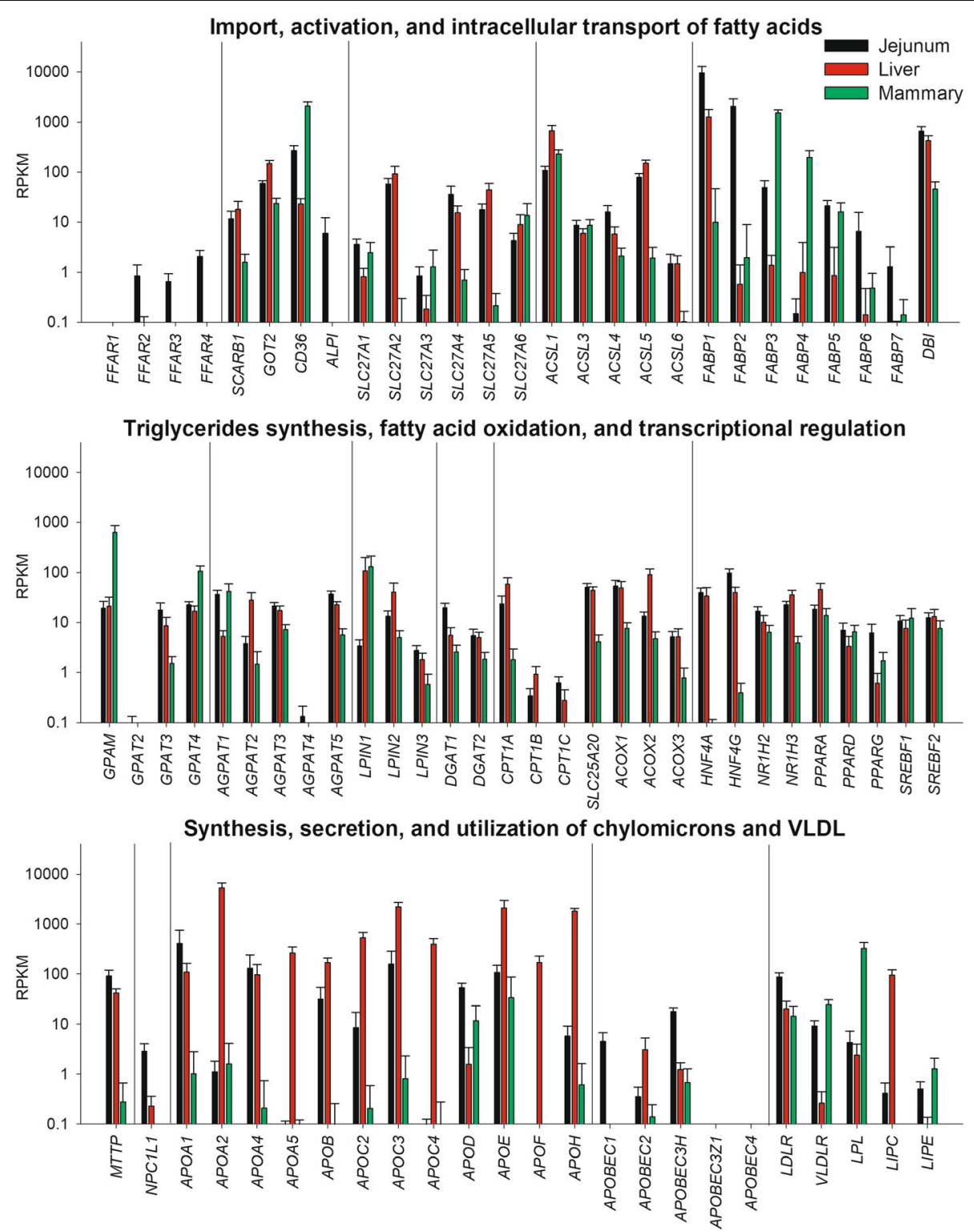

Fig. 1 Transcript abundance of various gene isoforms involved in fatty acid absorption in jejunum, liver, and mammary tissue from Chinese Holstein lactating cows [54]. Data were downloaded from Gene Expression Omnibus, dataset GSE78524. Data are mean \pm SD of reads per kilo base per million mapped reads (RPKM) of all 18 cows

\section{Fatty acid transport proteins}

The FATP (or soluble carrier protein 27A; SLC27A) play two simultaneous roles in FA uptake: membrane translocation and activation to acyl-CoA for downstream metabolic pathways [94]. Upon conversion to acyl-CoA thioesters, FA cannot escape the cell [95]. There are six isoforms of the SLC27A, with the SLC27A4 (or FATP4) being in monogastrics the main SLC27A expressed in the intestine [96]. In bovine jejunum, all isoforms appear to be expressed, with SLC27A2 followed by SLC27A4 and SLC27A5 being the most abundant (Fig. 1). The role of this transporter in intestine for the FA absorption appears to be however dispensable [93].

\section{Other systems possibly involved in enterocyte absorption of fatty acids}

Caveolin 1 Caveolins are proteins playing a major role in cellular endocytosis and signalling [97, 98]. Caveolins are known to play a major role in transcytosis, endocytosis, and exocytosis but also for intracellular trafficking between various organelles, including nucleus where they play important roles for transcriptional regulation 
[98]. The discovery of a role of caveolins in enterocytes uptake of FA is quite recent [53], with a role in apical absorption of FA but also in chylomicron formation (see below). Among the various caveolins, caveolin 1 is known to play a major role in import of FA in enterocytes [99] and its function is independent from CD36 [100]. However, CD36 translocation is regulated by caveolins, chiefly by caveolin-1 [101]. This suggests an inter-regulatory mechanism between proteins in charge of facilitating transmembrane FA crossing and those involved in the shuttling of FA inside the cytoplasm (such as caveolins) [100].

Approx. $15 \%$ of the albumin bound ${ }^{3} \mathrm{H}$-oleate was observed to be absorbed by mouse enterocytes via caveolin-mediated endocytosis [99]. A recent study carried out in zebrafish and mouse challenged the prior data on the role of caveolin 1 to import FA from the lumen into the enterocytes [102]. In that study caveolin 1 was found to be localized in the basolateral plasma membrane (i.e., associated with the submucosae that is facing the circulation) rather than apical (i.e., facing the lumen), supporting a role of caveolin 1 in either export of FA from enterocytes to the circulation or having functions in the regulation of insulin signalling in the intestine. Mice with intestinal caveolin 1 knockout had decreased level of cholesterol and increased non-esterified fatty acids (NEFA) in circulation, likely not associated with dietary cholesterol or FA absorption [102].

Endocytosis and the role of alkaline phosphatase Intestinal cells are also able to perform endocytosis of relatively large particles, including exosomes [103], other macromolecules [104], or polymeric micelles [105] via protein-mediated or protein-independent systems [106] indicating this being an additional mechanism for intestinal absorption. Clathrindependent type of endocytosis of fat has been reported in mouse in vitro model of enterocytes [107]. The clathrin-coated vesicles once inside the cytosol are stored into the enterocytes and processed for exocytosis via lipoprotein formation.

Alkaline phosphatase plays a critical role in FA endocytosis [107]. This enzyme also regulate CD36 activity via phosphorylation in the intestine [75]. Alkaline phosphatase appears to play a regulatory role of FA absorption in intestine, as knockout mice have higher transport of fat droplets through the intestinal epithelium [108]. Interestingly, as for the CD36, also the alkaline phosphatase is associated with lipid draft via glycosylphosphatidylinositol (GPI)-anchored [75]. The GPI are glycolipids that bind the $\mathrm{C}$ terminus of proteins tethering them to the plasma membrane. It has been previously reported in mammary tissue a large increase in importance of the GPI biosynthesis during lactation [109], where also increase in transcription of proteins involved in FA import was observed, including CD36 [110]. The gene coding for intestinal alkaline phosphatase $(A L P I)$ is expressed only in jejunum in dairy cows (Fig. 1). The above data appears to support a role of alkaline phosphatase in intestinal FA absorption in dairy cows.

\section{Intracellular transport and activation of absorbed FA}

In mammals, the large majority of LCFA are reesterified into TAG and secreted via chylomicrons that enter the lymphatic system; however, SCFA and MCFA instead enter into the portal vein $[111,112]$. The enterocyte processing and transport of those is poorly characterized, especially in ruminants but their absorption and utilization for metabolic purpose is more efficient that LCFA, as observed in monogastrics [112].

\section{Activation of fatty acids}

Activation of FA into acyl-CoA are necessary for metabolic utilization via TAG synthesis or oxidation [113]. Besides the SLC27A proteins, a major role in activating FA in mammals are the long-chain fatty-acid-coenzyme A ligase (ACSL). The various FATP also interact with ACSL to activate LCFA, as observed in mouse adipocytes [114].

In monogastrics, the acyl-CoA synthetase long chain family member 5 (ACSL5) appears to be the major acylCoA synthetase in intestine, among the 13 identified isoforms [93], despite being localized in the inner membrane of the mitochondria [115]. The intracellular localization of ACSL5 appears to be a big constraint in the activation of FA for TAG synthesis in the intestine. It is likely that other ACSLs play a role in activating FA for TAG synthesis in the intestine, as also previously proposed to explain the lack of any effect on TAG synthesis in enterocytes after Acsl5 knockout in mice [93]. In mouse jejunum, Acsl5 and Acsl1 were the only expressed isoform with Acsl5 being > 20-fold higher expressed than Acsl1 [116]. In bovine, ACSL1 and ACSL5 have similar transcription level and are the most abundant ACSL isoforms in jejunum (Fig. 1). The former is also the most abundant ACSL isoform in mammary tissue [117] (Fig. 1) where it likely plays a major role in activating FA for TAG synthesis [110]. It is possible that also in intestine of dairy cows ACSL1 plays the same role.

\section{Fatty acid binding proteins}

Once the LCFA enter the cytosolic side of the enterocyte membrane, due to their insolubility in the aqueous cytosol they are bound to fatty acid binding proteins, specifically FABP2 (a.k.a., intestinal FABP) 
and FABP1 (a.k.a., liver FABP) [118, 119], two of the 9 known FABP isoforms [119]. In jejunum of dairy cows most of the FABP are transcribed with the highest mRNA abundance detected for FABP1 and FABP2 with the former being $>3$-fold more abundant (Fig. 1). Those FABPs transport the FA to esterification, metabolic utilization, or control of gene transcription via PPAR as previously reviewed [118].

The FABP2 transports only FA while FABP1 transports also acyl-CoA (i.e., activated FA) that can enter oxidation or TAG synthesis and can transport FA into the nucleus for activation of PPAR, particularly PPAR $\alpha$ $[118,120]$. Data from monogastric animals indicate a lower affinity (between 2 to $>20$-fold) for UFA vs. SFA for FABP2 while for FABP1 the affinity for UFA is only slightly lower compared to SFA $[119,121]$. The FABP1 can bind two FA with a similar affinity between the two sites for SFA but the internal site, the first to bind FA, has $>10$-fold higher affinity for UFA vs. SFA [121]. The dissociation constants are in $\mathrm{nmol} / \mathrm{L}$ ranges $[120,121]$.

FABP1 transfers FA to and from plasma membranes via an aqueous phase diffusion while other FABPs, including FABP2, by interacting directly with the negatively-charged plasma membranes by the net positively charged Lys residues [120]. FABP2 presents a narrow ligand pocket and strictly binds only LCFA [120] while the FABP1 has a larger ligand pocket and can bind several other lipid molecules besides LCFA, including acyl-CoA [122]. Data on binding affinity between various FABPs in bovine are not available; however, FABP1 in bovine has a very similar affinity among various LCFA as human and mouse FABP1 for the first binding site but higher affinity for stearic acid compared to human (but similar to mouse) for the second binding site [123]. The sequence identity of FABP1 between bovine and the other two species is between $76 \%$ and $81 \%$, as determined using NCBI-deposited sequences. The FABP1 and FABP2 carry the LCFA toward the ER for the synthesis of TAG [118]; however, it has been proposed that FABP1 works as reservoir of FA or acyl-CoA in the intestine and can carry FA toward oxidation [124].

\section{Acyl-CoA binding protein}

The acyl-CoA binding protein (a.k.a., DBI diazepam binding inhibitor, coded by the $D B I$ gene) specifically binds and transports medium- and long-chain acyl-CoA $[113,125]$. Its function in the intestine is still unclear; however, it might be the main intracellular carrier of acyl-CoA for TAG synthesis [124]. It is generally highly expressed in tissues with high TAG and cholesterol synthesis [125]. Abundance of $D B I$ is almost at par with $F A B P 1$ and $F A B P 2$ in intestine of dairy cows (Fig. 1), supporting a role in FA transport in intestine in ruminants.

\section{Inhibition of feed intake by dietary FA: possible role of enteric FABP1 and free fatty acid receptors}

Supplementation of fat either in the diet or infused in the abomasum often decrease feed intake in dairy cows, especially if UFA are used. The effect was partly explained by a higher induction of intestinal cholecystokinin release, an appetite depressant, by UFA compared to SFA [1]. The increase in circulating NEFA following FA supplementation can also depress appetite through the hepatic oxidation [126]. The above however cannot fully explain the decreased in feed intake.

The role of FABP1 in directing the FA toward intestine catabolism is somewhat peculiar. The oxidation of FA in intestinal cells is minor, as observed in vitro in humans [127]; however, it might play a role in regulating feed intake via the vagal nervous system, as previously proposed [128], somewhat similar to the hepatic oxidation theory of the control of feed intake proposed by Allen et al. [126]. The fact that FABP1 is the most abundant FABP in intestine of dairy cows (at the least at transcriptional level), that carries FA towards oxidation, and that can bind two FA (thus, spike in FA absorbed by the intestine are likely taken up by FABP1 compared to FABP2, that can only bind one FA), provide some support for the theorized role of intestinal FA oxidation as an additional way for FA to control appetite. However, this needs to be proven.

Recently, it has been demonstrated that activation of the free fatty acid receptor 1 (FFAR1, a.k.a. G proteincoupled receptor 40) in the enterocytes plays an important role in reducing appetite in rodents [129]. The FFAR1 is activated by LCFA in monogastrics [130] and ruminants [131]. In the latter, the FFAR1 is activated by UFA but not C16:0 [131]. Transcription of FFAR1 is virtually absent in the jejunum, liver, and mammary tissue of dairy cows while the transcript of other FFAR, including FFAR4 (a.k.a., GPR120), is detectable in the jejunum, although at relatively low mRNA abundance compared to other transcripts in this tissue (Fig. 1). Transcription of various FFAR genes in several adipose tissue depots, liver, muscle, and mammary tissue in dairy cows was measured [132, 133]. The authors detected an overall low expression of the FFAR genes but with a greater transcription in adipose tissue compared to liver or mammary tissue, suggesting a greater role in the former compared to mammary tissue and liver. In monogastrics, FFAR1 plays a role in CLA-induced fatty liver but it is important to prevent CLA-induced inflammation and insulin resistance in the brain, as observed in Ffar1knockout mice [134], indicating somewhat tissuespecific effects of FFAR1. The FFAR4 is activated by MCFA and LCFA in monogastrics and can regulate appetite by inducing release of cholecystokinin [130]. To our knowledge, there are not studies in ruminants about 
the role of FFAR1 and FFAR4 in intestine and control of feed intake.

\section{Triglycerides synthesis}

The enzymatic pathways involved in the synthesis of TAG in the intestine of monogastric species has been previously reviewed in detail [93]. There are two pathways for the synthesis of TAG in the intestine: the monoacylglycerol and the glycerol-3-phosphate (G3P) pathways. Both pathways are operative in monogastric animals while the second is predominant in ruminants likely due to the negligible amount of absorbed monoacylglycerol [8], as observed in sheep [135].

As previously described for the synthesis of TAG in the mammary tissue [110], the first step for the G3P pathway is the formation of the lysophosphatidic acid by the binding of acyl-CoA [118] with glycerol-3-P by the glycerol-3-phosphate acyltransferase enzyme (GPAT). The second acyl-CoA is then added to the $s n-2$ position by the 1-acylglycerol-3-phosphate-O-acyltransferase (AGPAT) to form the phosphatidic acid. The P group is removed by lipin (LPIN) to form diacylglycerol (DAG). The last acyl-CoA is added to the DAG by the diglyceride acyltransferase (DGAT, specifically DGAT1 for secreted lipoproteins and DGAT2 for stored lipid TAGrich lipid droplets [93]).

Due to the large lipophilic property of the TAG, this is formed in between the two leaflets of the ER membrane. As the TAG are inserted into the ER membrane, a lipid droplet is formed. If there is active translation of the apolipoprotein B48 (apoB48) by the ribosomes docked to the ER, the growing lipid droplets lipidate the apoB48 forming the prechylomicron particle. This is exported to the Golgi [136], otherwise, it bud off entering the cytosol where it is stored in the apical part of the enterocyte forming a temporary "storage" but it is then used for the formation of chylomicron [93, 136, 137]. This is important in monogastric, especially human, where there is intermittent feeding of relatively high-fat diet with moments of large intestinal absorption followed by moments of low absorption; in ruminants, where the flow of digesta is quite constant and the level of fat in the diet is low, we expect the formation of storage lipid droplets in enterocytes being rare.

All the enzymes responsible for the TAG synthesis present several isoforms. In intestine, Gpat3, Gpat4, Agpat1, Agpat2, Agpat3, and Lpin3 are the most abundant or important among their respective isoforms in monogastrics [93]. Transcript abundance of the various isoforms of the TAG-synthesis related genes in dairy cows has been determined for the mammary tissue [117]. Transcript abundance of the various isoforms of the TAG-related genes in mammary, liver, and jejunum are remarkable similar between the three tissues, with few exceptions (Fig. 1). All three tissues are known to be involved in TAG synthesis in monogastrics; however, in bovine the liver is not considered an important site of TAG synthesis [138] except early post-partum in dairy cows, when NEFA significantly increase in circulation [139]. Thus, the high abundance of those isoforms in liver is peculiar and the reason for that is unclear.

Among GPAT, the transcription of GAPT3 and GPAT4 are the most abundant in the jejunum of dairy cows (Fig. 1). Those GPAT isoforms are localized in the ER [140]; however, also the mitochondrial isoform (GPAM, a.k.a. GPAT1) has a similar abundance (Fig. $1)$. Although the subcellular location of this isoform is in the mitochondria, the active enzymatic domain faces the cytosol [140]. The mitochondrial location of GPAM appears also to play a pivotal role in TAG synthesis by competing with utilization of FA for oxidation by carnitine-palmitoyl transferase 1 (CPT1) [140]. Among GPAT, GPAM has large preference for saturated LCFA and its transcription is regulated by SREBP1 while GPAT3 is regulated by PPAR $\gamma$ and GPAT4, initially classified as AGPAT6, appears to have not preferences among LCFA but its role in TAG synthesis remains undetermined [140]. Interestingly, transcription of PPAR $\alpha$ and PPAR $\gamma$ and of the two SREBF isoforms is abundant in jejunum of dairy cows (Fig. 1). An important role for GPAT4 (reported as AGPAT6) and GPAM in TAG synthesis in dairy cows is also supported by this GPAT isoforms being the most abundant in lactating mammary tissue, where synthesis of TAG is predominant [110].

Among AGPAT, the most abundant isoforms in jejunum of dairy cows are AGPAT1 and AGPAT5 followed by $A G P A T 3$ (Fig. 1). All those isoforms are located in the ER and AGPAT3 is known to be regulated by PPAR $\alpha$ in monogastric animals [140]. As for jejunum, also in mammary gland the AGPAT1 and AGPAT3 are the most abundant AGPAT isoforms (Fig. 1) [117].

A recent publication reviewed the most up-to-date information about LPIN isoforms in monogastrics [141]. According to data reported in that publication, the relative abundance between isoforms in intestine is to some extent similar to the one detected in jejunum of dairy cows (Fig. 1). Among LPIN isoforms, LPIN1 has been the most studied. The lipin proteins resides into the cytosol, but they are translocated into the ER when FA increase in the cytosol; interestingly, in monogastrics the UFA, but not SFA, induce translocation of lipin into the ER. Nuclear localization and a role in FA activation by PPAR were determined for lipin1 and lipin2. In bovine mammary tissue, among LPIN isoforms, only transcription of LPIN1 was increased through lactation, supporting a role of this lipin in TAG synthesis in this tissue [117]. 


\section{Formation and release of intestinal lipoproteins}

The study of lipoproteins in bovine was intense several years ago as previously reviewed [37, 111, 142]. It has been debated in the past about the production of verylow density lipoproteins (VLDL) instead of chylomicron in intestine of ruminants, due to the high proportion of VLDL in the lymph $[37,111]$. The high proportion of VLDL is due to the relatively low amount of dietary FA in ruminants; however, higher amount of fat in the diet increases production of chylomicrons, as well higher proportion of UFA are inserted into chylomicrons, as previously reviewed [111].

In bovine, lipoproteins have been well-characterized and, contrary to monogastrics, the HDL compose the large majority $(>80 \%)$ of circulating lipoproteins [37]. Little advance in our understanding of lipoproteins formation and metabolism have been made in dairy cows in the last decade and, to our knowledge, none on the synthesis of intestinal lipoproteins. The emergency and intensification of lipid-related diseases in humans has prompted an intense study of the molecular aspects of the lipoprotein metabolism, including the intestinal lipoproteins. Thus, most advances on molecular aspects of the lipoprotein metabolism have been made on human and other monogastric animals. Several excellent reviews have been published in this regards [42, 136, 137, 143]. In this section, we provide a summary of the most upto-date model on intestinal lipoprotein metabolism based on the above reviews and provide data obtained from dairy cows when available.

\section{$A p o B$ and the synthesis of chylomicrons}

There are several apolipoproteins secreted by the intestine, but the apoB48 is the one essential for the formation of chylomicrons [136]. The apoB48 is coded by the $A P O B$ gene in all mammals, including bovine. This gene in liver codes for the apoB100 protein; however, in the intestine the $A P O B$ mRNA editing complex (APOBEC) inserts a stop codon at approx. $48 \%$ of the full-length sequence of the $A P O B$, removing the C-terminus that binds light-density lipoprotein receptor (LDLR). The $A P O B E C 1$ and $A P O B E C 3 H$ are the two APOBEC most transcribed into the jejunum (Fig. 1). Of the two, only APOBEC1 is known to be involved in apoB editing and be expressed in intestine and liver in mice [144]. Contrary to mice, bovine $A P O B E C 1$ is not expressed in the liver (Fig. 1). There is not information on role of APO$\mathrm{BEC} 3 \mathrm{H}$ on lipoprotein synthesis. The $A P O B$ is the most transcriptionally abundant apolipoprotein in jejunum of dairy cows; however, its mRNA abundance is $>5$-fold lower compared to the liver (Fig. 1).

The $A P O B$ mRNA is initially translated in the cytosol; however, as the first 27 codons are translated the process pauses. The first 27 amino acids of the sequence are used as a signal to translocate the mRNA-ribosomal complex to the translocon of the ER, where the rest of the protein is translated in the ER lumen and TAG and phospholipids are transferred to lipidate the nascent protein by the microsomal triglyceride transfer protein (MTTP). The MTTP is essential for the formation of chylomicrons or VLDL in the intestine and liver. Interestingly, MTTP transcription is almost 2-fold larger in the jejunum compared to liver in dairy cows (Fig. 1). The nascent apoB48 is immediately degraded if not properly lapidated. The presence of TAG is essential for the formation of chylomicrons or VLDL (compositing $67-88 \%$ of lipids in lipoproteins in bovine), as well the presence of phospholipids (8-20\%) and cholesterol (210\%) [37].

\section{Importance of phospholipids and cholesterol for the synthesis of chylomicrons \\ Phospholipids}

The importance of phospholipids for synthesis of lipoproteins in dairy cows is supported by the fact that dietary supplements that help increasing synthesis of phospholipids, such as choline [145-147], improve the formation of VLDL in bovine hepatocytes [148] and/or decrease accumulation of fat in the liver [145, 147]. Phospholipids in intestine might not be limiting for ruminants, especially if grazing, considering the large amount of them present in chloroplasts. However, a large amount of phospholipids derives from the intestinal hydrolysis of biliary phospholipids, especially phosphocholine that represents the majority of bile lipids in ruminants [8].

\section{Cholesterol}

Cholesterol is also essential for the formation of chylomicrons. It has been reported previously that addition of cholesterol in the diet of preruminant calves increases the production of chylomicrons [111]. Cholesterol is however very low in the diet of dairy cows indicating that the cholesterol has to be almost completely synthesized by the animal [8]. In ruminants, the intestine appears to be the major site of cholesterol synthesis [8] as demonstrated in goats [149]. Adipose tissue and intestine accounted for the large majority of de novo synthesis of cholesterol using acetate and glucose, with liver accounting for $<5 \%$ in goats [149]. Despite the large importance of intestine and adipose tissue on cholesterol synthesis in ruminants, recent studies on cholesterol metabolism in dairy cows have concentrated on the liver $[150,151]$ with no studies on intestine or adipose tissue.

In monogastric animals, the cholesterol used for chylomicron or VLDL synthesis in enterocytes mainly derive from the biliary cholesterol reabsorption via the cannalicular sterol transporter Niemann-Pick C1-like 1 
(NPC1L1). This can be an important way to provide cholesterol for enterocytes of dairy cows, as supported by the high mRNA abundance of the NPC1L1 in the jejunum, especially compared to liver and mammary tissue (Fig. 1). Recent data in monogastrics indicate the existence of a reverse transport of cholesterol from blood to intestine via the LDLR with consequent endocytosis of hepatic-derived apoB-containing lipoproteins (apparently different than VLDL) that are made to eliminate excess free cholesterol from the liver [83]. This can be an additional pathway for the availability of cholesterol in enterocytes. In support of this, the transcription of LDLR is $>4$-fold larger in jejunum compared to liver in dairy cows (Fig. 1).

Although all the above means to provide cholesterol for chylomicron synthesis are possible also in ruminant, the major contributor of cholesterol for lipoprotein synthesis in enterocytes is the de novo synthesis of cholesterol by ruminant enterocytes. As observed earlier [8], cholesterol in plasma typically increases as fat is supplemented in the diet of dairy cows [152154] and decreases around parturition with a constant increase during the first two months postpartum [151, 155]. This change has a similar pattern as the typical increase in feed intake of the dairy cows post-partum [156].

It is unclear if an active regulation of cholesterol synthesis in the intestine exists. The main regulators of genes involved in cholesterol synthesis in monogastrics are the SREBP1 and SREBP2, with a more prominent role of SREBP2 [157], including for the intestine [158]. Change in mRNA abundance of SREBF1 and several down-stream targets related to cholesterol synthesis coordinately increase in liver of post- vs. pre- partum dairy cows, indicating an increased hepatic cholesterol synthesis [150]. These data appears to support the apparent increase in hepatic synthesis of apolipoproteins post-partum that can be compromised by inflammatory-like condition, since concentration of total cholesterol in blood can be used as index of liver activity in early post-partum cows $[155,159]$. The lower amount of cholesterol early post-partum might also indicate a lower capacity of the intestine to produce chylomicrons and, thus, likely a lower ability to use supplemental fat compared to cows in more advanced stage of lactation. Unfortunately, data on the FA absorption capacity of the intestine of dairy cows during the various stages of lactation are not available. However, two pieces of evidence support a lower intestinal FA absorption in early vs. late lactating dairy cows. The first piece of evidence is that $>65 \%$ of the circulating TAG are of gut origin in ruminants [111] and there is a lower level of TAG and phospholipids in plasma (mostly present in chylomicron remnant, VLDL, and light density lipoproteins) in cows during early vs. more advanced stages of lactation $[151,155]$. The second piece of evidence is the lack of response of cholesterol concentration in blood in cows supplemented with large amount of palmitic acid ( $4 \%$ dry matter intake ) during the first week post-partum while a strong response is observed in cows at 3 and 7 weeks into lactation [152].

\section{Additional apolipoproteins present in chylomicrons}

Once the prechylomicrons containing apoB48 are formed into the ER, they contain also apoA-IV and they bud-off from the ER and are transported to the Golgi by a combination of a chylomicron transport vesicle that implies several proteins, including CD36 and several FABP, and the COPII coatomer transport system [136]. The prechylomicrons then fuse with the cis-Golgi thanks to the COPII system [160]. In the Golgi, prechylomicrons acquire more apoA-IV and, by the activity of the MTTP, more TAG. The final mature chylomicrons containing apoB48, ApoA-IV, cholesterol ester, TAG, and phospholipids are then secreted via exocytosis facilitated by a $\mathrm{N}$-ethylmaleimide-sensitive factor attachment protein receptor (SNARE) from the basolateral membrane of enterocytes into the lymphatic system [136].

Among apolipoproteins, apoA-IV is essential for the formation and secretion of chylomicrons but has also several other functions, including regulation of lipid metabolism, satiety, and size of secreted chylomicrons (larger when apoA-IV is knockout), at the least as observed in monogastric animals [161]. One of its important function, especially for the apoA-IV produced by the liver, is the formation of HDL. This is also achieved by activating the lecithin-cholesterol acyltransferase, an enzyme present on HDL with an essential role in the conversion of free cholesterol into cholesteryl ester that is then accumulated into the core of HDL, essential for the formation of mature HDL [136]. Although the HDL are the majority of lipoproteins in circulation in dairy cows [37], the significance of this is still unclear. The importance of apoA-IV for the formation of chylomicrons in the intestine of dairy cows is supported by the mRNA abundance, which is similar to the one observed in liver (Fig. 1).

The chylomicrons acquire additional apolipoproteins while circulating in the lymphatic system and blood. However, several of those are expressed also in the intestine, such as apoA-I, apoC-II, apoC-III, and apoE (Fig. 1). Bauchart provided a list of apolipoproteins present in bovine lipoproteins [37]. The list included most of the apolipoproteins detected in monogastrics as reported recently by Ramasamy [136], except for apoE, apoA-II, and apoA-V which were only reported 
to be present in chylomicrons of humans by Ramasamy. Apolipoproteins are mostly synthesized between liver and intestine, with the exception of apoC-I, which in monogastrics is synthesized only in the liver [136]. In dairy cows, RNAseq data indicate that all apolipoproteins, except apoA-V and apoC-IV, are transcribed in the jejunum of dairy cows but, beside transcription of all apolipoproteins in liver, also mammary tissue can transcribe genes coding for apolipoproteins, such as apoE (Fig. 1). Among the apolipoproteins, it is important to highlight the function of other apolipoproteins present in chylomicrons. The apoA-V and apoC-II are activators of lipoprotein lipase (LPL) [162]. ApoC-III is an inhibitor of LPL and VLDL and LDL clearance by the liver [162]. ApoE activates LDLR [163], important for the removal of chylomicron remnants by the liver [136].

\section{Lymphatic transport of chylomicrons}

In general, intestinal chylomicrons and VLDL released by the basolateral membrane of enterocytes enter the lymphatic system via the lacteal system, as previously reviewed [164]. However, it has been determined in preruminant calves that between $20 \%$ to $67 \%$ of chylomicrons and between $50 \%$ and $80 \%$ of VLDL produced by the intestine are released into the portal vein, reaching a higher proportion at peak absorption after providing the milk to calves once a day [165]. This is likely due to the coagulation of milk in the abomasum of pre-ruminant calves and the consequent slow passage rate of fat in the intestine [37]. The importance of portal vein in the transport of intestinal chylomicrons and VLDL in adult ruminant is not known but could be important when the passage rate of lipids in the intestine is slow, as previously argued by Bauchart [37].

It is still unclear the mechanism for the entrance of chylomicrons into the lymphatic system via lymphatic endothelial cells. So far, two mechanisms have been proposed and supported by data: the flow through opening of intercellular gaps and transcytosis. Also the mechanism for the flow of the chylomicrons inside the lymphatic system is not fully characterized, but it appears to be mainly due to the peristaltic activity of the intestine [164]. Interestingly, the flow into the intestinal lymph was significantly stimulated by injecting oil in abomasum and duodenum of lambs [166] but was not affected by feeding cows with oil [76]. In the latter study, feed deprivation of the animals significantly affected lymphatic flow.

The flow of the intestinal lymphatic system in cows has been measured to be $2-3 \mathrm{~L} / \mathrm{h}$ (or $30-50 \mathrm{~mL} / \mathrm{min}$ ). Labelled FA appear in the lymph ca. $1 \mathrm{~h}$ after injecting oil in the abomasum with a significant increase in TAG absorption ca. $3 \mathrm{~h}$ after injection of oil in abomasum or duodenum in lambs. In the same study, when the oil was injected into the rumen of sheep or provided via stomach tube in lambs, the radioactivity in the intestinal lymph was observed after $6 \mathrm{~h}$ post-injection [166]. Similarly, in dairy cows significant absorption of TAG in the lymph was observed between 7 and $16 \mathrm{~h}$ post-feeding, with maximum absorption detected around $12 \mathrm{~h}$ postfeeding [76]. In the same study, it was calculated the rate of absorption of TAG into the lymphatic system: TAG were absorbed to a rate of $20-40 \mathrm{~g} / \mathrm{h}$ while phospholipids and cholesterol at rate of $4-6$ and $1-2 \mathrm{~g} / \mathrm{h}$, respectively.

The above study [76] was performed in 1966 using Jersey cows. Nowadays, cows have higher feed intake; thus, the rate of absorption is likely larger. However, the Jersey cows appears to have a higher passage rate compared to Holstein cows [167]. Assuming the above absorption rate, a Holstein cow eating $20 \mathrm{~kg}$ of dry matter $(\mathrm{DM}) / \mathrm{d}$ of a diet with $5 \%$ fat (i.e., $1 \mathrm{~kg}$ of fat) it would absorb the dietary fat in about $30 \mathrm{~h}$. From the nutrigenomic point of view those data are of importance when considering that the concentration of fed FA into the plasma has to achieve the desired effect (i.e., change in the transcriptome) [4].

With the above data, it is possible to estimate the amount of dietary FA needed to achieve an effective dose to optimize their nutrigenomic effect. For instance, when considering palmitic acid with a hypothetical maximal nutrigenomic effect achieved at or above $100 \mu \mathrm{mol} /$ $\mathrm{L}$, feeding $500 \mathrm{~g} / \mathrm{d}$ of pure palmitic acid should provide around $0.01 \mathrm{~g} / \mathrm{min}$ (or $50 \mu \mathrm{mol} / \mathrm{L} / \mathrm{min}$ ) of $\mathrm{C} 16: 0$ in the plasma. The calculations were based on $40 \mathrm{~g} / \mathrm{h}$ of dietary TAG transported into the lymphatic system and a basal concentration in plasma of $20 \mu \mathrm{mol} / \mathrm{L}$ of $\mathrm{C} 16: 0$ [4] in a dairy cow $(600 \mathrm{~kg} \mathrm{BW})$ receiving around $0.5 \mathrm{~kg}$ of fat from forages containing 30\% palmitic acid. However, recent data indicated that concentration of dietary FA in blood is probably not a correct approach, because it does not account for the local increase in concentration by the activity of LPL on lipoproteins [168].

\section{Utilization of dietary fatty acids by peripheral tissues \\ Catabolism of chylomicrons and other lipoproteins}

The clearance of TAG in chylomicrons is very fast, especially in ruminants. The turnover rate of FA in plasma of lactating cows is between 2 and 9 min $[8,111]$. In an elegant study performed approx. 40 years ago, Bergman and collaborators injected chylomicrons obtained from the intestinal lymphatic system of donor sheep where palmitic acid labelled with ${ }^{14} \mathrm{C}$ and ${ }^{3} \mathrm{H}$ was infused into the lymphatic system of the duodenum in recipient sheep [169]. It was determined that the turnover rate of TAG in chylomicrons after termination of lymph 
infusion was very rapid, between 8 and $9 \mathrm{~s}$. In the same study, it was detected that around $50 \%$ of TAG hydrolyzed from the chylomicrons were found circulating as NEFA, and that the peripheral tissue utilizes $11-15 \%$ of TAG in chylomicrons per each circulation while liver utilizes only about $2 \%$ per circulation, with a final utilization of $10 \%$ by the liver of infused TAG present in chylomicrons. In human chylomicrons disappear from circulation within 12-14 h after a meal [136].

Lipids included in lipoproteins can enter the cell in one of two main ways: through endocytosis of the entire lipoprotein molecule and eventual intracellular metabolization (mainly liver, but also macrophages, vascular smooth vascular cells, kidney, gonads, and adrenals) $[170,171]$ or by hydrolysis of the TAG contained within the lipoproteins (mostly for adipose tissue, skeletal muscle, and heart in non-lactating animals and mammary tissue in lactating animals), which occurs at the luminal surface of the capillary endothelial [172].

\section{Lipoprotein endocytosis}

Chylomicrons are too large to cross the tightly associated endothelium or be taken up via endocytosis and are mainly processed through hydrolysis [172]. The same cannot be said of HDL, where their smaller size allow them to be taken up via endocytosis by various tissues, including liver, macrophages, and kidney [170, 173, 174]; while LDL bind to the LDLR, and are taken up by hepatocytes through clathrin-coated pits [175]. Once the LDL-LDLR are in the endosome, the LDLR detaches from the LDL due to a decrease in $\mathrm{pH}$ [176] and the LDL is directed to the lysosomes, where it is subsequently degraded. Chylomicron remnants and VLDL remnants are taken up (mostly by hepatocytes) through a similar process, mediated by several receptors of the LDLR family, namely LDLR, VLDLR, LDLR-related protein 1 [170]. In monogastrics it has been determined that chylomicron remnants clearance by the liver requires the binding of four LDLR via the apo-E [136]. The TAG in VLDL remnant are also further hydrolyzed through hepatic lipase with production of LDL [170, 177].

\section{Hydrolysis of TAG in lipoproteins by lipases}

Hydrolysis of lipoproteins is mediated by the action of lipases [178]. Several lipases act on dietary lipids, chiefly among them are pancreatic lipase that acts on the intestine [179], while endothelial lipase [180], hepatic lipase [181], and most notably LPL [179] act on circulating lipoproteins. The aforementioned act upon TAG present in chylomicrons and VLDL, converting each TAG into a $s n$-2-monoacylglycerol and two NEFA [182].

Lipoprotein lipase The fast rate of utilization of circulating chylomicrons is due to the activity of LPL. The transcription and activity of LPL is the highest in adipose tissue followed by skeletal muscle, heart and lungs, and to a lesser extent spleen, rumen, and small intestine $[183,184]$. The lactating mammary gland also presents a larger transcript abundance and activity of LPL [185] (Fig. 1), with a marked increase in its transcription and activity at the onset of lactation [110, 186], possibly induced by prolactin [187]. Interestingly, in adipose tissue prolactin appears to inhibit LPL activity during lactation, at the least in humans [187], to augment availability of FA to the mammary tissue [188]. Transcription of $L P L$ in bovine mammary is also affected by diet as observed in dairy goats and cows [189-191].

The LPL activity in bovine is around $1000 \mathrm{mU}$ (i.e., 1 $\mathrm{U}=1 \mathrm{nmol} / \mathrm{L}$ of released $\mathrm{FA} / \mathrm{min}$ )/g of tissue in the adipose tissue, around $500 \mathrm{mU} / \mathrm{g}$ of tissue in muscle, around $300 \mu \mathrm{mol} / \mathrm{L}$ of $\mathrm{FA} / \mathrm{h} / \mathrm{g}$ of tissue in mammary gland [185], and $1000 \mathrm{nmol} / \mathrm{L} \mathrm{FA} / \mathrm{h} / \mathrm{mL}$ of plasma collected from the mammary vein [192].

In monogastrics, the abundance of LPL is tightly controlled by hormones, such as insulin, glucocorticoids, and adrenaline [136, 193, 194]. It has been also considered a PPAR $\gamma$ target gene, but its transcription is not increased by PPARY agonist in bovine [72] or goat [195] In bovine mammary tissue its transcription is decreased by milk fat depressing diet and several rumen biohydrogenated UFA, especially trans-10,cis-12 CLA [196-198].

The LPL is synthesized in various tissues, it is then folded and assembled in a homodimer before being excreted and transported to the endothelial lumen by the glycosylphosphatidylinositol-anchored high-density lipoprotein binding protein 1 (GPIHBP1) [199]. The GPIHBP1 is also essential for the LPL catalytic activity [200]. There are newly-discovered proteins important for LPL activity, as recently summarized [136]. In monogastric animals angiopoietin-like 4 (ANGPTL4) acts as LPL inhibitor [201] and lipase maturation factor 1 is essential for the folding and maturation of LPL [202]. No information exists in dairy cows on the role of those on LPL activity. ANGPL4 is highly expressed in liver and adipose tissue and its transcription is likely regulated by PPAR [5, 203]. A positive association between GPIHBP1 and milk fat synthesis has been detected in bovine [204], likely by promoting the activity of LPL.

The release of FA by the hydrolysis of TAG by LPL has a large increase in concentration of FA locally, likely reaching the desired biological activity of the fed FA, as recently demonstrated in vitro in our laboratory [168]. However, NEFA released from the chylomicrons and VLDL by LPL do not completely permeate into the extracellular space of tissues, rather they are taken up by albumin to be part of the circulating NEFA pool. It has been estimated that in ruminants not in negative energy balance, around $60 \%$ of circulating NEFA 
are derived from hydrolysis of TAG present in lipoproteins [111].

A pivotal role in regulating lipoprotein metabolism is mediated by the interaction of LPL with receptors of the LDLR family [205]. Several investigators have reported significant binding affinity of LPL with LDLR, LDLRrelated protein 1, VLDLR, and ApoE receptor 2 [206]. The interaction of lipases and the LDLR family seems to involve both lipoprotein endocytosis and hydrolysis: indeed, the LDLR was found to be required for LPLmediated lipoprotein uptake in mouse endothelial cells [207]. LPL is also transcribed in bovine liver and jejunum, although being about 100-fold lower than in mammary tissue (Fig. 1).

The VLDLR is crucial in tissues where FA are used as fuel, such as skeletal muscle and the heart, playing a major role in the regulation of LPL-mediated lipolysis [208]. This is mostly achieved by VLDLR binding VLDL and bringing the lipoprotein in proximity to LPL for hydrolysis. The VLDLR also aid in the transport of LPL to the endothelial surface and play a role in LPL-mediated endocytosis of lipoproteins, as observed in muscles [208]. In dairy cows, data indicated a coordinated work of VLDLR and LPL in the large uptake of FA from circulating chylomicrons and VLDL by the lactating mammary gland [110, 209].

Hepatic lipase and hormone-sensitive lipase In monogastrics, hepatic lipase (coded by the LIPC gene) is an important enzyme for the utilization by the liver of TAG in circulating lipoproteins [181]. Early studies found a markedly low activity of hepatic lipase in the bovine liver compared to monogastrics $(\sim 15$ fold less than in the liver of rats, per gram of tissue) [210]. We are not aware of any additional study on bovine hepatic lipase. Despite that study indicating a lower activity of hepatic lipase compared to monogastrics, the transcription of LIPC is relatively abundant in liver of dairy cows and at the least 10-fold higher than LPL (Fig. 1). Thus, the functional importance of hepatic lipase in dairy cows, in particular the role in the uptake of dietary FA by the liver, should be further investigated.

The role of hormone-sensitive lipase (HSL, encoded by the LIPE gene), originally thought to be solely involved in lipolysis of the adipose tissue in response to increased circulating epinephrine, was found to be expressed in rat mammary tissue, where it plays a role in mammary cell cholesterol esterase activity [211]. LIPE is expressed, although at low level, also in bovine mammary tissue (Fig. 1). Interestingly, LIPE is upregulated in response to FA (chiefly palmitate and stearate) in an in vitro bovine mammary epithelial cell model, which suggests that dietary regulation is a viable avenue [212].
However, the role and importance of mammary HSL in dairy cows needs to be further investigated.

\section{Transport of FA from endothelial lumen to cells}

Upon hydrolysis, some of the released FA are used by the surrounding tissues through interaction with cell surface receptors involved in uptake of lipids, such as CD36 [213], and can be utilized by the cell for fuel or added to the TAG storage in lipid droplets [214]. A portion of the released NEFA is not utilized by tissues, and instead enters blood circulation [214]; since the solubility of most FA in aqueous solutions is below $30 \mu \mathrm{mol} / \mathrm{L}$ [215], circulating NEFA bind to albumin, which acts as a FA transporter in the blood [216]. Albumin-FA complexes are then delivered to the tissues; the complexes can cross the endothelium either through fenestrated endothelium, the discontinuous sinusoidal endothelia of the liver, endothelial clefts, or via endothelium transcytosis through binding with the receptor albondin [217, 218]. Finally, albumin-FA complexes likely bind specific receptors (such as gp60) at the surface of cells allowing the uptake of FA by the cells [216, 219, 220], even by endocytosis of albumin, although the quantitative importance of this is unclear [221].

Free FA (i.e., unbound from albumin) are then imported by the cell through the fatty acid import mechanisms that are described for the enterocyte absorption of FA (described above). The circulation of dietary FA shuttled through albumin allows for delivery of NEFA to tissues where rates of LPL-mediated hydrolysis of lipoprotein is low, and as such, the activity of LPL is a major factor in facilitating and regulating the cellular uptake of FA and other lipids [222], including cholesteryl esters [213].

\section{Chylomicron clearance and uptake of dietary FA by the liver}

The chylomicrons after the TAG have been hydrolyzed by the peripheral tissue become chylomicron remnant [136]. The clearance of those particles by the liver is not fully clear. Based on the review by Ramasamy [136], the TAG remaining in those lipoproteins are further hydrolyzed by LPL and hepatic lipase present in the space of Disse of the liver. Liver of dairy cows expressed both enzymes, as determined by mRNA abundance, supporting a similar role in this species (Fig. 1), although the hydrolysis of TAG present in chylomicron remnants by lipases in the liver of dairy cows is likely lower than in monogastrics [210].

As for other mammals, in dairy cows dietary FA reach the liver mostly through endocytosis of chylomicron remnants. In sheep, uptake of FA derived from TAG present in lipoproteins by the liver accounts for about $10 \%$ of the total TAG removed from the blood [169]; 
thus, a relatively low amount of dietary FA is taken by the liver.

Dietary LCFA can also reach the liver via the hydrolysis of chylomicrons by LPL in the peripheral tissues. This activity releases a large amount of NEFA that are partly taken up by albumin and participate to the circulating NEFA pool. Liver is known to take up around 25\% of circulating NEFA and can be catabolized or reesterified and stored as TAG [223]. In lactating goats, infused palmitic acid is mostly stored as TAG in the liver [224], indicating that the majority of NEFA released by LPL that reach the liver are likely stored as TAG.

\section{Cellular fate of fatty acids}

\section{Cellular import, intracellular shuttling, and utilization of}

\section{FA by the liver}

Different than monogastric species, the adipose tissue of ruminants accounts for $>90 \%$ of de novo FA synthesis in non-lactating ruminants, while the liver plays a minor role [138]; thus, most of the FA present in the hepatocytes of dairy cows are derived from the diet and from the lipolysis of the adipose tissue. The FA are imported and activated for metabolic utilization as described in the section titled "Molecules involved in intestinal FA absorption". The topic of FA metabolism has been reviewed extensively by other authors [1, 3, 225], so here we will only include a brief summary of the main intracellular processes related to FA metabolism. Acyl-CoA thioesters are recognized by multiple proteins in charge of directing FA to the appropriate organelles, such as FABP and DBI [226]. A model summarizing the various steps in FA uptake by the liver and their utilization is available in Fig. 2.

\section{Catabolism of fatty acids}

The main pathway for FA catabolism is $\beta$-oxidation, which occurs, albeit with key differences, in the mitochondria and the peroxisomes [54]. In order to enter the mitochondria, acyl-CoA must be conjugated to carnitine, which binds to the LCFA forming acylcarnitine [227]. This action is catalyzed by CPT1, of which three isoforms are known (CPT1A, CPT1B and CPT1C) [228] with CPT1A being the most abundantly transcribed in intestine, liver, and mammary (Fig. 1). Acylcarnitine then cross the mitochondrial membrane through the action of carnitine acylcarnitine translocase (CACT, coded by the SLC25A20 gene, Fig. 1). Upon removal of carnitine from acylcarnitine, CACT also returns carnitine to the cytoplasm, where another cycle can begin [227], while the acyl-CoA is oxidized to produce acetyl-CoA for TCA cycle and ultimately production of energy via oxidative phosphorylation, or, if not completely oxidized, ketone bodies production in the liver [226]. While the oxidation of MCFA and LCFA is handled by the mitochondria, very long-chain FA $(\geq 22$ carbons) are not substrate of CPT1 and cannot enter the mitochondria. As such they are shuttled to peroxisomes

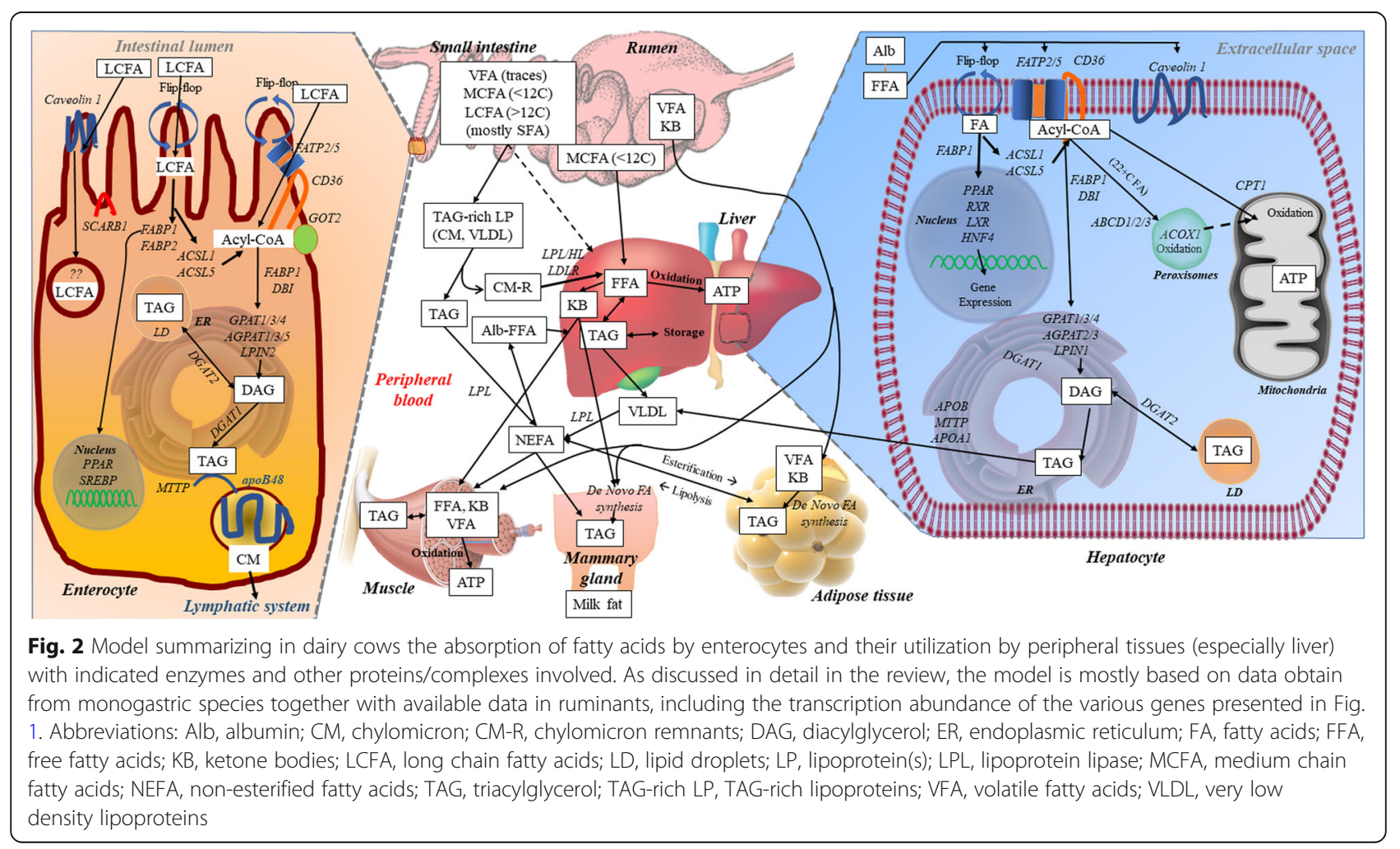


by ATP-binding cassette transporters $(\mathrm{ABCD} 1 / 2 / 3)$ where they undergo incomplete oxidation, are conjugated with carnitine through carnitine O-octanoyltransferase, and are transported to the mitochondria to complete their oxidation [226].

\section{Esterification of fatty acids in triglycerides}

Besides $\beta$-oxidation, intracellular FA can also be esterified into TAG, mainly through the G3P pathway, as described for the enterocytes above. In the final step of TAG synthesis in liver, DGAT1 channels newly formed TAG into VLDL while DGAT2 synthesizes TAG for storage in lipid droplets. Transcription abundance of both DGAT isoforms are very similar in liver (Fig. 1). Finally, lipid droplets can be hydrolyzed, and the resulting FA can be routed into VLDL for secretion, again by DGAT1 [229].

Synthesis and secretion of VLDL from hepatocytes is regulated by rates of synthesis of apolipoprotein B100. Lipid components are added to apolipoprotein B by MTTP [230]; after glycosylation of the apolipoproteins and secretion from the Golgi membrane, VLDL fuse with membrane and are released into the blood.

In liver of monogastrics, exogenous FA are preferentially stored as TAG in lipid droplets, while de novo synthesized FA are likely channeled to TAG synthesis for VLDL formation [231], this is also true in ruminants, as most of the $1-{ }^{14} \mathrm{C}$ palmitic acid infused into jugular is stored as TAG in the liver of lactating goats [224]. As a consequence of the different fates of de novo-synthesized and exogenous FA in liver, animals with lower rates of FA synthesis in the liver display lower rates of VLDL secretion: in ruminants (cows [232] and goats [233]), that is indeed the case. Lower secretion of VLDL in ruminants vs. monogastrics has been known for some time, as reviewed by others more than two decades ago [111, 234, 235]. The liver in ruminants has a low capacity for de novo FA synthesis compared to monogastrics where, in the latter, the liver is the main lipogenic organ [138]. The low de novo synthesis of FA in the liver can help to explain the low VLDL secretion in ruminants; however, the fundamental reason for the observed difference in VLDL secretion between ruminants and monogastric animals has not been fully elucidated.

Availability of FA in the hepatocyte, while certainly a factor in determining VLDL secretion, is less important than the source of said FA, as is noted in monogastrics, where an increase in plasma NEFA stimulates VLDL secretion in the liver [236]. This is of particular interest in the context of dairy cattle nutrition in the transition from pregnancy to lactation, where a significant increase in circulating NEFA is expected, due to the lipolysis of the adipose tissue in response to the negative energy balance experienced by the animals [223]. However, despite the ability of the liver to decrease hepatic TAG content by increasing VLDL secretion when circulating NEFA are high, an imbalance between FA import and secretion is possible in the peripartum period, which leads to hepatic TAG accumulation [111, 237]. When the accumulation of TAG in liver becomes severe $(>10 \% \mathrm{DM})$ the organ is unable to work properly [238]. Moderate and severe fatty liver in dairy cows are associated with several metabolic diseases, negatively affecting reproductive performance and the immune system $[239,240]$. Interestingly, cows that are overfed in the dry period display greater accumulation of TAG in the liver post-partum likely due to higher NEFA in plasma, as well as increased transcription of stress and inflammation-related genes compared to cows fed a balanced diet [241]. This is in line with the finding that NEFA are preferentially stored as TAG. On the other hand, if NEFA are mostly reesterified in the liver, they are less available to affect the transcriptome. However, it has been previously argued that NEFA may be important to control the transcriptome of the liver of dairy cows early postpartum [5]. Results from our laboratory show that NEFA can modulate PPAR, with a marked dose-dependent response [168].

\section{Regulation of the transcriptome by fatty acids}

Fatty acids are bioactive in several ways, including affecting the transcriptome. This is mediated by certain TF that serve as transcriptional regulators. The activity of the TF is modulated either directly via the binding of FA to a ligand pocket and subsequent activation or repression or indirectly. Review about transcription factors that respond to FA in ruminants [4] or monogastrics [225] are available elsewhere. Here we provide an overview and some updated information regarding the role of those TF and their modulation by FA in ruminants in general but more specifically in dairy cows.

\section{Peroxisome proliferator-activated receptors}

A comprehensive review on PPAR in ruminants was published few years ago [5]. The PPAR are transcription factors belonging to the nuclear receptor superfamily. Three isotypes have been characterized: PPAR $\alpha$, highly transcribed in tissues that rely significantly on FA catabolism such as liver, kidney, adipose tissue, and muscle; $\operatorname{PPAR} \beta / \delta$ with a widespread transcription pattern; and PPAR $\gamma$, of which two isoforms are known: PPAR 1 , with a widespread transcription pattern, and PPAR $\gamma 2$, detected at high level in the adipose tissue [5].

Ligands of PPAR are primarily LCFA and eicosanoids. These interact with PPAR by directly binding its ligandbinding domain, causing it to form a heterodimer with another nuclear receptor, the retinoid X receptor (RXR). The PPAR-RXR complex subsequently bind the DNA at 
specific recognition sites termed PPAR response elements initiating the transcriptional cascade [242].

The three PPAR isotypes are primarily involved in transcriptional regulation of genes coding for proteins related to lipid metabolism [5]. PPAR $\alpha$ plays a pivotal role in all aspect of the catabolism of FA, including uptake of FA, carnitine synthesis and carnitine uptake into cells, FA transfer into mitochondrion by CACT, and $\beta$ oxidation in mitochondria and peroxisomes, especially in the liver [243] (Fig. 1). PPAR $\beta / \delta$ regulates fatty acid catabolism in the muscle of monogastric animals [244]. Recent studies revealed this PPAR isotype playing essential roles in many more functions than regulation of lipid metabolism in the muscle, including FA oxidation in the liver and immune system [245]. There are few studies in ruminants about $P P A R \beta / \delta$. It was originally hypothesized that this PPAR isotype plays a role in regulating glucose uptake and lactose synthesis in bovine mammary gland $[4,5]$ but in vitro data using bovine mammary cells did not support the hypothesis [246]. However, data indicated a role of PPAR $\beta / \delta$ in lipid metabolism in goat mammary cells, particularly FA oxidation and lipid secretion [247]. The PPAR $\gamma$ has been the most studied in dairy cows. In monogastrics this PPAR isotype is a pivotal player in adipogenesis and insulin sensitivity, but in dairy cows it has been specifically studied for its role in modulating milk fat synthesis [248-250], its involvement in the mTOR pathway, particularly mTORC2 [251], and its anti-inflammatory role $[4,5]$. All PPAR isotypes play a role in improving reproductive parameters of dairy cows, such as the mitigation of endometritis [252], contribution to folliculogenesis [253], reproductive hormone synthesis [253], and the development of embryos [254]. All PPAR isotypes were found to be upregulated in response to naturally occurring prostaglandins in bovine uterine cells [255]. All above support a role of the three PPAR isotypes in bovine reproductive health.

In studies previously reviewed $[4,5]$, all PPAR isotypes, including PPAR $\gamma$, appears to be activated mainly by SFA, with UFA only displaying partial or null activation. The insensitivity of PPAR to UFA, which is contrary to what observed in monogastrics $[4,5]$, is also supported by recent studies on the regulation of milk fat synthesis by trans-10,cis-12 CLA, which is known to depress milk fat synthesis [256]. PPARY and some of its putative target genes were downregulated upon trans-10,cis-12 CLA supplementation in goat mammary cells and mouse mammary tissue $[257,258]$. Though in vitro the PPARy agonist rosiglitazone upregulates the transcription of several lipogenic genes in bovine mammary cells [72] and appears to be a central player in the mouse mammary response to CLA [258], supplementation of rosiglitazone in vivo did not attenuate milk fat depression caused by CLA in mice [259]. Similarly, the use of the putative PPAR $\gamma$ agonist 2,4-thiazolidinedione did not prevent milk fat depression induced by CLA in dairy sheep [260]. Data from our laboratory do not support 2, 4-thiazolidinedione be a PPARY agonist [4, 261, 262]. As argued previously $[4,263]$, PPAR $\gamma$ is one of the players in a larger network of transcription factors regulating milk fat synthesis, with a pivotal role of SREBP1. The presence and activation of SREBP1 is essential for milk fat synthesis and PPAR $\gamma$ appears unable to rescue milk fat synthesis once SREBP1 activity is compromised.

The study of PPAR activation by FA was mainly carried out using transcription of established or putative target genes based on studies in monogastric species. As argued previously [4], there is the need to use more precise molecular techniques to study the activation of each PPAR isotypes by FA. Using a combination of a PPAR $\gamma$ synthetic agonist and inhibitor with various LCFA in goat mammary cells, it was determined that C18:0 is an agonist of PPARy but not C16:0. Interestingly, in that study it was observed that a basal activation of PPAR $\gamma$ is essential for the down-regulation of lipogenic genes by CLA, while activation of PPARy blocks the negative effect of DHA on the same genes [195]. More recent data generated using a gene reporter assay support C16:0 to be an agonist of PPAR $\alpha$ and PPAR $\beta / \delta$ but not PPAR $\gamma$ in bovine mammary and hepatic cells [168].

Evidences for activation of ruminant PPAR in vivo exist: activation of PPAR $\alpha$ with a synthetic agonist increased hepatic FA oxidation in goats [264] and beef steers fed a whole shelled corn diet, higher in fat, had greater transcription of PPAR $\alpha$ and PPAR target genes [265]; however, supplementation of FA in vivo do not always activate PPAR [4]. Additionally, PPAR $\beta / \delta$ and PPAR $\gamma$, but not PPAR $\alpha$ are activated by circulating NEFA present in plasma of early lactation cows [168]. Finally, an interesting but yet unexplored avenue is the activation of bovine PPAR by non-FA ligands, such as those naturally occurring in plants, such as boiogito [266], honokiol [267], berberine [268], and cannabinoids [269].

\section{Sterol regulatory element-binding proteins}

The SREBP exist in three isoforms: SREBP1a, SREBP1c, and SREBP2. The SREBP are part of the transcriptional regulators of the basic helix-loop-helix leucine zipper family. The mechanism of SREBP formation and activation is well established as previously reviewed [157]. The immature and inactive SREBP is retained in the ER by the interaction with the cleavage-activating protein (SCAP) and insulin induced gene 1 (INSIG1). The latter retains the complex in the ER preventing SREBP activation. Upon lower level of cholesterol or FA, the INSIG1 is degraded after ubiquitylation and releases the SCAPSREBP complex. SREBP is then cleaved and the $\mathrm{N}$ - 
terminal domain relocates to the nucleus and activates transcription of SREBP target genes via a sterolregulatory elements in the promoter region of target genes [157]. SREBP are involved in the regulation of lipid metabolism, with SREBP1 mainly involved in FA synthesis and desaturation (especially SREBP1c), and SREBP2 in cholesterol biosynthesis [270].

Research on the role of SREBP in ruminant was initiated with the work of Bauman's group at Cornell in the regulation of milk fat synthesis, specifically in milk fat depression, as previously reviewed [263]. More evidences have accumulated providing a strong support for this transcription factor to be a central player in the control of milk fat synthesis in several ruminant species [271-275]. Its regulation of milk fat appears to be by a direct regulation of milk-fat synthesis related genes and through mTOR, as previously proposed [263]. Interestingly, it has been posited that the connection between SREBP1 and the mTOR pathway is through regulation of nuclear entry of lipin 1 (phosphorylated by mTOR), which would inhibit activity of SREBP1 [276]. Interestingly, LPIN1 is a target of PPAR, which would suggest a possible connection between PPAR and SREBP1 as well [5].

Unlike other receptors, SREBP do not bind FA directly; however, the effect of FA on SREBP is indirect [263]. Activity of SREBP1 is inhibited by UFA, particularly PUFA [157]. The UFA can interact with ubiquitin regulatory $\mathrm{X}$ domain-containing protein 8 , an essential enzyme for the ubiquitylation of INSIG1, inhibiting its action and, thus, reducing the activity of SREBP, as demonstrate in monogastric species [157]. Besides the role of UFA on SREBP, also SFA can affect this TF. In an in vitro study in bovine mammary epithelial cells, upregulation of SREBP1 and its target genes was detected in response to C18:0 treatment [271]. In the same study, treatment with $\mathrm{C} 18: 0$ also increased the transcription of PPARG. It is possible that the effect of C18:0 is not directly on SREBP1 but via activation of PPAR $\gamma$, as previously argued [263]; however, the relation between SREBP1 and PPAR in bovine mammary and the concerted regulation of milk fat synthesis is far from being fully elucidated.

Additional nutritional compounds beside FA can regulate SREBP1 in bovine mammary epithelial cells, such as methionine [277] which is partly mediated by FABP5 [278]. Alongside milk fat synthesis, SREBP1 plays other roles in dairy cows, such as the demonstrated role in regulating homeostasis of the sodium/iodide symporter in mammary epithelial cells, as observed in humans [279], and it is involved in liver lipid metabolism in peripartum cows [263], including regulation of TAG synthesis in bovine hepatocytes $[280,281]$. Interestingly, the mRNA abundance of SREBF1 and SREBF2 is remarkable similar between jejunum, liver, and mammary tissue in dairy cows (Fig. 1). Based on these results, dietary modulation of SREBP in ruminants would seem an avenue worth investigating.

\section{Hepatocyte nuclear factor 4}

A member of the nuclear hormone receptor superfamily, the hepatocyte nuclear factor 4 (HNF4) is a transcription factor mainly involved in the regulation of transcripts in the liver [282]. Its canonical activation mechanism is different than that of PPAR: while PPAR form a heterodimer with RXR, HNF4 bind its response element as a homodimer, that is, a fusion of two HNF4 monomers [283]. Two isotypes of HNF4 (HNF4 $\alpha$ and HNF4 $\gamma$ ) have been characterized. Among the two, HNF4 $\alpha$ is the most important for the liver and intestine. In dairy cows, the transcription of the two HNF4 is very low in mammary tissue but more abundant and similar in intestine and liver (Fig. 1). In adult mice, HNF4 $\alpha$ is involved in the regulation of inflammation in the liver and intestine [284], mediating cytokines relays in hepatocytes and tight junction formation in the intestine [285], and it is associated with transcriptional regulation at the early stages of embryonic hepatocyte differentiation [286], possibly through remodeling of chromatin structure and the ensuing modulation of transcripts [287]. In the intestine $\mathrm{HNF} 4 \alpha$ regulates FA oxidation and differentiation, as recently observed in mice [288].

In ruminants, information on the role of HNF4 is scarce. Possible roles of this TF in ruminants were previously reviewed $[4,263]$. Very little information on the function of HNF4 $\alpha$ was generated after those reviews. A recent study has found HNF4 binding sites in the proximal promoter of the cytochrome P450 3A gene in the bovine genome, suggesting that HNF4 might play a role in the response to xenobiotic [289]. While a complete picture of the ligands of HNF4 is not available, evidence in monogastrics supports a role of FA and acyl-CoA thioesters in the regulation of its activity: HNF4 $\alpha$ was found to bind strongly to linoleic acid [290], as well as C17:0 cyclo, and, to a less extent, C16:0 [291]. Whether HNF4 can be activated by dietary FA or other dietary compounds in dairy cows remains to be determined.

\section{Liver $\mathrm{X}$ receptor}

Discovered and subsequently characterized in 1994 [292], LXR is another member of the nuclear receptor superfamily. Two LXR isotypes are known, LXR $\alpha$ and LXR $\beta$ (coded by NR1H3 and NR1H2, respectively). Transcription of LXR isoforms is somewhat similar between liver, intestine, and mammary tissue, with a higher mRNA abundance of NR1H3 in liver and intestine compared to mammary tissue (Fig. 1). Both LXR isoforms play a crucial role in regulating cholesterol homeostasis [293]. As such, it is perhaps 
unsurprising that the main ligands of LXR are oxysterols, monooxygenated derivates of cholesterol [294]; other known LXR ligands are $D$-glucose and $D$ glucose-6-phosphate [295]. LXR activation is achieved through the formation of a heterodimer with RXR, and the subsequent binding to an LXR response element in the promoter region of target genes [296].

In monogastrics LXR is involved with regulating cholesterol excretion in the intestine [297], generating more cholesterol by shifting acetyl-CoA from cholesterol biosynthesis to de novo FA synthesis, mainly via regulation of SREBP-1c [298] and fatty acid synthase (FASN) [299], and regulating intestinal absorption of cholesterol [300].

Research on the role and possible dietary activation of LXR in ruminants is still in its infancy and was previously reviewed $[4,263]$. More recent data support important role of both LXR isoforms in regulating milk fat synthesis partly via modulation of SREBF1 transcription in goat mammary epithelial cells [273, 301, 302]. In bovine vascular cells activation of both LXR isoforms increased synthesis of SFA, particularly C18:0, and MUFA and increased calcification of the vascular cells [303]. In the same study, it was demonstrated that C18:0 increases mineralization of the cells by increasing transcription of alkaline phosphatase. Unfortunately, the researchers did not test if C18:0 is an agonist of LXR, but it might be a possibility. A role of the LXR pathway in determining milk cholesterol content was postulated by using data from a genome-wide association study [304]. Data in monogastrics indicate a negative effect of UFA on the activity of LXR [225]; however, the effect of UFA is not fully substantiated as previously argued [4]. To our knowledge, there are not data available in ruminants on the role of FA in modulating LXR.

\section{Free fatty acid receptors}

Besides TF, also the $\mathrm{G}$ protein-coupled receptors (a.k.a., FFAR) can sense the level of extracellular FA and affect the biology of cells, although not directly by altering the transcription of specific genes. The FFAR affect metabolic functions, including glucose metabolism, and regulate immune system, especially FFAR2 and FFAR3, that are activated by SCFA, as recently reviewed for monogastrics $[305,306]$.

An excellent review on functions and activation by FA of FFAR in dairy cows was recently published [307]. According to that review, FFAR1 and FFAR4 are activated by LCFA, especially UFA, and FFAR2 and FFAR3 are activated by SCFA. All play important roles in the innate immune system with an apparent pro-inflammatory role, especially FFAR1, involving neutrophils and mammary epithelial cells. Recently, it was demonstrated a role of DHA in activating FFAR4 in bovine neutrophils increasing superoxide production which could improve the killing capacity of those cells [308]. The FFAR also play a role in reproduction in dairy cows, as in bovine endometrial cells and granulosa cells DHA activates FFAR4 inducing intracellular release of calcium in the endometrium [309], important for prostaglandins synthesis, and proliferation of the granulosa cells [310]. The FFAR1 and the FFAR2 were detected to be expressed in liver of peripartum cows with the transcription of FFAR1 being decreased by high level of BHBA, although the roles of those receptors in the liver of dairy cows is still unclear [311] and their transcription is relatively low in liver of dairy cows (Fig. 1).

\section{Role of dietary fatty acids on milk FA composition and health and performance of dairy cows}

Dietary FA affect milk fat but also affect reproductive performance and can help animals to cope with the biological stress during the peripartum. In this section, we review the most recent findings associated with the role of dietary FA on milk fat composition, especially the ones associated with human health, and their role in health and performance of dairy cows.

Milk is an interesting food matrix where fat is present mostly as TAG (98\%), and other type of lipids such as DAG (around 2\% of the lipid fraction), cholesterol (less than $0.5 \%$ ), phospholipids (about 1\%) and free FA (about $0.1 \%$ ) [312] are a minor part. Milk FA are originated from two sources, the preformed FA found in the feed and from microbial activity in the rumen [313]. In other words, FA in bovine milk are produced by de novo synthesis in the mammary gland mostly using byproducts of the rumen microbial fermentation or taken up from plasma lipids. The latter are also somewhat a mixture of dietary FA, microbial FA, and de novo synthesized FA mainly produced by the adipose tissue also using acetate from the rumen. Generally, C4:0 to C14:0 and some C16:0 are produced de novo in the mammary gland [314]. Preformed FA are generally considered to contain approx. half of the C16:0 and all the other FA with more than 16 carbon atoms [315]. Most of the FA in milk are SFA (such as C16:0 and C18:0) with high amount of some UFA (such as cis-9 C18:1) (Table 1).

\section{Role of dietary fatty acids on milk yield}

The response of dairy cows in term of milk yield to fat supplement is likely mostly the consequence of the energy content of the fat as it provides energy to sustain lactation and other energy expenditures in productive cows. Because of this and the fact that early post-partum cows experience negative energy balance, fat supplementation could have greater effects during early lactation than in late lactation [317].

Milk yield is mostly driven by dry matter intake. Supplementing dairy cow diets with high amounts of UFA 
Table 1 Typical fatty acid profile from retail whole milk in Chile (3.5\% of fat content)

Fatty acids, g/L

Mean \pm SE

De novo synthesis

C4:0

$1.18 \pm 0.18$

C6:0

$0.68 \pm 0.01$

C8:0

$0.37 \pm 0.01$

C10:0

$0.87 \pm 0.03$

C11:0

$0.10 \pm 0.01$

C12:0

$1.04 \pm 0.04$

C13:0

$0.02 \pm 0.001$

C14:0

$3.62 \pm 0.14$

C14:1 cis-9

$0.17 \pm 0.06$

C15:0

$0.34 \pm 0.02$

C15:1 iso

$0.07 \pm 0.004$

De novo synthesis and performed

$$
\text { C16:0 }
$$

$9.89 \pm 0.29$

Preformed fatty acid

C16:1 cis-9

$0.48 \pm 0.05$

C17:0

$0.23 \pm 0.04$

C17:1 cis-9

$0.07 \pm 0.01$

C18:0

$2.84 \pm 0.40$

C18:1 trans-9

$0.01 \pm 0.01$

C18:1 trans-10

$0.007 \pm 0.01$

C18:1 trans-11

$0.22 \pm 0.09$

C18:1 cis-9 ${ }^{\mathrm{a}}$

$6.23 \pm 0.41$

C18:2 trans-9, trans-12

$0.09 \pm 0.01$

C18:2 cis-9, cis-12

$1.31 \pm 0.74$

C20:0

$0.40 \pm 0.29$

C18:3 cis-6, cis-9, cis-12

$0.03 \pm 0.01$

C18:3 cis-9, cis-12, cis-15

$0.05 \pm 0.03$

C18:2 cis-9, trans-11

$0.05 \pm 0.03$

C21:0

$0.20 \pm 0.05$

C20:2

$0.009 \pm 0.002$

C20:3 n-6

$0.03 \pm 0.02$

C20:3 n-3

$0.03 \pm 0.01$

C20:4 n-6

$0.02 \pm 0.005$

C22:2

$0.013 \pm 0.003$

C20:5 n-3

$0.01 \pm 0.004$

C22:6 n-3

$0.03 \pm 0.01$

$\Sigma$ Saturated fatty acids

$21.85 \pm 0.30$

$\Sigma$ Monounsaturated fatty acids

$7.28 \pm 0.50$

$\Sigma$ Polyunsaturated fatty acids

$1.73 \pm 0.71$

Adapted from Vargas-Bello-Pérez et al [316]. Data was based on 8 samples

a18:1 cis-9 is partly derived from the delta-9 desaturase activity, which can be considered part of de novo synthesis, although preformed FA are used as substrate 
Table 2 Effect of dietary vegetable or marine supplements on the fatty acid composition of bovine milk when animals are fed on corn silage-based diets

\begin{tabular}{|c|c|c|c|}
\hline Lipid supplements used & Effect on milk fatty acids & Milk yield & Ref. \\
\hline $\begin{array}{l}\text { 1) Control (corn silage based TMR) } \\
\text { 2) Fish oil (FO; 3\%DM) } \\
\text { 3) Soybean oil (SO; 3\%DM) }\end{array}$ & $\begin{array}{l}\uparrow \text { SFA FO and SO } \\
\uparrow \text { trans- C18:1; } \uparrow \text { cis-9, trans-11 C18:2 by FO }\end{array}$ & No effect & [319] \\
\hline $\begin{array}{l}\text { 1) Control (corn silage based TMR) } \\
\text { 2) Olive oil (OO; } 3 \% \mathrm{DM}) \\
\text { 3) Hydrogenated palm oil (HPO; } 3 \% \mathrm{DM})\end{array}$ & $\begin{array}{l}\downarrow \text { SFA by } O 0 \\
\uparrow \text { cis-9 C18:1; } \uparrow \text { cis-9, cis-12, cis-15 C18:3 by OO }\end{array}$ & $\uparrow$ by $\mathrm{OO}$ & [320] \\
\hline $\begin{array}{l}\text { 1) Control (corn silage based TMR) } \\
\text { 2) Soybean oil (SO; } 3 \% \mathrm{DM}) \\
\text { 3) Hydrogenated palm oil (HPO; 3\%DM) }\end{array}$ & $\uparrow \mathrm{C} 18: 1$ trans including trans- $11 \mathrm{C} 18: 1$ by SO & No effect & [321] \\
\hline $\begin{array}{l}\text { 1) Control (corn silage based TMR) } \\
\text { 2) Fish oil (FO; } 2.6 \% \mathrm{DM}) \\
\text { 3) FO (1.3\%DM) + HPO (1.3\%DM) }\end{array}$ & $\begin{array}{l}\uparrow \mathrm{C} 18: 1 \text { trans- } 11 ; \uparrow \mathrm{DHA} ; \downarrow \text { C6:0, C8:0, C10:0 and } \\
\mathrm{C} 14: 0 \text { by FO }\end{array}$ & No effect & [322] \\
\hline $\begin{array}{l}\text { 1) Control (corn silage based TMR) } \\
\text { 2) Soybean oil (SO; } 2.3 \% \mathrm{DM}) \\
\text { 3) Linseed oil (LO; } 2.3 \% \mathrm{DM})\end{array}$ & $\begin{array}{l}\uparrow \text { PUFA; } \uparrow \text { cis-9, trans-11 C18:2; } \downarrow \text { SFA by SO } \\
\text { and LO }\end{array}$ & No effect & [154] \\
\hline $\begin{array}{l}\text { 1) Control (corn silage based TMR) } \\
\text { 2) Extruded linseed (EL; } 22 \mathrm{~g} / \mathrm{kg} \mathrm{DM)} \\
\text { 3) Ca salts of palm and linseed oils (PLO; } 22 \mathrm{~g} / \mathrm{kg} \mathrm{DM} \text { ) } \\
\text { 4) Milled rapeseed (MR; } 22 \mathrm{~g} / \mathrm{kg} \mathrm{DM)}\end{array}$ & $\uparrow C L A ; \downarrow$ SFA by EL, PLO, and MR & $\begin{array}{l}\uparrow \text { by } \mathrm{EL} \\
\uparrow \text { by } \mathrm{PLO} \\
\uparrow \text { by } \mathrm{MR}\end{array}$ & [323] \\
\hline $\begin{array}{l}\text { 1) Prilled fat ( } 3.5 \% \mathrm{DM}) \\
\text { Unprocessed oilseeds: } \\
\text { 2) Rapeseed (6.9\%DM) } \\
\text { 3) Cottonseed (18.4\%DM) } \\
\text { 4) Linseed (7.5\%DM) }\end{array}$ & $\begin{array}{l}\uparrow \text { MUFA; } \uparrow \text { PUFA by all three unprocessed } \\
\text { oilseeds }\end{array}$ & No effect & [324] \\
\hline $\begin{array}{l}\text { 1) Control (corn silage based TMR) } \\
\text { 2) Microalgae } 2 \mathrm{~g} / \mathrm{kg} \mathrm{DM} \\
\text { 3) Microalgae } 4 \mathrm{~g} / \mathrm{kg} \mathrm{DM} \\
\text { 4) Microalgae } 6 \mathrm{~g} / \mathrm{kg} \mathrm{DM}\end{array}$ & $\begin{array}{l}\downarrow \text { C18:0, } \downarrow \text { cis-9 C18:1, } \downarrow \text { cis-9, cis-12 C18:2; } \downarrow \text { cis-9,12,15 } \\
\text { C18:3; } \uparrow \text { cis-9, trans- } 11 \text { C18:2; } \uparrow \text { trans-9 C18:1; } \uparrow \text { trans- } 11 \\
\text { C18:1 by microalgae }\end{array}$ & No effect & [325] \\
\hline $\begin{array}{l}\text { 1) Control (corn silage based TMR } \\
\text { 2) Rubber seed oil (RO; } 4 \% \mathrm{DM}) \\
\text { 3) Flaxseed oil (FO; } 4 \% \mathrm{DM}) \\
\text { 4) } 2 \% \mathrm{DM} \text { of } \mathrm{RO} \text { and } 2 \% \mathrm{DM} \text { of } \mathrm{FO}\end{array}$ & $\uparrow$ trans-11 C18:1; $\uparrow$ cis-9, trans- 11 C18:2 by RO and FO & $\begin{array}{l}\uparrow \text { by } R O \\
\uparrow \text { by } F O \\
\uparrow \text { by } R O+F O\end{array}$ & [326] \\
\hline $\begin{array}{l}\text { 1) Control (corn silage TMR) } \\
\text { 2) Palmitic acid TAG (PA; } 1.7 \% \mathrm{DM}) \\
\text { 3)Ca-salts of palm FA (CAF; } 1.8 \% \mathrm{DM})\end{array}$ & $\begin{array}{l}\downarrow \text { de novo/preformed FA by PA and CAF } \\
\uparrow \text { C16:0 by PA }\end{array}$ & $\uparrow$ by PA and CAF & [327] \\
\hline $\begin{array}{l}\text { 1) Control (sorghum silage TMR) } \\
\text { 2) Palmitic acid (PA; } 4 \% \mathrm{DM})\end{array}$ & $\uparrow$ SFA by PA & $\uparrow$ by PA & [152] \\
\hline $\begin{array}{l}\text { Corn silage TMR's with: } \\
\text { 1) Ca salts of palm oil (PA; } 12.3 \% \mathrm{DM}) \\
\text { 2) Corn grain and wheat (GW; } 13.4 \% \text { corn } \\
\text { silage, } 4 \% \mathrm{DM} \text { barley grain, } 12 \% \mathrm{DM} \text { wheat } \\
\text { starch, } 25 \% \mathrm{DM} \text { wheat middlings) } \\
\text { 3) Extruded rapeseeds (RS; } 24.5 \% \mathrm{DM}) \\
\text { 4) Extruded sunflower seeds (SS; } 24.5 \% \mathrm{DM})\end{array}$ & $\begin{array}{l}\uparrow \text { SFA by PA and GW } \\
\uparrow \text { MUFA by RS and SS }\end{array}$ & No effect & [328] \\
\hline $\begin{array}{l}\text { 1) Corn silage TMR } \\
\text { 2)C16:0 (PA; } 1.5 \% \mathrm{DM}) \\
\text { 3)C16:0 and C18:0 (MIX; } 1.5 \% \mathrm{DM})\end{array}$ & $\begin{array}{l}\downarrow \text { de novo synthesis by PA and MIX } \\
\uparrow \mathrm{C} 16: 0 ; \uparrow \text { cis-9 } \mathrm{C} 16: 1 \text { by PA and MIX }\end{array}$ & No effect & [329] \\
\hline $\begin{array}{l}\text { 1)Control } \\
\text { 2)C16:0 (PA; 2\%DM) } \\
\text { 3) Ca salt of C16:0 (CaPA; 2\%DM) }\end{array}$ & $\downarrow$ de novo synthesis by PA and CaPA & No effect & [330] \\
\hline $\begin{array}{l}\text { 1) Enriched C16:0 (P; } 20 \mathrm{~g} / \mathrm{kg} \mathrm{DM}) \\
\text { 2) C16 + C18 (PS; } 13 \text { and } 7 \mathrm{~g} / \mathrm{kg} \mathrm{DM}) \\
\text { 3) C16 + C18 (SP; } 7 \text { and } 13 \mathrm{~g} / \mathrm{kg} \mathrm{DM}) \\
\text { 4) Enriched C18:0 (S; } 20 \mathrm{~g} / \mathrm{kg} \mathrm{DM})\end{array}$ & $\begin{array}{l}\uparrow \text { UFA by } S \\
\uparrow \text { de novo FA by } S\end{array}$ & No effect & [331] \\
\hline
\end{tabular}

$\uparrow=$ increase; $\downarrow=$ decrease. 
often cause a drop in feed intake, as discussed in the "Inhibition of feed intake by dietary FA" section of this review. The drop in DMI by high amount of dietary UFA can negatively affect milk yield [318]. However, as observed in the various studies presented in Table 2, when animals are fed with free oils (i.e., soybean and linseed oils) at an inclusion of $\leq 3 \% \mathrm{DM}$, there is not a detrimental effect on milk yield and may be associated to the fact that at that inclusion rate these oils do not affect DMI [154]. Bu et al. [332], supplemented cows with soybean oil or fish oil alone or in combination at 4\% DM resulting in an increase in milk yield compared with the control treatment with no added fat. Other experiments with higher amounts of oil supplementation have not reported negative effects on milk yield such as Huang et al. [333] where animals were fed with either 5\% DM of soybean oil, $5 \%$ DM of Ca salts of CLA or 5\% DM of both. Similarly, in a grazing system, cows were fed with linseed oil at 2.5\% DM, 5.1\% DM and 7.7\% DM without changes in milk yield [334].

The forage to concentrate ratio (F:C) can play an important role in determining the effect of supplemented oils on milk yield in dairy cows [1]. As an example, in the study by Ueda et al. [335], supplementation of up to 3\% DM of linseed oil depressed rumen digestibility only in dairy cows receiving a low $\mathrm{F}: \mathrm{C}$ ratio $(35: 65)$ but not in cows receiving a high F:C ratio (65:35). Jenkins and Harvatine [336] argued that a proper fat supplementation to dairy cows should account for the total UFA present in the fat supplemented and the amount of dietary fiber. Therefore, it is crucial to balance the amount of fat supplemented in the diet, which should not exceed 5\% DM, and the amount, type, and the digestibility of dietary fiber [337]. Other factors affecting DMI when animals are supplemented with oils are palatability, chain length and saturation of FA, and the form of fat (e.g., free FA, TAG, glycolipids) [338].

If all the above variables are considered, then the animal should be able to benefit from the energy supplied by the dietary FA and have a proper rumen function. Taken together, different effects of oil supplements on the DMI and milk yields presented in Table 2 may be attributed to the oil palatability, the amounts added, and the varying $\mathrm{F}: \mathrm{C}$ ratio [326].

In Table 2 are summarized six recent studies were dairy cows were supplemented with SFA. In two out of six studies milk yield was increased in animals supplemented with SFA (all using C16:0) with not effects of SFA supplementation on milk yield in the other four studies, Thus, feeding SFA can improve milk yield but not always.

\section{Role of dietary fatty acids on milk fat composition}

Today, there is an active debate on whether consuming milk fat is positive for human health [339]. It is known that unique individual milk FA are bioactive and can prevent metabolic diseases at least in animal models [340]. Nutrition of dairy cows is the most practical and economical way to increase the contents of bioactive FA in milk and dairy products. Efforts have been done to modulate the milk FA profile towards a healthier fat (less SFA) for human consumption. A metanalysis on the effect of supplementing oil to milk fatty acid composition in dairy cows was published more than 10 years ago [341]. Since then, extensive research was accomplished in assessing the supplementation of different feedstuffs to improve milk fat composition such as microalgae, cottonseed, flaxseed, extruded soybean, extruded linseeds, rubber oil, fish oil, soybean oil, hydrogenated vegetable oil, calcium salts of palm and fish oil (Table 2).

Most of the studies presented in Table 2 encompass the use of UFA to supplement dairy cows. These studies were designed to reduce the total contents of SFA in milk [319, 320, 323]. Cows were fed with different lipid sources, most of them UFA that promoted a shifts in the rumen biohydrogenation process and thereby increasing intermediate byproducts (i.e., CLA and trans-11 C18:1), and decreasing SFA (i.e., C16:0 and C18:0). Marine feedstuffs such as fish oil and microalgae have strong impacts on rumen biohydrogenation that often leads to increase in some trans C18:1 and CLA [322, 325]. Dietary vegetable oils such as soybean oil often leads to changes in ruminal microbial populations and shifts in ruminal fermentation parameters affecting cellulolytic bacteria such as Fibrobacter succinogenes, Ruminococcus flavefaciens, Ruminococcus albus and Butyrivibrio fibrisolvens that are important in the biohydrogenation process of PUFA [342]. Cellulolytic bacteria are affected by dietary supplementation of lipids with high concentrations of PUFA, as discussed in the "Effects of fatty acids on microbiota of the rumen" section of this review.

Production systems can also be different in their milk FA profile, for example, compared with cows fed on total mixed ratios (based on corn silage), milk of cows fed on pasture-based diets (either full grazing or based on grass silage) has higher concentration of some UFA such as various trans C18:1, C18:2, and C18:3 [313]. The high proportion of C18:3 in milk of grazing cows is due to the high amount of this FA in the galactosyl diacylglycerols constituting the thylakoids [343], the main membrane structure of the chloroplast. Due to the large amount of PUFA and the concomitant high fermentability, fresh pasture can induce milk fat depression [344]. However, the rumen dynamic of biohydrogenation of PUFA in fresh grazing plants is complex and is affected by several factors, as reviewer by Buccioni et al. [343]. The biohydrogenation of $\mathrm{C} 18: 3$ in the rumen is decreased when this FA is associated with the membrane fraction [343]. Recent in vitro data demonstrated that 
biohydrogenation of PUFA is decreased when associated with complex lipid fractions, such as phospholipids and cholesterol ester, compared to simple lipid fractions, such as TAG [17]. The utilization of FA from grazing plants is also determined by the composition of the pastures. There are secondary compounds that can affect the lipolysis and rumen utilization of plant-derived FA in the rumen, such as the presence of polyphenol oxidase in red clover that protect glycerol-based lipid from lipolysis in the rumen [345].

\section{Effect of dietary fatty acids on reproductive performance} Dietary FA are crucial in the reproductive performance of dairy cows due to their influence on the energy balance and reproductive processes that are not just related to energy supply [346]. Fat supplementation has been associated with positive and negative effects on reproduction [347] and the amount of supplemental fat needed to elicit an effect on reproductive function may vary. For example, while some studies indicated that the amount of added vegetable oil necessary to maximize positive ovarian effects is not less than $4 \%$ DM [348], others have reported that fat supplementation at 3\% DM has often positive influence in the reproductive status of the dairy cows [349].

Feeding fat to cattle generally improves establishment and maintenance of pregnancy. Potential improvements in fertility of cows caused by supplementing cows with fat have generally been associated with enhanced follicle development postpartum, increased diameter of the ovulatory follicle [346], increased progesterone (PG) concentrations during the luteal phase of the cycle [349], altered uterine/embryo cross-talk by modulating PG synthesis, and improved oocyte and embryo quality [350]. Some of these effects have been more influenced by the type of FA than by fat feeding per se as differential responses in vivo to FA feeding suggest that UFA of the $\mathrm{n}-6$ and n-3 families are most beneficial for fertility [351, 352].

\section{Unsaturated fatty acids}

Lipids play critical roles in the structure and function of cell membranes and cytoplasm of oocytes affecting their development competence [353]. Diets enriched with n3 PUFA increase membrane fluidity and n-3 PUFA derived eicosanoids, such as prostaglandins, leukotrienes, thromboxane and lipoxins [354]. In monogastrics, the n3 PUFA bind FFAR1 and FFAR4 [306] affecting fertility as FFAR4 can modulate signaling of mitogen-activated protein kinases MAPK1/3 and MAPK14, which are known to be involved in bovine granulosa cell proliferation and steroidogenesis [310]. The FFAR1 and FFAR2 are expressed in the endometrium and are activated by DHA inducing increase in intracellular calcium mobilization, important for uterine contraction and prostaglandin synthesis [309].

Addition of C20:5n-3 to granulosa cells in vitro increases progesterone and estradiol secretion with concomitant increase in protein expression levels of several steroidogenic enzymes and the cholesterol transporter steroidogenic acute regulatory protein (a.k.a. StAR) [310]. Increase in progesterone level was also reported in sheep after feeding n-3 enriched diet [355]. These effects on granulosa cell function could thus be related to the improved reproduction observed after n-3 enriched diet supplementation.

Compared to dietary supplementation with SFA where palmitic acid is predominant, dietary PUFA from rumenprotected fish oil improve pregnancy and decrease pregnancy loss in dairy cows [356]. Similarly, when cows are supplemented with $10 \mathrm{~g}$ of $\mathrm{C} 20: 5 \mathrm{n}-3$, their rate of pregnancy and pregnancy per artificial insemination are increased [357]. Enrichment of $n-3$ PUFA in membrane of ovarian compartment can also affect prostaglandins synthesis in cows as demonstrated by supplementation of dairy cows with extruded linseed [358].

Besides affecting membrane composition of reproductive cells, the positive effect of FA on fertility can be exerted via PPAR as mentioned in the section "Peroxisome proliferator-activated receptors" in this review. All three PPAR isotypes are important for early embryo development, fetus development, and in various compartments of the reproductive system (i.e., uterus and testis) of many species, including cattle [359]. However, PPAR $\gamma$ appears to be the most important in monogastrics and is associated with ovarian function and female fertility [360], but it is also the most studied in ruminants fertility. PPAR $\gamma$ is expressed and activated during all the stages of bovine embryo development (both in the inner mass and in the trophectoderm) and in the placenta (cotyledons and caruncles) in bovine and sheep [5]. From the review of the literature by Ribeiro [361], PPARY appears to coordinate lipid metabolism of trophectoderm cells which is crucial for conceptus elongation and survival. Ribeiro suggested a role of PUFA, and their derivatives, present in the histotroph as important natural ligands of PPAR $\gamma$ in the trophectoderm cells affecting conceptus biology. This is a very interesting idea with tremendous practical application; however, fundamental data are still needed since activation of bovine PPAR $\gamma$ by PUFA has not yet been demonstrated. Furthermore, data obtained from mammary, liver, and kidney cells from ruminants indicate a minor effect of UFA and PUFA on activation of PPAR $[4,5]$.

\section{Saturated fatty acids}

The agonistic effect of SFA on bovine PPAR [4] could suggest a positive effect on reproduction. Saturated FA 
are instead detrimental to oocyte and embryo development compared to UFA [362]. In fact, oleic acid in cumulus cells protects oocytes from lipotoxic effects from C16:0 or C18:0 [363]. Feeding fats enriched with UFA at the beginning of the dry period and during the postpartum period improves postpartum reproductive health and milk production [1]. Silvestre et al. [356] fed cows with Ca salts of safflower oil (1.5\% DM) from $30 \mathrm{~d}$ prepartum until $30 \mathrm{~d}$ postpartum and then Ca salts of fish oil $(1.5 \% \mathrm{DM})$ from 30 to $160 \mathrm{~d}$ postpartum. Overall, pregnancy rate was greater in cows fed Ca salts of unsaturated lipid sources compared to animals that received Ca salts of palm oil. This feeding management also aided to improve embryo development and subsequent pregnancy rates [1]. The negative role of SFA on reproduction is not fully elucidated. It is possible that SFA induce increase in systemic oxidative stress [145] or cellular ER stress damaging reproduction [364]. Induction of ER stress by SFA was observed in liver of monogastrics [365]. Not similar data are available for dairy cows; however, a mixture of SFA and UFA typical of NEFA in early post-partum elicited a dose-dependent increase in ER stress in calf hepatocytes [366].

\section{Role of unsaturated fatty acids on prostaglandin $F_{2 a}$ metabolite}

The influence of $n-3$ and n- 6 PUFA on circulating PG concentrations have been variable due to the type of lipid and dietary supplements fed [351], parity and days post-partum [367]. Prostaglandin $\mathrm{F}_{2 \alpha}$ metabolite (PGFM) concentrations following stimulation are a measure of the potential of the animal to secrete prostaglandin in response to a stimulus. Prostaglandin is commonly stimulated by an injection of oxytocin, as this is indicative of PG release in response to endogenous oxytocin [368]. Interestingly, as summarized in Table 3, the results are variable between studies; however, the overall effects appear to be consistent, with n-6 FA (for example from soybeans byproducts) increasing and n-3 FA (for example from linseed and fishmeal) decreasing PGFM response to oxytocin. Few studies reported a lack of any effect of PGFM response to fat supplement $[372,373]$. The reason for such an effect is not clear; however it might be due to the small difference in $n-6: n-3$ ratio between diets [368] and this factor needs to be accounted for improving reproductive responses when animals are fed with PUFA.

\section{Unsaturated fatty acids and the reduction of negative energy balance}

PUFA enriched diets in cattle are known to reduce the extent of negative energy balance (NEB) experienced in early lactation [374]. Supplementation of PUFA positively affects the oocyte metabolism [375]. For example, DHA was found to modulate lipid metabolism in oocyte-cumulus complex and improve oocyte cytoplasm maturation during in vitro maturation [376]. The size of dominant follicles is reported to increase in cows fed

Table 3 Effect of dietary polyunsaturated fatty acids on oxytocin-stimulated prostaglandin $F_{2 a}$ metabolite (PGFM) in dairy cows

\begin{tabular}{|c|c|c|c|c|}
\hline Animals & Treatments & Oxytocin & Results & Ref. \\
\hline $\begin{array}{l}\text { Holstein } \\
116 \text { DIM }^{*} \\
\text { Day } 15 \text { of synchronized oestrous cycle }\end{array}$ & $\begin{array}{l}\text { 1) } 2.6 \% \text { fish meal (FM) } \\
\text { 2) } 5.2 \% \mathrm{FM} \\
\text { 3) } 7.8 \% \mathrm{FM} \\
\text { 4) Corn silage, corn grain, soybean meal }\end{array}$ & $100 \mathrm{IU}$ & PGFM response lower in cows fed FM & {$[369]$} \\
\hline $\begin{array}{l}\text { Holstein } \\
25 \text { DIM } \\
\text { Day } 15 \text { of synchronized oestrous cycle }\end{array}$ & $\begin{array}{l}\text { Maize silage, alfalfa, maize supplemented } \\
\text { with: } \\
\text { 1) Extruded linseed ( } 5.5 \%) \\
\text { 2) Extruded soybean (4.9\%) }\end{array}$ & $100 \mathrm{IU}$ & $\begin{array}{l}\text { PGFM not significantly lower at base line } \\
\text { with linseed. PGFM response was not } \\
\text { different between treatments. }\end{array}$ & {$[370]$} \\
\hline $\begin{array}{l}\text { Holstein } \\
38 \text { DIM } \\
\text { Day } 14 \text { of synchronized oestrous cycle }\end{array}$ & $\begin{array}{l}\text { Grass and maize silage, barley supplemented } \\
\text { with: } \\
\text { 1) Flaxseed (4\%) } \\
\text { 2) Megalac (4\%) } \\
\text { 3) Sunflower seeds (4\%) }\end{array}$ & $20 \mathrm{IU}$ & $\begin{array}{l}\text { PGFM response higher with sunflower seeds } \\
\text { and lower with flaxseed }\end{array}$ & {$[371]$} \\
\hline $\begin{array}{l}\text { Breed not described } \\
38 \text { DIM } \\
\text { Day } 14 \text { of synchronized oestrous cycle }\end{array}$ & $\begin{array}{l}\text { 1) Corn silage, alfalfa hay, ground corn, } \\
\text { soybean meal supplemented with: } \\
\text { 2) } 1.25 \% \text { fish meal (FM) } \\
\text { 3) } 2.5 \% \mathrm{FM} \\
\text { 4) } 5.0 \% \mathrm{FM} \\
\text { 5) } 2.3 \% \text { Ca salts of fish oil fatty acids }\end{array}$ & $100 \mathrm{IU}$ & $\begin{array}{l}\text { PGFM response was not different between } \\
\text { treatments. }\end{array}$ & {$[372]$} \\
\hline $\begin{array}{l}\text { Holstein } \\
63 \text { DIM } \\
\text { Day } 15 \text { of synchronized oestrous cycle }\end{array}$ & $\begin{array}{l}\text { Grass + maize silage, barley supplemented } \\
\text { with: } \\
\text { 1) Flaxseed (10\%) } \\
\text { 2) Megalac (4\%) } \\
\text { 3) Micronized soybeans (17\%) }\end{array}$ & $100 \mathrm{IU}$ & $\begin{array}{l}\text { PGFM response was not different between } \\
\text { treatments. }\end{array}$ & {$[373]$} \\
\hline
\end{tabular}


with PUFA diets as compared to cows fed with MUFA [351]. Increased follicle size improves oocyte quality and corpus luteum function in cows [377]. For example, larger ovulatory follicles with lower rates of pregnancy losses were found in cows fed with rolled flaxseed compared to those fed with rolled sunflower seeds [378].

\section{Additional effects}

Among other dietary FA, rumenic acid increases plasma concentration of insulin-like growth factor-1 (IGF-1) in cows and consequently promoting conception rates [379]. Recently, CLA was reported to affect follicular granulosa cells morphology and function, which may result in a compromised ovarian cyclicity and impaired fertility [380].

\section{Effect of dietary fat on health of transition cows}

The transition from late gestation to early lactation is regarded as one of the most challenging period in the life of dairy cows [223]. Reasons for feeding fat during the transition period are several. The degree of lipid supplementation has been mostly within the range of traditional recommendations (normally 3 to $4 \%$ of supplemental lipid to a maximum of $6 \%$ of DM as total lipid) [381]. It is important to note that extreme rates of lipid mobilization lead to increased uptake of NEFA by liver and increased TAG accumulation in this tissue. Then, if this lipid infiltration becomes severe, the syndrome of hepatic lipidosis or fatty liver may result, which can lead to prolonged recovery and lastly, the animal can die [382]. Increased lipid accumulation and decreased glycogen in the liver are associated with an increased susceptibility to induction of ketosis [223].

As previously reviewed, supplementation of dairy cows early post-partum with SFA, especially palmitic and stearic acids are beneficial to dairy cows [3]; however, the effect of supplementing early postpartum cows with UFA is less clear. Increasing the energy supply by feeding dietary fat sources or decrease energy expenditure by supplying specific FA such as trans-10, cis-12 CLA to decrease milk fat output during early lactation, do not appear to be beneficial, since they fail to decrease the concentration of circulating NEFA early post-partum, the major index of NEB [379, 383, 384]. Bernal-Santos et al. [384] fed cows a mixture of CLA isomers as Ca-salts from $14 \mathrm{~d}$ prepartum through $140 \mathrm{~d}$ postpartum and reported that concentration of TAG in liver was not affected by feeding CLA. In addition, in that study, milk fat percentage and yield decreased during the first three weeks postpartum. Similar results were obtained by Castañeda-Gutiérrez et al. [379], who reported similar effects on milk fat percentage and yield beginning during the third week postpartum in response to feeding CLA. Selberg et al. [383] fed cows with calcium salts of CLA and trans-octadecenoic acids during the transition period and early lactation and reported that TAG in liver decreased in response to feeding the trans-octadecenoic acid source. Those studies dealing with CLA supplementation were based on the rationale that CLA should decrease energy output by decreasing milk fat yield during early lactation [385] and in turn it decreases the extent and duration of NEB [382].

In cows on a grazing system, Kay et al. [386] fed animals with only pasture and pasture supplemented with hydrogenated palm oil $(540 \mathrm{~g} / \mathrm{d})$ or rumen inert CLA $(600 \mathrm{~g} / \mathrm{d})$ from $27 \mathrm{~d}$ prepartum to $36 \mathrm{~d}$ post-partum. They reported no treatment differences in plasma glucose, insulin, leptin, or NEFA concentrations. This study used trans-10, cis-12 CLA isomer and authors attributed those results to the fact that the supplemented cows had similar net energy balance.

Other strategies have considered the use of oilseeds by-products fed during the transition period. Petit and Benchaar [387] supplemented transition dairy cow with either whole flaxseed, a commercial product containing mainly palmitic, oleic, and linoleic acids (Megalac), or micronized soybeans from 6 weeks before calving to 120 days after calving. The authors detected no treatments effect on either milk composition or milk yield but concentration of plasma NEFA was higher with cows fed with Megalac compared with whole flaxseed and micronized soybeans. Santschi et al. [388] fed transition dairy cows from $40 \mathrm{~d}$ before to $40 \mathrm{~d}$ after calving with extruded linseed $(1.8 \mathrm{~kg} \mathrm{DM} /$ d). They did not find negative effects on plasma metabolites such as glucose, TAG, BHBA and NEFA. Both studies were based on the fact that flaxseed and linseed are excellent sources of $\mathrm{C} 18: 3$, one of the most beneficial FA for the liver because its addition to bovine hepatocytes resulted in decreased TAG concentrations and greater rates of gluconeogenesis compared with other LCFA [389]. Leiber et al. [390] fed cows with crushed linseed as a source of linolenic acid and sunflower seed as a source of linoleic acid and a mix of both from 7 weeks before to 6 weeks after parturition. They reported that plasma metabolites (TAG, leptin, glucose, insulin, IGF-1, NEFA and BHBA) were similar between treatments.

The immune system also is positively affected by feeding prepartum cows with oilseed by-products as shown by Lessard et al. [391] who fed animals with calcium salts of palm oil (Megalac), micronized soybeans (rich in linoleic acid), or whole flaxseed (rich in linoleic and linolenic acid) for six weeks before calving. They reported that flaxseed increased interferon $-\gamma$ compared to the 
other treatments. This is partly explained by the PUFA influence on cellular communication and activation through the synthesis of PG, tumor necrosis factor- $\alpha$, and interferon- $\gamma$, [392].

\section{Conclusion}

In this review, we have provided the most up-to-date information available on utilization of dietary FA and their effects on performance and health of dairy cows. We did not cover all the possible biological effects of FA, such as the role of dietary FA on the lipidome and insulin sensitivity in dairy cows during the peripartum which were recently reviewed [145]. However, based on the literature reviewed we can make some concluding remarks and propose some prospective research for each main topic covered in the present review.

\section{Utilization of $F A$ in the rumen}

Our review of the literature highlighted few advances made in the last decade or so on the utilization of FA by the rumen microbiota, with an emphasis on biohydrogenation of PUFA. Microbiota in the rumen can have a substantial effect on dietary lipids affecting the type and form of FA reaching the intestine. The microbiota can be rather negatively affected by various FA, especially UFA, and biohydrogenation can be considered a way to decrease toxicity of PUFA towards bacteria. We expect important advances in the next decade or so on the interactions between FA and rumen microbiota due to the rapid increase in data and data analysis via high-throughput techniques and associated bioinformatics tools. The large emphasis on environmental issues associated with dairy cows, such as methane production and $\mathrm{N}$ leaching, are both dependent from the activity of rumen microbiota; thus, a better understanding of the interaction between FA and rumen microbiota can aid in formulation of more efficacious dietary supplementation of FA. Furthermore, the complex effects of rumen microbiota on dietary FA, including the synthesis of volatile fatty acids, provide an additional complexity in the application of nutrigenomics via feeding FA in dairy cows.

\section{Absorption and utilization of FA by dairy cows}

Once the FA arrive into the intestine the digestion and absorption is very effective in ruminants and it is becoming more clear the molecular processes and the main molecular players involved; however, advances in knowledge of those were mostly on monogastric animals. Thus, more research should be performed to understand the absorption of FA in dairy cows. Very important in this contest is the understanding of the nutrigenomic roles of various FA in the intestine, especially considering that several of the main transporters of FA are likely regulated by FA via PPAR. Thus, future studies should focus on dissecting the molecular mechanisms of FA absorption in ruminants and their nutrigenomic modulation.

Transport of FA from the intestine to peripheral tissue happens mainly via lipoproteins; however, most of the studies conducted in bovine date back few decades and there is a paucity of new data. Even less data are available for uptake of FA by cells, including liver. As for intestinal absorption of FA, major scientific advances were made in monogastric animals. This clearly indicate that more studies should be carried out in dairy cows to understand the molecular player involved in those processes.

\section{Nutrigenomic role of FA via activation of transcription factors}

Among the few TF known to be modulated by FA, data support the activation of PPAR by SFA and inhibition of SREBP1 by PUFA in dairy cows. The roles of those TF are somewhat clear in bovine mammary tissue, with SREBP1, LXR isoforms, and PPAR $\gamma$ involved in the regulation of milk fat synthesis, but the role of the other TF or of all the above TF in other tissues remains somewhat unclear. Paucity of data exist on the activation of LXR isoforms and HNF4A by FA, especially in dairy cows. New data are being generated in the activation of bovine PPAR isotypes by FA, but more data are needed, such as the identification of FA that are agonists of PPAR and the dose of each of FA (or the combination of FA) that maximizes PPAR activation. The above information is important to move toward nutrigenomic applications via precision feeding.

Despite the above, it is clear that feeding dairy cows to tailor specific TF with FA (i.e., nutrigenomics) can be further complicated by the dynamic of FA released via LPL, that are only partly taken up by the cells, and the presence of circulating NEFA, also those partly derived from the LPL activity. The complexity of such dynamism makes in vivo prediction of FA dose that modulate a TF based on in vitro data difficult, indicating the need of complex in vivo experiments, such as dose-effect trials in combination with the use of more holistic approaches using techniques for high-throughput data in association with systems biology approaches [139].

Effect of feeding dairy cows with supplemental fatty acids Feeding FA to dairy cows can be very beneficial, especially considering the positive role of UFA for fertility and the enrichment of n-3 PUFA in milk. Despite great advances in techniques to protect FA from the rumen microbiota, rumen biohydrogenation remains an important challenge to fully exploit those beneficial effects. Furthermore, the reason for the beneficial effects of $n-3$ PUFA on fertility is not yet fully revealed. A positive 
effect of supplementing FA on milk yield is observed, but it is inconsistent. This is partly due to the complexity of the various processes FA undergo before reaching the various tissues, including the anorexic effect of UFA, but it is also due to a lack of knowledge on nutrigenomic effects of various FA in each tissue.

The development of Omic technologies as well as advanced molecular biology techniques to study ruminant nutrition has helped to improve our understanding of lipid biology. The complexity of the absorption and peripheral utilization of FA as reviewed above, the lack of specific molecular studies carried out in dairy cows about some of those processes, and the relatively poor understanding about TF that can be modulated by FA are all "black-boxes" that still need to be open considering that most of the advances of the molecular aspects of dietary FA metabolism were generated in monogastrics, which are different than ruminants.

\section{Abbreviations \\ ABC: ATP-binding cassette; ACSL: Acyl-CoA synthetase long chain; AGPAT: 1- acylglycerol-3-phosphate acyltransferase; ANGPTL4: Angiopoietin-like 4; apo: Apolipoprotein; APOBEC: APOB mRNA editing complex; BHBA: Beta- hydroxybutyrate; CACT: Carnitine acylcarnitine translocase; CLA: Conjugated linoleic acid(s); CPT1: Carnitine palmitoyltransferase I; DAG: Diacylglycerol; DBI: Diazepam binding inhibitor; DHA: Docosahexaenoic acid; \\ DGAT: Diglyceride acyltransferase; DIM: Day in milk; DM: Dry matter; DMI: Dry matter intake; ER: Endoplasmic reticulum; FA: Fatty acid(s); FABP: Fatty acid- binding protein; FABPpm: Plasma membrane fatty acid-binding protein; FATP: Fatty acid transport protein; FFAR: Free fatty acid receptor; F:C: Forage to concentrate ratio; G3P: Glycerol-3-phosphate; GPAT: Glycerol-3-phosphate acyltransferase; GPIHBP1: Glycosylphosphatidylinositol-anchored high-density lipoprotein binding protein 1; HDL: High-density lipoproteins; HSL: Hormone- sensitive lipase; LCFA: Long-chain fatty acid(s); LDL: Low density lipoproteins; LDLR: Low density lipoproteins receptor; LPIN: Lipin; LPL: Lipoprotein lipase; LXR: Liver X receptor; MCFA: Medium-chain fatty acid(s); MCT: Proton-linked monocarboxylate transporters; MTTP: Microsomal triglyceride transfer protein; NEB: Negative energy balance; NEFA: Non-esterified fatty acids; NPC1L1: Cannalicular sterol transporter Niemann-Pick C1-like 1; PG: Progesterone; PGFM: Prostaglandin F2a metabolite; PPAR: Peroxisome proliferator-activated receptor; PUFA: Poly-unsaturated fatty acid(s); RXR: Retinoid X receptor; SCFA: Short-chain fatty acids; SFA: Saturated fatty acid(s); SLC27A: Solute carrier family 27; SR-B1 or SCARB1: Scavenger receptor class B type 1; SMCT: Sodium-coupled monocarboxylate-transporter; SLC9A: Sodium-coupled monocarboxylate-transporter; SREBF: Sterol regulatory element-binding factor; SREBP: Sterol regulatory element-binding protein; TAG: Triacylglycerol; UFA: Unsaturated fatty acid(s); VFA: Volatile fatty acid(s); VLDL: Very-low density lipoproteins; VLDLR: Very-low density lipoproteins receptor}

\section{Acknowledgements}

The authors thanks the three anonymous reviewers for their through review of this long manuscript and their excellent and very pertinent feedback that allowed to substantially improve the manuscript.

\section{Authors' contributions}

MS wrote the introduction and conclusion and the sections on fatty acid digestion, intestinal absorption, and chylomicron catabolism, helped writing all the other sections, generated Fig. 1, and helped to generate Fig. 2; SB wrote the section of fatty acid uptake and utilizations by cells, transcription factors, and generated Fig. 2; EV wrote the section of the effect of fat supplementation on health and performance of dairy cows and generated all the Tables. The authors read and approved the final manuscript.

\section{Funding}

No funding was used to write this manuscript.

\section{Availability of data and materials}

The datasets used and/or analyzed during the current study are publicly available.

\section{Ethics approval and consent to participate}

N/A

\section{Consent for publication}

N/A

\section{Competing interests}

The authors declare that they have no competing interests.

\section{Author details}

'Department of Animal and Rangeland Sciences, Oregon State University, Corvallis, OR 97331, USA. ${ }^{2}$ Department of Veterinary and Animal Sciences, Faculty of Health and Medical Sciences, University of Copenhagen, Grønnegårdsvej 3, DK-1870 Frederiksberg C, Denmark.

Received: 22 April 2020 Accepted: 8 September 2020 Published online: 16 November 2020

\section{References}

1. Palmquist DL, Jenkins TC. A 100-Year Review: Fat feeding of dairy cows. J Dairy Sci. 2017;100(12):10061-77.

2. Santos JE, Bisinotto RS, Ribeiro ES, Lima FS, Greco LF, Staples CR, et al. Applying nutrition and physiology to improve reproduction in dairy cattle. Soc Reprod Fertil Suppl. 2010;67:387-403.

3. Loften JR, Linn JG, Drackley JK, Jenkins TC, Soderholm CG, Kertz AF. Invited review: palmitic and stearic acid metabolism in lactating dairy cows. J Dairy Sci. 2014;97(8):4661-74..

4. Bionaz M, Osorio J, Loor JJ. TRIENNIAL LACTATION SYMPOSIUM: Nutrigenomics in dairy cows: Nutrients, transcription factors, and techniques. J Anim Sci. 2015;93(12):5531-53.

5. Bionaz M, Chen $\mathrm{S}$, Khan MJ, Loor JJ. Functional role of PPARs in ruminants: potential targets for fine-tuning metabolism during growth and lactation. PPAR Res. 2013:2013:684159.

6. Bauman DE, Harvatine KJ, Lock AL. Nutrigenomics, rumen-derived bioactive fatty acids, and the regulation of milk fat synthesis. Annu Rev Nutr. 2011;31: 299-319.

7. Dawson KA. Nutrigenomics: feeding the genes for improved fertility. Anim Reprod Sci. 2006;96(3-4):312-22.

8. Noble RC. Digestion, absorption and transport of lipids in ruminant animals. Prog Lipid Res. 1978;17(1):55-91.

9. Jenkins TC. Lipid metabolism in the rumen. J Dairy Sci. 1993;76(12):3851-63.

10. Harfoot CG, Hazlewood GP. Lipid metabolism in the rumen. In: Hobson PN, Stewart CS, editors. The Rumen Microbial Ecosystem. Dordrecht: Springer Netherlands; 1997. p. 382-426.

11. Jenkins TC, Wallace RJ, Moate PJ, Mosley EE. Board-invited review: Recent advances in biohydrogenation of unsaturated fatty acids within the rumen microbial ecosystem. J Anim Sci. 2008:86(2):397-412.

12. Jarvis GN, Moore ERB: Lipid Metabolism and the Rumen Microbial Ecosystem. In: Handbook of Hydrocarbon and Lipid Microbiology. Edited by Timmis KN. Berlin, Heidelberg: Springer Berlin Heidelberg; 2010: 2245-2257.

13. Lourenco M, Ramos-Morales E, Wallace RJ. The role of microbes in rumen lipolysis and biohydrogenation and their manipulation. Animal. 2010;4(7): 1008-23.

14. Prive F, Kaderbhai NN, Girdwood S, Worgan HJ, Pinloche E, Scollan ND, et al. Identification and characterization of three novel lipases belonging to families II and V from Anaerovibrio lipolyticus 5ST. PLoS One. 2013;8(8): e69076.

15. Abdelmegeid MK, Elolimy AA, Zhou Z, Lopreiato V, McCann JC, Loor JJ. Rumen-protected methionine during the peripartal period in dairy cows and its effects on abundance of major species of ruminal bacteria. J Anim Sci Biotechnol. 2018;9:17

16. Bauman DE, Lock AL. Conjugated linoleic acid: biosynthesis and nutritional significance. In: Advanced Dairy Chemistry Volume 2 Lipids. Edited by Fox PF, McSweeney PLH. Boston: Springer US; 2006: 93-136.

17. Lashkari S, Bonefeld Petersen M, Krogh Jensen S. Rumen biohydrogenation of linoleic and linolenic acids is reduced when esterified to phospholipids or steroids. Food Sci Nutr. 2020;8(1):79-87. 
18. Jenkins TC, Bridges WC Jr. Protection of fatty acids against ruminal biohydrogenation in cattle. Eur J Lipid Sci Technol. 2007;109(8):778-89.

19. Massart-Leën AM, Roets E, Peeters G, Verbeke R. Propionate for fatty acid synthesis by the mammary gland of the lactating goat. J Dairy Sci. 1983; 66(7):1445-54

20. Smith SB, Crouse JD. Relative contributions of acetate, lactate and glucose to lipogenesis in bovine intramuscular and subcutaneous adipose tissue. J Nutr. 1984;114(4):792-800.

21. Urrutia NL, Harvatine KJ. Acetate dose-dependently stimulates milk fat synthesis in lactating dairy cows. J Nutr. 2017;147(5):763-9.

22. Bauman DE, Mather $\mathrm{H}$, Wall RJ, Lock AL. Major advances associated with the biosynthesis of milk. J Dairy Sci. 2006;89(4):1235-43.

23. Aluwong T, Kobo PI, Abdullahi A. Volatile fatty acids production in ruminants and the role of monocarboxylate transporters: a review. Afr J Biotechnol. 2010;9(38):6229-32.

24. Graham C, Gatherar I, Haslam I, Glanville M, Simmons NL. Expression and localization of monocarboxylate transporters and sodium/proton exchangers in bovine rumen epithelium. Am J Physiol Regul Integr Comp Physiol. 2007;292(2):R997-1007.

25. Storm AC, Kristensen NB, Hanigan MD. A model of ruminal volatile fatty acid absorption kinetics and rumen epithelial blood flow in lactating Holstein cows. J Dairy Sci. 2012;95(6):2919-34.

26. Parada Venegas D, De la Fuente MK, Landskron G, Gonzalez MJ, Quera R, Dijkstra G, et al. Short chain fatty acids (SCFAs)-mediated gut epithelial and immune regulation and its relevance for inflammatory bowel diseases. Front Immunol. 2019;10:277.

27. Baldwin RVI, WU ST, Li WZ, Li CJ, Bequette BJ, Li RW. Quantification of transcriptome responses of the rumen epithelium to butyrate infusion using RNA-seq technology. Gene Regul Syst Biol. 2012;6:67-80.

28. Enjalbert F, Combes S, Zened A, Meynadier A. Rumen microbiota and dietary fat: a mutual shaping. J Appl Microbiol. 2017;123(4):782-97.

29. Cremonesi P, Conte G, Severgnini M, Turri F, Monni A, Capra E, et al. Evaluation of the effects of different diets on microbiome diversity and fatty acid composition of rumen liquor in dairy goat. Animal. 2018;12(9):1856-66.

30. Faciola AP, Broderick GA. Effects of feeding lauric acid or coconut oil on ruminal protozoa numbers, fermentation pattern, digestion, omasal nutrient flow, and milk production in dairy cows. J Dairy Sci. 2014;97(8): 5088-100.

31. Faciola AP, Broderick GA. Effects of feeding lauric acid on ruminal protozoa numbers, fermentation, and digestion and on milk production in dairy cows. J Anim Sci. 2013;91(5):2243-53.

32. Hankel J, Popp J, Meemken D, Zeiger K, Beyerbach M, Taube V, et al. Influence of lauric acid on the susceptibility of chickens to an experimental Campylobacter jejuni colonisation. PLoS One. 2018;13(9):e0204483.

33. Lopez-Colom P, Castillejos L, Rodriguez-Sorrento A, Puyalto M, Mallo JJ, Martin-Orue SM. Efficacy of medium-chain fatty acid salts distilled from coconut oil against two enteric pathogen challenges in weanling piglets. J Anim Sci Biotechnol. 2019;10:89.

34. Hristov AN, Callaway TR, Lee C, Dowd SE. Rumen bacterial, archaeal, and fungal diversity of dairy cows in response to ingestion of lauric or myristic acid. J Anim Sci. 2012;90(12):4449-57.

35. Soliva CR, Hindrichsen IK, Meile L, Kreuzer M, Machmuller A. Effects of mixtures of lauric and myristic acid on rumen methanogens and methanogenesis in vitro. Lett Appl Microbiol. 2003;37(1):35-9.

36. Soliva CR, Meile L, Cieslak A, Kreuzer M, Machmuller A. Rumen simulation technique study on the interactions of dietary lauric and myristic acid supplementation in suppressing ruminal methanogenesis. Br J Nutr. 2004; 92(4):689-700

37. Bauchart D. Lipid absorption and transport in ruminants. J Dairy Sci. 1993; 76(12):3864-81.

38. Bauer E, Jakob S, Mosenthin R. Principles of physiology of lipid digestion. Asian-Aust J Anim Sci. 2005;18(2):282-95.

39. Cifarelli V, Abumrad NA. Intestinal CD36 and other key proteins of lipid utilization: role in absorption and gut homeostasis. Compr Physiol. 2018;8(2): 493-507.

40. Suys EJA, Warren DB, Porter CJH, Benameur H, Pouton CW, Chalmers DK Computational models of the intestinal environment. 3. The impact of cholesterol content and pH on mixed micelle colloids. Mol Pharm. 2017; 14(11):3684-97.

41. Shiau YF. Mechanism of intestinal fatty acid uptake in the rat: the role of an acidic microclimate. J Physiol. 1990;421:463-74.
42. Wang TY, Liu M, Portincasa P, Wang DQ. New insights into the molecular mechanism of intestinal fatty acid absorption. Eur J Clin Invest. 2013;43(11): 1203-23.

43. Sutton JD, Reynolds C: Nutrients, Digestion and Absorption | Small Intestine of Lactating Ruminants. In.; 2011: 989-995.

44. Boerman JP, Firkins JL, St-Pierre NR, Lock AL. Intestinal digestibility of longchain fatty acids in lactating dairy cows: A meta-analysis and metaregression. J Dairy Sci. 2015;98(12):8889-903.

45. Gallagher ND, Playoust MR. Absorption of saturated and unsaturated fatty acids by rat jejunum and ileum. Gastroenterology. 1969;57(1):9-18.

46. Lawson LD, Hughes BG. Human absorption of fish oil fatty acids as triacylglycerols, free acids, or ethyl esters. Biochem Biophys Res Commun. 1988;152(1):328-35.

47. Ramirez M, Amate L, Gil A. Absorption and distribution of dietary fatty acids from different sources. Early Hum Dev. 2001;65 Suppl:S95-S101.

48. Smithson KW, Millar DB, Jacobs LR, Gray GM. Intestinal diffusion barrier: unstirred water layer or membrane surface mucous coat? Science. 1981; 214(4526):1241-4.

49. Wang $\mathrm{HH}$, Afdhal NH, Gendler SJ, Wang DQ-H. Lack of the intestinal Muc1 mucin impairs cholesterol uptake and absorption but not fatty acid uptake in Muc1-/- mice. Am J Physiol Gastroin Liver Physiol. 2004;287(3):G547-54.

50. Hoorens PR, Rinaldi M, Li RW, Goddeeris B, Claerebout E, Vercruysse J, et al. Genome wide analysis of the bovine mucin genes and their gastrointestinal transcription profile. BMC Genomics. 2011;12(1):140.

51. Huang SM, Wu ZH, Li TT, Liu C, Han DD, Tao SY, et al. Perturbation of the lipid metabolism and intestinal inflammation in growing pigs with low birth weight is associated with the alterations of gut microbiota. Sci Total Environ. 2020;719:137382.

52. Sangild PT, Trahair JF, Loftager MK, Fowden AL. Intestinal macromolecule absorption in the fetal pig after infusion of colostrum in utero. Pediatr Res. 1999;45(4 Pt 1):595-602

53. Stremmel W, Staffer $S$, Wannhoff A, Pathil A. The overall fatty acid absorption controlled by basolateral chylomicron excretion under regulation of p-JNK1. Biochim Biophys Acta. 2017;1862(9):917-28.

54. Sun HZ, Zhou M, Wang O, Chen Y, Liu JX, Guan LL. Multi-omics reveals functional genomic and metabolic mechanisms of milk production and quality in dairy cows. Bioinformatics. 2020;36(8):2530-7.

55. Miyazawa K, Hondo T, Kanaya T, Tanaka S, Takakura I, Itani W, et al. Characterization of newly established bovine intestinal epithelial cell line. Histochem Cell Biol. 2010;133(1):125-34.

56. Zhan K, Lin M, Liu MM, Sui YN, Zhao GQ. Establishment of primary bovine intestinal epithelial cell culture and clone method. Vitro Cell Dev Biol Anim. 2017;53(1):54-7.

57. Zhan K, Jiang M, Gong X, Zhao G. Effect of short-chain fatty acids on the expression of genes involved in short-chain fatty acid transporters and inflammatory response in goat jejunum epithelial cells. Vitro Cell Dev Biol Anim. 2018;54(4):311-20.

58. Honigmann A, Pralle A. Compartmentalization of the cell membrane. J Mol Biol. 2016;428(24 Part A):4739-48

59. Pomorski TG, Menon AK. Lipid somersaults: Uncovering the mechanisms of protein-mediated lipid flipping. Prog Lipid Res. 2016;64:69-84.

60. López-Montero I, Rodriguez N, Cribier S, Pohl A, Vélez M, Devaux PF. Rapid transbilayer movement of ceramides in phospholipid vesicles and in human erythrocytes. J Biol Chem. 2005;280(27):25811-9.

61. Kleinfeld AM, Chu P, Romero C. Transport of long-chain native fatty acids across lipid bilayer membranes indicates that transbilayer flip-flop is rate limiting. Biochemistry. 1997;36(46):14146-58.

62. Simard JR, Pillai BK, Hamilton JA. Fatty acid flip-flop in a model membrane is faster than desorption into the aqueous phase. Biochemistry. 2008;47(35): 9081-9.

63. Coleman JA, Quazi F, Molday RS. Mammalian P4-ATPases and ABC transporters and their role in phospholipid transport. Biochim Biophysica Acta. 2013:1831(3):555-74.

64. Pownall HJ, Hamilton JA. Energy translocation across cell membranes and membrane models. Acta Physiol Scand. 2003;178(4):357-65.

65. Massey JB, Bick DH, Pownall HJ. Spontaneous transfer of monoacyl amphiphiles between lipid and protein surfaces. Biophys J. 1997;72(4): 1732-43.

66. Schaffer JE. Fatty acid transport: the roads taken. Am J Physiol Endocrinol Metab. 2002;282(2):E239-46. 
67. Glatz JFC, Luiken JJFP: From fat to FAT (CD36/SR-B2): Understanding the regulation of cellular fatty acid uptake. Biochimie 2017, 136:21-26.

68. Su X, Abumrad NA. Cellular fatty acid uptake: a pathway under construction. Trends Endocrinol Metab. 2009;20(2):72-7.

69. Febbraio M, Silverstein RL. CD36: Implications in cardiovascular disease. Int J Biochem Cell Biol. 2007:39(11):2012-30.

70. Jay AG, Hamilton JA. The enigmatic membrane fatty acid transporter CD36: New insights into fatty acid binding and their effects on uptake of oxidized LDL. Prostaglandins Leukotrienes Essential Fatty Acids. 2018;138:64-70.

71. Pownall H, Moore K. Commentary on Fatty Acid Wars. Arteriosclerosis Thromb Vasc Biol. 2014;34(5):e8-9.

72. Kadegowda AK, Bionaz M, Piperova LS, Erdman RA, Loor JJ. Peroxisome proliferator-activated receptor-gamma activation and long-chain fatty acids alter lipogenic gene networks in bovine mammary epithelial cells to various extents. J Dairy Sci. 2009;92(9):4276-89.

73. Bionaz M, Thering BJ, Loor JJ. Fine metabolic regulation in ruminants via nutrient-gene interactions: saturated long-chain fatty acids increase expression of genes involved in lipid metabolism and immune response partly through PPAR-alpha activation. Br J Nutr. 2012;107(2): 179-91.

74. Doepel L, Lobley GE, Bernier JF, Dubreuil P, Lapierre H. Differences in splanchnic metabolism between late gestation and early lactation dairy cows. J Dairy Sci. 2009;92(7):3233-43.

75. Lynes MD, Widmaier EP. Involvement of CD36 and intestinal alkaline phosphatases in fatty acid transport in enterocytes, and the response to a high-fat diet. Life Sci. 2011;88(9-10):384-91.

76. Hartmann PE, Harris JG, Lascelles AK. The effect of oil-feeding and starvation on the composition and output of lipid in thoracic duct lymph in the lactating cow. Aust J Biol Sci. 1966;19(4):635-44.

77. Nassir F, Wilson B, Han X, Gross RW, Abumrad NA. CD36 is important for fatty acid and cholesterol uptake by the proximal but not distal intestine. J Biol Chem. 2007:282(27):19493-501.

78. Febbraio M, Abumrad NA, Hajjar DP, Sharma K, Cheng W, Pearce SF, et al. A null mutation in murine CD36 reveals an important role in fatty acid and lipoprotein metabolism. J Biol Chem. 1999;274(27):19055-62.

79. Drover VA, Ajmal M, Nassir F, Davidson NO, Nauli AM, Sahoo D, et al. CD36 deficiency impairs intestinal lipid secretion and clearance of chylomicrons from the blood. J Clin Invest. 2005;115(5):1290-7.

80. Sundaresan S, Shahid R, Riehl TE, Chandra R, Nassir F, Stenson WF, et al. CD36-dependent signaling mediates fatty acid-induced gut release of secretin and cholecystokinin. FASEB J. 2013;27(3):1191-202.

81. Altmann SW, Davis HR Jr, Yao X, Laverty M, Compton DS, Zhu LJ, et al. The identification of intestinal scavenger receptor class B, type I (SR-BI) by expression cloning and its role in cholesterol absorption. Biochim Biophys Acta. 2002;1580(1):77-93.

82. Bietrix F, Yan D, Nauze M, Rolland C, Bertrand-Michel J, Comera C, et al. Accelerated lipid absorption in mice overexpressing intestinal SR-BI. J Biol Chem. 2006;281(11):7214-9.

83. Yamanashi $Y$, Takada $T$, Kurauchi $R$, Tanaka $Y$, Komine $T$, Suzuki $H$. Transporters for the intestinal absorption of cholesterol, vitamin $E$, and vitamin K. J Atheroscler Thromb. 2017;24(4):347-59.

84. Park H, Seo S, Cho YM, Oh SJ, Seong HH, Lee SH, et al. Identification of candidate genes associated with beef marbling using QTL and pathway analysis in Hanwoo (Korean cattle). Asian-Australas J Anim Sci. 2012;25(5):613-20.

85. Gregson E, Webb R, Sheldrick EL, Campbell BK, Mann GE, Liddell S, et al. Molecular determinants of a competent bovine corpus luteum: first- vs final-wave dominant follicles. Reproduction (Cambridge, England). 2016; 151(6):563-75.

86. Rajapaksha WR, McBride M, Robertson L, O'Shaughnessy PJ. Sequence of the bovine HDL-receptor (SR-BI) CDNA and changes in receptor mRNA expression during granulosa cell luteinization in vivo and in vitro. Mol Cell Endocrinol. 1997:134(1):59-67.

87. Bertolini F, Chinchilla-Vargas J, Khadse JR, Juneja A, Deshpande PD, Bhave $\mathrm{K}$, et al. Marker discovery and associations with beta-carotene content in Indian dairy cattle and buffalo breeds. J Dairy Sci. 2019; 102(11):10039-55

88. Silva PRB, Weber WJ, Crooker BA, Collier RJ, Thatcher WW, Chebel RC. Hepatic mRNA expression for genes related to somatotropic axis, glucose and lipid metabolisms, and inflammatory response of periparturient dairy cows treated with recombinant bovine somatotropin. J Dairy Sci. 2017; 100(5):3983-99.
89. Lucy MC. Functional differences in the growth hormone and insulin-like growth factor axis in cattle and pigs: implications for post-partum nutrition and reproduction. Reprod Domestic Anim. 2008;43(Suppl 2):31-9.

90. Roepstorff C, Helge JW, Vistisen B, Kiens B. Studies of plasma membrane fatty acid-binding protein and other lipid-binding proteins in human skeletal muscle. Proc Nutr Soc. 2004;63(2):239-44.

91. Clarke DC, Miskovic D, Han XX, Calles-Escandon J, Glatz JF, Luiken JJ, et al. Overexpression of membrane-associated fatty acid binding protein (FABPpm) in vivo increases fatty acid sarcolemmal transport and metabolism. Physiol Genomics. 2004;17(1):31-7.

92. Chabowski A, Gorski J, Luiken JJ, Glatz JF, Bonen A. Evidence for concerted action of FAT/CD36 and FABPpm to increase fatty acid transport across the plasma membrane. Prostaglandins Leukot Essent Fatty Acids. 2007;77(5-6): 345-53.

93. Yen $\mathrm{CL}$, Nelson DW, Yen MI. Intestinal triacylglycerol synthesis in fat absorption and systemic energy metabolism. J Lipid Res. 2015;56(3):489501.

94. Anderson CM, Stahl A. SLC27 fatty acid transport proteins. Mol Aspects Med. 2013;34(2-3):516-28.

95. Cooper DE, Young PA, Klett EL, Coleman RA. Physiological consequences of compartmentalized acyl-CoA metabolism. J Biol Chem. 2015;290(33):20023-31.

96. Stahl A, Hirsch DJ, Gimeno RE, Punreddy S, Ge P, Watson N, et al. Identification of the major intestinal fatty acid transport protein. Mol Cell. 1999;4(3):299-308

97. Frank PG, Woodman SE, Park DS, Lisanti MP. Caveolin, caveolae, and endothelial cell function. Arterioscler Thromb Vasc Biol. 2003;23(7): $1161-8$.

98. Fridolfsson HN, Roth DM, Insel PA, Patel HH. Regulation of intracellular signaling and function by caveolin. FASEB J. 2014;28(9):3823-31.

99. Siddiqi S, Sheth A, Patel F, Barnes M, Mansbach CM, 2nd: Intestinal caveolin1 is important for dietary fatty acid absorption. Biochim Biophys Acta 2013, 1831(8):1311-1321.

100. Meshulam T, Simard JR, Wharton J, Hamilton JA, Pilch PF. Role of caveolin-1 and cholesterol in transmembrane fatty acid movement. Biochemistry. 2006; 45(9):2882-93

101. Ring A, Le Lay S, Pohl J, Verkade P, Stremmel W. Caveolin-1 is required for fatty acid translocase (FAT/CD36) localization and function at the plasma membrane of mouse embryonic fibroblasts. Biochim Biophys Acta. 2006; 1761(4):416-23.

102. Otis JP, Shen MC, Quinlivan V, Anderson JL, Farber SA. Intestinal epithelial cell caveolin 1 regulates fatty acid and lipoprotein cholesterol plasma levels. Dis Model Mech. 2017;10(3):283-95.

103. Wolf T, Baier SR, Zempleni J. The intestinal transport of bovine milk exosomes is mediated by endocytosis in human colon carcinoma Caco-2 cells and rat small intestinal IEC-6 cells. J Nutr. 2015:145(10):2201-6.

104. Michael Danielsen E, Hansen GH. Small molecule pinocytosis and clathrin-dependent endocytosis at the intestinal brush border: Two separate pathways into the enterocyte. Biochim Biophys Acta. 2016; 1858(2):233-43.

105. Mathot F, des Rieux A, Arien A, Schneider YJ, Brewster M, Preat V. Transport mechanisms of mmePEG750P(CL-Co-TMC) polymeric micelles across the intestinal barrier. J Control Release. 2007;124(3):134-43.

106. Kou L, Sun J, Zhai Y, He Z. The endocytosis and intracellular fate of nanomedicines: Implication for rational design. Asian J Pharm Sci. 2013;8(1): $1-10$.

107. Hansen GH, Niels-Christiansen LL, Immerdal L, Nystrom BT, Danielsen EM. Intestinal alkaline phosphatase: selective endocytosis from the enterocyte brush border during fat absorption. Am J Physiol Gastrointest Liver Physiol. 2007;293(6):G1325-32.

108. Narisawa S, Huang L, Iwasaki A, Hasegawa H, Alpers DH, Millan JL. Accelerated fat absorption in intestinal alkaline phosphatase knockout mice. Mol Cell Biol. 2003:23(21):7525-30.

109. Bionaz M, Periasamy K, Rodriguez-Zas SL, Everts RE, Lewin HA, Hurley WL, et al. Old and new stories: revelations from functional analysis of the bovine mammary transcriptome during the lactation cycle. PLoS One. 2012;7(3): e33268.

110. Bionaz M, Loor JJ. Gene networks driving bovine milk fat synthesis during the lactation cycle. BMC Genomics. 2008;9:366.

111. Hocquette JF, Bauchart D. Intestinal absorption, blood transport and hepatic and muscle metabolism of fatty acids in preruminant and ruminant animals. Reprod Nutr Dev. 1999;39(1):27-48. 
112. Papamandjaris AA, MacDougall DE, Jones PJ. Medium chain fatty acid metabolism and energy expenditure: obesity treatment implications. Life Sci. 1998;62(14):1203-15.

113. Grevengoed TJ, Klett EL, Coleman RA. Acyl-CoA metabolism and partitioning. Ann Rev Nutr. 2014;34(1):1-30.

114. Richards MR, Harp JD, Ory DS, Schaffer JE. Fatty acid transport protein 1 and long-chain acyl coenzyme A synthetase 1 interact in adipocytes. J Lipid Res. 2006;47(3):665-72.

115. Klaus C, Jeon MK, Kaemmerer E, Gassler N. Intestinal acyl-CoA synthetase 5: activation of long chain fatty acids and behind. World J Gastroenterol. 2013; 19(42):7369-73.

116. Meller N, Morgan ME, Wong WP, Altemus JB, Sehayek E. Targeting of acylCoA synthetase 5 decreases jejunal fatty acid activation with no effect on dietary long-chain fatty acid absorption. Lipids Health Dis. 2013;12:88.

117. Bionaz M, Loor JJ. ACSL1, AGPAT6, FABP3, LPIN1, and SLC27A6 are the most abundant isoforms in bovine mammary tissue and their expression is affected by stage of lactation. J Nutr. 2008;138(6):1019-24.

118. Gajda AM, Storch J. Enterocyte fatty acid-binding proteins (FABPs): different functions of liver and intestinal FABPs in the intestine. Prostaglandins Leukot Essent Fatty Acids. 2015;93:9-16.

119. Glatz JF, van der Vusse GJ. Cellular fatty acid-binding proteins: their function and physiological significance. Prog Lipid Res. 1996;35(3):243-82.

120. Storch J, McDermott L. Structural and functional analysis of fatty acidbinding proteins. J Lipid Res. 2009;50:S126-31.

121. Richieri GV, Ogata RT, Kleinfeld AM. Equilibrium-constants for the binding of fatty-acids with fatty-acid-binding proteins from adipocyte, intestine, heart, and liver measured with the fluorescent-probe ADIFAB. J Biol Chem. 1994; 269(39):23918-30.

122. Smathers $R L$, Petersen $D R$. The human fatty acid-binding protein family: Evolutionary divergences and functions. Hum Genomics. 2011;5(3):170.

123. Wolfrum C, Börchers T, Sacchettini JC, Spener F. Binding of fatty acids and peroxisome proliferators to orthologous fatty acid binding proteins from human, murine, and bovine liver. Biochemistry. 2000;39(6):1469-74.

124. Niot I, Besnard P. Intestinal uptake and transport of fatty acids. Adv Mol Cell Bio. 2003;33:9-28.

125. Knudsen J, Neergaard TBF, Gaigg B, Jensen MV, Hansen JK. Role of acyl-CoA binding protein in acyl-CoA metabolism and acyl-CoA-mediated cell signaling. J Nutr. 2000;130(2):294S-8S.

126. Allen M, Bradford B, Oba M. BOARD-INVITED REVIEW: the hepatic oxidation theory of the control of feed intake and its application to ruminants. J Anim Sci. 2009:87:3317-34.

127. Trotter PJ, Storch J. Fatty acid uptake and metabolism in a human intestinal cell line (Caco-2): comparison of apical and basolateral incubation. J Lipid Res. 1991;32(2):293-304.

128. Langhans W, Leitner C, Arnold M. Dietary fat sensing via fatty acid oxidation in enterocytes: possible role in the control of eating. Am J Physiol Regul Integr Comp Physiol. 2011;300(3):R554-65.

129. Ueno $H$, Ito R, Abe SI, Ogino H, Maruyama M, Miyashita $H$, et al. GPR40 full agonism exerts feeding suppression and weight loss through afferent vagal nerve. PLoS One. 2019;14(9):e0222653.

130. Vangaveti V, Shashidhar V, Jarrod G, Baune BT, Kennedy RL. Free fatty acid receptors: emerging targets for treatment of diabetes and its complications. Ther Adv Endocrinol Metab. 2010;1(4):165-75.

131. Manosalva C, Mena J, Velasquez Z, Colenso CK, Brauchi S, Burgos RA, et al. Cloning, identification and functional characterization of bovine free fatty acid receptor-1 (FFAR1/GPR40) in neutrophils. PLoS One. 2015;10(3): e0119715.

132. Friedrichs $P$, Saremi B, Winand S, Rehage J, Danicke S, Sauerwein $H$, et al. Energy and metabolic sensing $G$ protein-coupled receptors during lactation-induced changes in energy balance. Domest Anim Endocrinol. 2014:48:33-41.

133. Friedrichs $P$, Sauerwein $H$, Huber $K$, Locher LF, Rehage J, Meyer U, et al. Expression of metabolic sensing receptors in adipose tissues of periparturient dairy cows with differing extent of negative energy balance. Animal. 2016;10(4):623-32.

134. Sartorius T, Drescher A, Panse M, Lastovicka P, Peter A, Weigert C, et al. Mice lacking free fatty acid receptor 1 (GPR40/FFAR1) are protected against conjugated linoleic acid-induced fatty liver but develop inflammation and insulin resistance in the brain. Cell Physiol Biochem. 2015;35(6):2272-84.

135. Bickerstaffe $R$, Annison EF. Triglyceride synthesis by the small-intestinal epithelium of the pig, sheep and chicken. Biochem J. 1969;111(4):419-29.
136. Ramasamy I. Recent advances in physiological lipoprotein metabolism. Clin Chem Lab Med. 2014;52(12):1695-727.

137. Hussain MM. Intestinal lipid absorption and lipoprotein formation. Curr Opin Lipid. 2014:25(3):200-6.

138. Pearce J. Fatty acid synthesis in liver and adipose tissue. Proc Nutr Soc. 1983;42(2):263-71

139. Loor JJ, Bionaz M, Drackley JK. Systems physiology in dairy cattle: nutritional genomics and beyond. Annu Rev Anim Biosci. 2013;1:365-92.

140. Takeuchi K, Reue K. Biochemistry, physiology, and genetics of GPAT, AGPAT, and lipin enzymes in triglyceride synthesis. Am J Physiol Endocrinol Metab. 2009;296(6):E1195-209.

141. Zhang P, Reue K. Lipin proteins and glycerolipid metabolism: Roles at the ER membrane and beyond. Biochim Biophys Acta Biomembr. 2017;1859(9 Pt B):1583-95.

142. Grummer RR. Etiology of lipid-related metabolic disorders in periparturient dairy cows. J Dairy Sci. 1993;76(12):3882-96.

143. Giammanco A, Cefalu AB, Noto D, Averna MR. The pathophysiology of intestinal lipoprotein production. Front Physiol. 2015;6:61

144. Cao W, Wu W. Apolipoprotein B mRNA editing enzyme, catalytic polypeptide-like gene expression, RNA editing, and microRNAs regulation. Methods Mol Biol (Clifton, NJ). 2018;1699:75-81.

145. McFadden JW. Review: Lipid biology in the periparturient dairy cow: contemporary perspectives. Animal. 2020;14(S1):s165-75.

146. Abbasi IHR, Abbasi F, Soomro RN, Abd El-Hack ME, Abdel-Latif MA, Li W, et al. Considering choline as methionine precursor, lipoproteins transporter, hepatic promoter and antioxidant agent in dairy cows. AMB Express. 2017; $7(1): 214$.

147. Jayaprakash G, Sathiyabarathi M, Robert MA, Tamilmani T. Rumen-protected choline: A significance effect on dairy cattle nutrition. Vet World. 2016;9(8):837-41.

148. Chandler TL, White HM. Choline and methionine differentially alter methyl carbon metabolism in bovine neonatal hepatocytes. PLoS One. 2017;12(2): e0171080.

149. Liepa G, Beitz D, Linder J. Cholesterol synthesis in ruminating and nonruminating goats. J Nutr. 1978;108:535-43.

150. Viturro E, Koenning M, Kroemer A, Schlamberger G, Wiedemann S, Kaske M, et al. Cholesterol synthesis in the lactating cow: Induced expression of candidate genes. J Steroid Biochem Mol Biol. 2009;115(1-2):62-7.

151. Kessler EC, Gross JJ, Bruckmaier RM, Albrecht C. Cholesterol metabolism, transport, and hepatic regulation in dairy cows during transition and early lactation. J Dairy Sci. 2014:97(9):5481-90.

152. Mathews AT, Rico JE, Sprenkle NT, Lock AL, McFadden JW. Increasing palmitic acid intake enhances milk production and prevents glucosestimulated fatty acid disappearance without modifying systemic glucose tolerance in mid-lactation dairy cows. J Dairy Sci. 2016;99(11):8802-16.

153. Vargas-Bello-Perez E, Bionaz M, Garrido-Sartore M, Cancino-Padilla N, Morales MS, Romero J, et al. Effect of soybean oil and fish oil on lipidrelated transcripts in subcutaneous adipose tissue of dairy cows. Animals. 2019;10(1):54

154. Castro T, Martinez D, Isabel B, Cabezas A, Jimeno V. Vegetable oils rich in polyunsaturated fatty acids supplementation of dairy cows' diets: effects on productive and reproductive performance. Animals. 2019;9(5):205.

155. Bionaz M, Trevisi E, Calamari L, Librandi F, Ferrari A, Bertoni G. Plasma paraoxonase, health, inflammatory conditions, and liver function in transition dairy cows. J Dairy Sci. 2007;90(4):1740-50.

156. Ingvartsen $\mathrm{KL}$, Andersen JB. Integration of metabolism and intake regulation: a review focusing on periparturient animals. J Dairy Sci. 2000; 83(7):1573-97

157. Shimano H, Sato R. SREBP-regulated lipid metabolism: convergent physiology divergent pathophysiology. Nat Rev Endocrinol. 2017;13(12):710-30.

158. Engelking LJ, MCFarlane MR, Li CK, Liang G. Blockade of cholesterol absorption by ezetimibe reveals a complex homeostatic network in enterocytes. J Lipid Res. 2012;53(7):1359-68.

159. Bertoni G, Trevisi E, Han X, Bionaz M. Effects of inflammatory conditions on liver activity in puerperium period and consequences for performance in dairy cows. J Dairy Sci. 2008;91(9):3300-10.

160. Siddiqi SA, Gorelick FS, Mahan JT, Mansbach CM. COPII proteins are required for Golgi fusion but not for endoplasmic reticulum budding of the prechylomicron transport vesicle. J Cell Sci. 2003;116(2):415-27.

161. Kohan AB, Wang F, Lo CM, Liu M, Tso P. ApoA-IV: current and emerging roles in intestinal lipid metabolism, glucose homeostasis, and satiety. Am J Physiol Gastrointest Liver Physiol. 2015;308(6):G472-81. 
162. Mendivil CO, Zheng C, Furtado J, Lel J, Sacks FM. Metabolism of very-lowdensity lipoprotein and low-density lipoprotein containing apolipoprotein C-III and not other small apolipoproteins. Arterioscler Thromb Vasc Biol. 2010;30(2):239-45.

163. Huang Y, Mahley RW. Apolipoprotein E: structure and function in lipid metabolism, neurobiology, and Alzheimer's diseases. Neurobiol Dis. 2014; 72(Pt A):3-12

164. Dixon JB. Mechanisms of chylomicron uptake into lacteals. Ann N Y Acad Sci. 2010;1207(Suppl 1):E52-7.

165. Durand D, Bauchart D, Laplaud PM, Lefaivre J, Chapman MJ. Importance of the portal venous pathway to the transport of intestinal triglyceride-rich lipoproteins in the preruminant calf. Reprod Nutr Dev. 1990;(Suppl 2):228s.

166. Heath TJ, Morris B. The absorption of fat in sheep and lambs. Q J Exp Physiol Cogn Med Sci. 1962;47:157-69.

167. Aikman PC, Reynolds CK, Beever DE. Diet digestibility, rate of passage, and eating and rumination behavior of Jersey and Holstein cows. J Dairy Sci. 2008;91(3):1103-14.

168. Busato S, Bionaz M: The interplay between non-esterified fatty acids and bovine peroxisome proliferator-activated receptors: results of a hybrid in vitro approach. J Animal Sci Biotechnol. 2020;11:91.

169. Bergman E, Havel R, Wolfe B, Bøhmer T. Quantitative studies of the metabolism of chylomicron triglycerides and cholesterol by liver and extrahepatic tissue of sheep and dogs. J Clin Invest. 1971;50:1831-9.

170. Zanoni P, Velagapudi S, Yalcinkaya M, Rohrer L, von Eckardstein A. Endocytosis of lipoproteins. Atherosclerosis. 2018;275:273-95.

171. Goldstein JL, Anderson RG, Brown MS. Receptor-mediated endocytosis and the cellular uptake of low density lipoprotein. Ciba Found Symp. 1982(92): 77-95.

172. Mead JR, Irvine SA, Ramji DP. Lipoprotein lipase: structure, function, regulation, and role in disease. J Mol Med (Berlin, Germany). 2002;80(12) 753-69.

173. Rhainds D, Brissette L. Low density lipoprotein uptake: holoparticle and cholesteryl ester selective uptake. Int J Biochemist Cell Biol. 1999;31(9):915-31.

174. Röhrl C, Stangl H. HDL endocytosis and resecretion. Biochimica Biophysica Acta. 2013;1831(11):1626-33.

175. Chen WJ, Goldstein JL, Brown MS. NPXY, a sequence often found in cytoplasmic tails, is required for coated pit-mediated internalization of the low density lipoprotein receptor. J Biol Chemist. 1990;265(6):3116-23.

176. Davis CG, Goldstein JL, Südhof TC, Anderson RGW, Russell DW, Brown MS. Acid-dependent ligand dissociation and recycling of LDL receptor mediated by growth factor homology region. Nature. 1987;326(6115):760-5.

177. Zambon A, Bertocco S, Vitturi N, Polentarutti V, Vianello D, Crepaldi G. Relevance of hepatic lipase to the metabolism of triacylglycerol-rich lipoproteins. Biochem Soc Transact. 2003;31(5):1070-4.

178. Casas-Godoy L, Gasteazoro F, Duquesne S, Bordes F, Marty A, Sandoval G. Lipases: An Overview. In: Lipases and Phospholipases: Methods and Protocols. Edited by Sandoval G. New York: Springer; 2018:3-38.

179. Zechner R, Zimmermann R, Eichmann TO, Kohlwein SD, Haemmerle G, Lass A, et al. FAT SIGNALS - lipases and lipolysis in lipid metabolism and signaling. Cell Metab. 2012;15(3):279-91

180. Griffon N, Budreck EC, Long CJ, Broedl UC, Marchadier DH, Glick JM, et al. Substrate specificity of lipoprotein lipase and endothelial lipase: studies of lid chimeras. J Lipid Res. 2006:47(8):1803-11.

181. Kobayashi J, Miyashita K, Nakajima K, Mabuchi H. Hepatic lipase: a comprehensive view of its role on plasma lipid and lipoprotein metabolism. J Atheros Thromb. 2015;22(10):1001-11.

182. Kheirolomoom A, Yoshida K-I, Katoh S, Sada E. Substrate specificity and positional preference of a lipoprotein lipase. J Ferment Bioeng. 1992;73(5): 403-4.

183. Zhao WS, Hu SL, Yu K, Wang H, Wang W, Loor J, et al. Lipoprotein lipase, tissue expression and effects on genes related to fatty acid synthesis in goat mammary epithelial cells. Int J Mol Sci. 2014;15(12):22757-71.

184. Semenkovich CF, Chen SH, Wims M, Luo CC, Li WH, Chan L. Lipoprotein lipase and hepatic lipase mRNA tissue specific expression, developmental regulation, and evolution. J Lipid Res. 1989;30(3):423-31.

185. Askew EW, Emery RS, Thomas JW. Lipoprotein lipase of the bovine mammary gland. J Dairy Sci. 1970;53(10):1415-23.

186. Liesman JS, Emery RS, Akers RM, Tucker HA. Mammary lipoprotein lipase in plasma of cows after parturition or prolactin infusion. Lipids. 1988;23(5):504-7.

187. Ling C, Svensson L, Odén B, Weijdegård B, Edén B, Edén S, et al. Identification of functional prolactin (PRL) receptor gene expression: PRL inhibits lipoprotein lipase activity in human white adipose tissue. J Clin Endocrinol Metab. 2003;88(4):1804-8.

188. Palmquist DL. Milk fat: origin of fatty acids and influence of nutritional factors thereon. In: Fox PF, McSweeney PLH. (eds) Advanced Dairy Chemistry Volume 2 Lipids. Boston: Springer; 2006. https://doi.org/10.1007/ 0-387-28813-9_2.

189. Zhang H, Ao C, Khas E, Dan N. Effects of isonitrogenous and isocaloric total mixed ration composed of forages with different quality on milk fatty acid composition and gene expression of mammary lipogenic enzymes in midlactating dairy cows. Anim Sci J. 2019;90(2):214-21.

190. Piperova LS, Teter BB, Bruckental I, Sampugna J, Mills SE, Yurawecz MP, et al. Mammary lipogenic enzyme activity, trans fatty acids and conjugated linoleic acids are altered in lactating dairy cows fed a milk fat-depressing diet. J Nutr. 2000;130(10):2568-74

191. Fougère $H$, Bernard L. Effect of diets supplemented with starch and corn oil, marine algae, or hydrogenated palm oil on mammary lipogenic gene expression in cows and goats: A comparative study. J Dairy Sci. 2019;102(1): 768-79.

192. Hocquette JF, Graulet B, Olivecrona T. Lipoprotein lipase activity and mRNA levels in bovine tissues. Comp Biochem Physiol B Biochem Mol Biol. 1998; 121(2):201-12.

193. Arndt L, Burkhardt R. Lipid metabolism: spotlight on modulators of lipoprotein lipase activity. Curr Opin Lipidol. 2018;29(2):164-5.

194. He PP, Jiang T, OuYang XP, Liang YQ, Zou JQ, Wang Y, et al. Lipoprotein lipase: biosynthesis, regulatory factors, and its role in atherosclerosis and other diseases. Clin Chim Acta. 2018;480:126-37.

195. Vargas-Bello-Perez E, Zhao W, Bionaz M, Luo J, Loor JJ. Nutrigenomic effect of sturated and unsaturated long chain fatty acids on lipid-related genes in goat mammary epithelial cells: what is the role of PPARgamma? Vet Sci. 2019;6(2):54

196. Harvatine KJ, Boisclair YR, Bauman DE. Time-dependent effect of trans-10,cis-12 conjugated linoleic acid on gene expression of lipogenic enzymes and regulators in mammary tissue of dairy cows. J Dairy Sci. 2018;101(8):7585-92.

197. Hussein M, Harvatine KH, Weerasinghe WM, Sinclair LA, Bauman DE. Conjugated linoleic acid-induced milk fat depression in lactating ewes is accompanied by reduced expression of mammary genes involved in lipid synthesis. J Dairy Sci. 2013;96(6):3825-34.

198. Harvatine KJ, Perfield JW, 2nd, Bauman DE: Expression of enzymes and key regulators of lipid synthesis is upregulated in adipose tissue during CLAinduced milk fat depression in dairy cows. J Nutr 2009, 139(5):849-854.

199. Liu C, Li L, Guo D, Lv Y, Zheng X, Mo Z, et al. Lipoprotein lipase transporter GPIHBP1 and triglyceride-rich lipoprotein metabolism. Clin Chim Acta. 2018; 487:33-40.

200. Birrane G, Beigneux AP, Dwyer B, Strack-Logue B, Kristensen KK, Francone OL, et al. Structure of the lipoprotein lipase-GPIHBP1 complex that mediates plasma triglyceride hydrolysis. Proc Natl Acad Sci U S A. 2019;116(5):1723-32.

201. Dijk W, PMM R, Oost L, Kersten S. Angiopoietin-like 4 promotes the intracellular cleavage of lipoprotein lipase by PCSK3/furin in adipocytes. J Biol Chem. 2018:293(36):14134-45.

202. Doolittle MH, Ehrhardt N, Peterfy M. Lipase maturation factor 1: structure and role in lipase folding and assembly. Curr Opin Lipidol. 2010;21(3):198-203.

203. Mamedova L, Robbins K, Johnson B, Bradford B. Tissue expression of angiopoietin-like protein 4 in cattle. J Anim Sci. 2009:88:124-30.

204. Yang J, Liu X, Wang D, Ning C, Wang H, Zhang Q, et al. Functional validation of GPIHBP1 and identification of a functional mutation in GPIHBP1 for milk fat traits in dairy cattle. Sci Rep. 2017;7(1):8546.

205. Nykjaer A, Willnow TE. The low-density lipoprotein receptor gene family: a cellular Swiss army knife? Trends Cell Biol. 2002;12(6):273-80.

206. Strickland DK, Gonias SL, Argraves WS. Diverse roles for the LDL receptor family. Trends Endocrinol Metab. 2002;13(2):66-74.

207. Loeffler B, Heeren J, Blaeser M, Radner H, Kayser D, Aydin B, et al. Lipoprotein lipase-facilitated uptake of LDL is mediated by the LDL receptor. J Lipid Res. 2007:48(2):288-98.

208. Tacken PJ, Hofker MH, Havekes LM, van Dijk KW. Living up to a name: the role of the VLDL receptor in lipid metabolism. Curr Opin Lipid. 2001;12(3):275-9.

209. Uchide T, Onda K, Bonkobara M, Thongsong B, Matsuki N, Inaba M, et al. Utilization of intestinal triglyceride-rich lipoproteins in mammary gland of cows. J Vet Med Sci. 1999;61(10):1143-6.

210. Cordle SR, Yeaman SJ, Clegg RA. Salt-resistant (hepatic) lipase: Evidence for its presence in bovine liver and adrenal cortex. Biochim Biophys Acta. 1983; 753(2):213-9. 
211. Small CA, Yeaman SJ, West DW, Clegg RA. Cholesterol ester hydrolysis and hormone-sensitive lipase in lactating rat mammary tissue. Biochim Biophys Acta. 1991;1082(3):251-4.

212. Yonezawa T, Haga S, Kobayashi Y, Katoh K, Obara Y. Regulation of hormone-sensitive lipase expression by saturated fatty acids and hormones in bovine mammary epithelial cells. Biochem Biophys Res Commun. 2008;376(1):36-9.

213. Goldberg IJ, Eckel RH, Abumrad NA. Regulation of fatty acid uptake into tissues: lipoprotein lipase- and CD36-mediated pathways. J Lipid Res. 2009; 50(Suppl):S86-90.

214. Frayn KN. Non-esterified fatty acid metabolism and postprandial lipaemia. Atherosclerosis. 1998;141:S41-6.

215. Vorum H, Brodersen R, Kragh-Hansen U, Pedersen AO. Solubility of longchain fatty acids in phosphate buffer at pH 7.4. Biochim Biophys Acta. 1992; 1126(2):135-42.

216. van der Vusse GJ. Albumin as fatty acid transporter. Drug Metab Pharma. 2009;24(4):300-7.

217. Schnitzer JE, Oh P. Albondin-mediated capillary permeability to albumin Differential role of receptors in endothelial transcytosis and endocytosis of native and modified albumins. J Biol Chem. 1994;269(8):6072-82.

218. Merlot AM, Kalinowski DS, Richardson DR. Unraveling the mysteries of serum albumin-more than just a serum protein. Front Physiol. 2014;5:299.

219. Glatz JF, Luiken JJ, Bonen A. Involvement of membrane-associated proteins in the acute regulation of cellular fatty acid uptake. J Mol Neurosci. 2001; 16(2-3):123-32.

220. Trigatti BL, Gerber GE. A direct role for serum albumin in the cellular uptake of long-chain fatty acids. Biochemical Journal. 1995;308(Pt 1):155-9.

221. Frei E. Albumin binding ligands and albumin conjugate uptake by cancer cells. Diabetol Metab Syndr. 2011;3(1):11.

222. Beisiegel U. Receptors for triglyceride-rich lipoproteins and their role in lipoprotein metabolism. Curr Opin Lipid. 1995;6(3):117-22.

223. Drackley JK. ADSA Foundation Scholar Award. Biology of dairy cows during the transition period: the final frontier? J Dairy Sci. 1999;82(11):2259-73.

224. Yamdagni S, Schultz LH. Metabolism of $1-{ }^{14} \mathrm{C}$ palmitic acid in goats in various metabolic states. J Dairy Sci. 1969;52(8):1278-88.

225. Nakamura MT, Yudell BE, Loor JJ. Regulation of energy metabolism by longchain fatty acids. Prog Lipid Res. 2014;53:124-44.

226. Longo N, Frigeni M, Pasquali M. Carnitine transport and fatty acid oxidation. Biochim Biophys Acta. 2016;1863(10):2422-35.

227. Longo N, Amat di San Filippo C, Pasquali M. Disorders of carnitine transport and the carnitine cycle. Am J Med Genet C Semin Med Genet. 2006;142C(2): 77-85.

228. Bonnefont J-P, Djouadi F, Prip-Buus C, Gobin S, Munnich A, Bastin J. Carnitine palmitoyltransferases 1 and 2: biochemical, molecular and medical aspects. Mol Aspects Med. 2004;25(5):495-520.

229. Alves-Bezerra M, Cohen DE. Triglyceride metabolism in the liver. Compr Physiol. 2017;8(1):1-8.

230. White DA, Bennett AJ, Billett MA, Salter AM. The assembly of triacylglycerolrich lipoproteins: an essential role for the microsomal triacylglycerol transfer protein. Br J Nutr. 1998;80(3):219-29.

231. Wurie HR, Buckett L, Zammit VA. Diacylglycerol acyltransferase 2 acts upstream of diacylglycerol acyltransferase 1 and utilizes nascent diglycerides and de novo synthesized fatty acids in HepG2 cells. FEBS J. 2012;279(17): 3033-47.

232. Grummer RR. Impact of changes in organic nutrient metabolism on feeding the transition dairy cow. J Anim Sci. 1995;73(9):2820-33.

233. Kleppe BB, Aiello RJ, Grummer RR, Armentano LE. Triglyceride accumulation and very low density lipoprotein secretion by rat and goat hepatocytes in vitro. J Dairy Sci. 1988;71(7):1813-22.

234. Gruffat D, Durand D, Graulet B, Bauchart D. Regulation of VLDL synthesis and secretion in the liver. Reprod Nutr Dev. 1996;36(4):375-89.

235. Bauchart D, Gruffat D, Durand D. Lipid absorption and hepatic metabolism in ruminants. Proceed Nutr Soc. 1996;55(1B):39-47.

236. Julius $U$. Influence of plasma free fatty acids on lipoprotein synthesis and diabetic dyslipidemia. Exp Clin Endocrinol Diab. 2003;111(5):246-50.

237. Vernon RG. Lipid metabolism during lactation: a review of adipose tissueliver interactions and the development of fatty liver. J Dairy Res. 2005;72(4): 460-9.

238. Bobe G, Young JW, Beitz DC. Invited review: pathology, etiology, prevention, and treatment of fatty liver in dairy cows. J Dairy Sci. 2004; 87(10):3105-24.
239. Angeli E, Rodríguez FM, Rey F, Santiago G, Matiller V, Ortega HH, et al. Liver fatty acid metabolism associations with reproductive performance of dairy cattle. Anim Reprod Sci. 2019;208:106104.

240. Zerbe H, Schneider N, Leibold W, Wensing T, Kruip TA, Schuberth HJ. Altered functional and immunophenotypical properties of neutrophilic granulocytes in postpartum cows associated with fatty liver. Theriogenology. 2000;54(5):771-86.

241. Khan MJ, Jacometo CB, Riboni MV, Trevisi E, Graugnard DE, Corrêa MN, et al Stress and inflammatory gene networks in bovine liver are altered by plane of dietary energy during late pregnancy. Funct Integ Genomics. 2015;15(5): 563-76

242. Kliewer SA, Umesono K, Noonan DJ, Heyman RA, Evans RM. Convergence of 9-cis retinoic acid and peroxisome proliferator signalling pathways through heterodimer formation of their receptors. Nature. 1992;358(6389):771-4.

243. Kersten S. Integrated physiology and systems biology of PPARalpha. Mol Metab. 2014;3(4):354-71.

244. Dubois V, Eeckhoute J, Lefebvre P, Staels B. Distinct but complementary contributions of PPAR isotypes to energy homeostasis. J Clin Invest. 2017; 127(4):1202-14.

245. Liu Y, Colby JK, Zuo X, Jaoude J, Wei D, Shureiqi I. The role of PPAR-delta in metabolism, inflammation, and cancer: many characters of a critical transcription factor. Int J Mol Sci. 2018;19(11).

246. Lohakare J, Osorio JS, Bionaz M. Peroxisome proliferator-activated receptor beta/delta does not regulate glucose uptake and lactose synthesis in bovine mammary epithelial cells cultivated in vitro. J Dairy Res. 2018;85(3): 295-302.

247. Shi HB, Zhang $\mathrm{CH}$, Zhao W, Luo J, Loor JJ. Peroxisome proliferator-activated receptor delta facilitates lipid secretion and catabolism of fatty acids in dairy goat mammary epithelial cells. J Dairy Sci. 2017;100(1):797-806.

248. Zhang MQ, Gao JL, Liao XD, Huang TH, Zhang MN, Wang MQ, et al. miR454 regulates triglyceride synthesis in bovine mammary epithelial cells by targeting PPAR- $\gamma$. Gene. 2019;691:1-7.

249. Tang KQ, Wang YN, Zan LS, Yang WC. miR-27a controls triacylglycerol synthesis in bovine mammary epithelial cells by targeting peroxisome proliferator-activated receptor gamma. J Dairy Sci. 2017;100(5):4102-12.

250. Yang WC, Guo WL, Zan LS, Wang YN, Tang KQ. Bta-miR-130a regulates the biosynthesis of bovine milk fat by targeting peroxisome proliferatoractivated receptor gamma. J Anim Sci. 2017;95(7):2898-906.

251. Guo Z, Zhao K, Feng X, Yan D, Yao R, Chen Y, et al. mTORC2 Regulates lipogenic gene expression through PPARY to control lipid synthesis in bovine mammary epithelial cells. BioMed Res Int. 2019;2019:5196028.

252. Socha BM, Łada P, Szczepańska AA, Łupicka M, Korzekwa AJ. The influence of experimentally induced endometritis on the PPAR expression profile in the bovine endometrium. Theriogenology. 2018;122:74-83.

253. Xu D, He H, Jiang X, Hua R, Chen H, Yang L, et al. SIRT2 plays a novel role on progesterone, estradiol and testosterone synthesis via PPARs/LXRa pathways in bovine ovarian granular cells. J Steroid Biochem Mol Biol. 2019; 185:27-38.

254. Idrees $M, X u L$, El Sheikh M, Sidrat T, Song SH, Joo MD, et al. The PPAR 8 agonist GW501516 improves lipolytic/lipogenic balance through CPT1 and PEPCK during the development of pre-implantation bovine embryos. Int J Mol Sci. 2019;20(23):6066.

255. Szczepańska AA, Łupicka M, Socha BM, Korzekwa AJ. The influence of arachidonic acid metabolites on PPAR and RXR expression in bovine uterine cells. Gen Comp Endocrinol. 2018;262:27-35.

256. Baumgard LH, Sangster JK, Bauman DE. Milk fat synthesis in dairy cows is progressively reduced by increasing supplemental amounts of trans-10, cis12 conjugated linoleic acid (CLA). J Nutr. 2001;131(6):1764-9.

257. Shi H, Zhang T, Li C, Wang J, Huang J, Li Z. Trans-10,cis-12-conjugated linoleic acid affects expression of lipogenic genes in mammary glands of lactating dairy goats. J Agr Food Chem. 2017;65(43):9460-7.

258. Kadegowda AK, Khan MJ, Piperova LS, Teter BB, Rodriguez-Zas SL, Erdman RA, et al. Trans-10, cis 12-conjugated linoleic acid-induced milk fat depression is associated with inhibition of PPARgamma signaling and inflammation in murine mammary tissue. J Lipids. 2013;2013: 890343.

259. Vyas D, Teter BB, Delmonte P, Erdman RA. Rosiglitazone, a PPAR- $\gamma$ agonist, fails to attenuate CLA-induced milk fat depression and hepatic lipid accumulation in lactating mice. Lipids. 2014;49(7):641-53.

260. Sandri EC, Camêra M, Sandri EM, Harvatine KJ, de Oliveira DE. Peroxisome proliferator-activated receptor gamma (PPARY) agonist fails to overcome 
trans-10, cis-12 conjugated linoleic acid (CLA) inhibition of milk fat in dairy sheep. Animal. 2018;12(7):1405-12.

261. Rosa F, Moridi M, Osorio JS, Lohakare J, Trevisi E, Filley S, et al. 2,4Thiazolidinedione in well-fed lactating dairy goats: II. response to intramammary infection. Vet Sci. 2019;6(2).

262. Jaaf S, Rosa F, Moridi M, Osorio JS, Lohakare J, Trevisi E, et al. 2,4Thiazolidinedione in well-fed lactating dairy goats: I. effect on adiposity and milk fat synthesis. Vet Sci. 2019;6(2):45.

263. Osorio JS, Lohakare J, Bionaz M. Biosynthesis of milk fat, protein, and lactose: roles of transcriptional and posttranscriptional regulation. Physioll Genom. 2016:48(4):231-56

264. Cappon GD, Liu RCM, Frame SR, Hurtt ME. Effects of the rat hepatic peroxisome proliferator, Wyeth 14,643 , on the lactating goat. Drug Chem Toxicol. 2002;25(3):255-66.

265. Teixeira PD, Oliveira DM, Chizzotti ML, Chalfun-Junior A, Coelho TC, Gionbelli $M$, et al. Subspecies and diet affect the expression of genes involved in lipid metabolism and chemical composition of muscle in beef cattle. Meat Sci. 2017;133:110-8.

266. Kobayashi K, Matsuyama W, Arai Y, Koizumi S, Shimizu T, Tomioka R, et al. Boiogito increases the metabolism of fatty acids in proximal tubular cells through peroxisome proliferators-activated receptor (PPAR) a agonistic activity. Biol Pharm Bull. 2016;39(1):143-7.

267. Zhong X, Liu H. Honokiol attenuates diet-induced non-alcoholic steatohepatitis by regulating macrophage polarization through activating peroxisome proliferator-activated receptor ү. J Gastroenterol Hepatol. 2018; 33(2):524-32.

268. Liu X, Li G, Zhu H, Huang L, Liu Y, Ma C, et al. Beneficial effect of berberine on hepatic insulin resistance in diabetic hamsters possibly involves in SREBPS, LXRa and PPARa transcriptional programs. Endocrine J. 2010;57(10): 881-93.

269. O'Sullivan SE. An update on PPAR activation by cannabinoids. Br J Pharmacol. 2016;173(12):1899-910.

270. Shimano H. Sterol regulatory element-binding proteins (SREBPs): transcriptional regulators of lipid synthetic genes. Prog Lipid Res. 2001;40(6): 439-52.

271. Li N, Zhao F, Wei C, Liang M, Zhang N, Wang C, et al. Function of SREBP1 in the milk fat synthesis of dairy cow mammary epithelial cells. Int J Mol Sci. 2014;15(9):16998-7013.

272. Carcangiu V, Mura MC, Daga C, Luridiana S, Bodano S, Sanna GA, et al. Association between SREBP-1 gene expression in mammary gland and milk fat yield in Sarda breed sheep. Meta Gene. 2013;1:43-9.

273. Xu HF, Luo J, Zhao WS, Yang YC, Tian HB, Shi HB, et al. Overexpression of SREBP1 (sterol regulatory element binding protein 1) promotes de novo fatty acid synthesis and triacylglycerol accumulation in goat mammary epithelial cells. J Dairy Sci. 2016;99(1):783-95.

274. Han LQ, Gao TY, Yang GY, Loor JJ. Overexpression of SREBF chaperone (SCAP) enhances nuclear SREBP1 translocation to upregulate fatty acid synthase (FASN) gene expression in bovine mammary epithelial cells. J Dairy Sci. 2018;101(7):6523-31.

275. Xu HF, Luo J, Wang HP, Wang H, Zhang TY, Tian HB, et al. Sterol regulatory element binding protein-1 (SREBP-1) c promoter: Characterization and transcriptional regulation by mature SREBP-1 and liver $X$ receptor $a$ in goat mammary epithelial cells. J Dairy Sci. 2016; 99(2):1595-604

276. Peterson TR, Sengupta SS, Harris TE, Carmack AE, Kang SA, Balderas E, et al. mTOR complex 1 regulates lipin 1 localization to control the SREBP pathway. Cell. 2011;146(3):408-20.

277. Qi H, Meng C, Jin X, Li X, Li P, Gao X. Methionine promotes milk protein and fat synthesis and cell proliferation via the SNAT2-PI3K signaling pathway in bovine mammary epithelial cells. J Agricult Food Chem. 2018; 66(42):11027-33.

278. Li P, Yu M, Zhou C, Qi H, Wen X, Hou X, et al. FABP5 is a critical regulator of methionine- and estrogen-induced SREBP-1c gene expression in bovine mammary epithelial cells. J Cell Physiol. 2018;234(1):537-49.

279. Wen G, Pachner LI, Gessner DK, Eder K, Ringseis R. Sterol regulatory element-binding proteins are regulators of the sodium/iodide symporter in mammary epithelial cells. J Dairy Sci. 2016;99(11):9211-26.

280. Li X, Li Y, Yang W, Xiao C, Fu S, Deng Q, et al. SREBP-1c overexpression induces triglycerides accumulation through increasing lipid synthesis and decreasing lipid oxidation and VLDL assembly in bovine hepatocytes. J Steroid Biochem Mol Biol. 2014;143:174-82.
281. Deng Q, Li X, Fu S, Yin L, Zhang Y, Wang T, et al. SREBP-1c gene silencing can decrease lipid deposits in bovine hepatocytes cultured in vitro. Cell Physiol Biochem. 2014;33(5):1568-78.

282. Watt AJ, Garrison WD, Duncan SA. HNF4: a central regulator of hepatocyte differentiation and function. Hepatology (Baltimore, Md). 2003;37(6):124953.

283. Helsen C, Claessens F. Looking at nuclear receptors from a new angle. Mol Cell Endocrinol. 2014;382(1):97-106

284. Babeu J-P, Boudreau F. Hepatocyte nuclear factor 4-alpha involvement in liver and intestinal inflammatory networks. World J Gastroenterol. 2014;20(1): $22-30$.

285. Li X, Shen J, Ran Z. Crosstalk between the gut and the liver via susceptibility loci: Novel advances in inflammatory bowel disease and autoimmune liver disease. Clin Immunol (Orlando, Fla). 2017;175:115-23.

286. Li J, Ning G, Duncan SA. Mammalian hepatocyte differentiation requires the transcription factor HNF-4a. Genes Dev. 2000;14(4):464-74.

287. Soutoglou E, Talianidis I. Coordination of PIC assembly and chromatin remodeling during differentiation-induced gene activation. Science. 2002; 295(5561):1901-4.

288. Chen L, Vasoya RP, Toke NH, Parthasarathy A, Luo S, Chiles E, et al. HNF4 regulates fatty acid oxidation and is required for renewal of intestinal stem cells in mice. Gastroenterology. 2020;158(4):985-99.

289. Giantin M, Küblbeck J, Zancanella V, Prantner V, Sansonetti F, Schoeniger A, et al. DNA elements for constitutive androstane receptor- and pregnane $X$ receptor-mediated regulation of bovine CYP3A28 gene. PloS One. 2019; 14(3):e0214338.

290. Yuan X, Ta TC, Lin M, Evans JR, Dong Y, Bolotin E, et al. Identification of an endogenous ligand bound to a native orphan nuclear receptor. PLoS One. 2009;4(5):e5609.

291. Dhe-Paganon S, Duda K, Iwamoto M, Chi Yl, Shoelson SE. Crystal structure of the HNF4a ligand binding domain in complex with endogenous fatty acid ligand. J Biol Chem. 2002;277(41):37973-6.

292. Apfel R, Benbrook D, Lernhardt E, Ortiz MA, Salbert G, Pfahl M. A novel orphan receptor specific for a subset of thyroid hormone-responsive elements and its interaction with the retinoid/thyroid hormone receptor subfamily. Mol Cell Biol. 1994;14(10):7025-35.

293. Bovenga F, Sabbà C, Moschetta A. Uncoupling nuclear receptor LXR and cholesterol metabolism in cancer. Cell Metab. 2015;21(4):517-26.

294. Janowski BA, Willy PJ, Devi TR, Falck JR, Mangelsdorf DJ. An oxysterol signalling pathway mediated by the nuclear receptor LXRa. Nature. 1996; 383(6602):728-31.

295. Mitro N, Mak PA, Vargas L, Godio C, Hampton E, Molteni V, et al. The nuclear receptor LXR is a glucose sensor. Nature. 2007;445(7124):219-23.

296. Baranowski M. Biological role of liver X receptors. J Physiol Pharmacol. 2008; 59(Suppl 7):31-55.

297. Repa JJ, Berge KE, Pomajzl C, Richardson JA, Hobbs H, Mangelsdorf DJ. Regulation of ATP-binding cassette sterol transporters ABCG5 and ABCG8 by the liver $X$ receptors $a$ and $\beta$. J Biol Chem. 2002;277(21):18793-800.

298. Repa JJ, Liang G, Ou J, Bashmakov Y, Lobaccaro JMA, Shimomura I, et al. Regulation of mouse sterol regulatory element-binding protein-1c gene (SREBP-1c) by oxysterol receptors, LXRa and LXRß. Genes Dev. 2000;14(22): 2819-30.

299. Joseph SB, Laffitte BA, Patel PH, Watson MA, Matsukuma KE, Walczak R, et al. Direct and indirect mechanisms for regulation of fatty acid synthase gene expression by liver $X$ receptors. J Biol Chem. 2002;277(13):11019-25.

300. Duval C, Touche V, Tailleux A, Fruchart JC, Fievet C, Clavey V, et al. Niemann-Pick C1 like 1 gene expression is down-regulated by LXR activators in the intestine. Biochem Biophys Res Commun. 2006;340(4): 1259-63.

301. Shi HB, Zhang CH, Xu ZA, Xu XF, Lv ZB, Luo J, Loor JJ. Nuclear receptor subfamily 1 group $\mathrm{H}$ member 2 ( $(\mathrm{XXRB})$ is the predominant liver $X$ receptor subtype regulating transcription of 2 major lipogenic genes in goat primary mammary epithelial cells. J Dairy Sci. 2017;100(8):6743-52.

302. Yao DW, Luo J, He QY, Xu HF, Li J, Shi HB, et al. Liver X receptor alpha promotes the synthesis of monounsaturated fatty acids in goat mammary epithelial cells via the control of stearoyl-coenzyme A desaturase 1 in an SREBP-1-dependent manner. J Dairy Sci. 2016;99(8): 6391-402.

303. Ting TC, Miyazaki-Anzai S, Masuda M, Levi M, Demer LL, Tintut Y, et al. Increased lipogenesis and stearate accelerate vascular calcification in calcifying vascular cells. J Biol Chem. 2011;286(27):23938-49. 
304. Do DN, Schenkel FS, Miglior F, Zhao X, Ibeagha-Awemu EM. Genome wide association study identifies novel potential candidate genes for bovine milk cholesterol content. Sci Rep. 2018;8(1):13239.

305. Milligan G, Shimpukade B, Ulven T, Hudson BD. Complex pharmacology of free fatty acid receptors. Chem Rev. 2017;117(1):67-110.

306. Miyamoto J, Hasegawa S, Kasubuchi M, Ichimura A, Nakajima A, Kimura I. Nutritional signaling via free fatty acid receptors. Int J Mol Sci. 2016;17(4):450.

307. Alarcon P, Manosalva C, Carretta MD, Hidalgo Al, Figueroa CD, Taubert A, et al. Fatty and hydroxycarboxylic acid receptors: the missing link of immune response and metabolism in cattle. Vet Immunol Immunopathol. 2018;201:77-87

308. Olmo I, Teuber S, Larrazabal C, Alarcon P, Raipane F, Burgos RA, et al. Docosahexaenoic acid and TUG-891 activate free fatty acid-4 receptor in bovine neutrophils. Vet Immunol Immunopathol. 2019;209:53-60.

309. Valenzuela P, Teuber S, Manosalva C, Alarcon P, Figueroa CD, Ratto M, et al. Functional expression of the free fatty acids receptor-1 and -4 (FFA1/GPR40 and FFA4/GPR120) in bovine endometrial cells. Vet Res Commun. 2019; 43(3):179-86.

310. Maillard V, Desmarchais A, Durcin M, Uzbekova S, Elis S. Docosahexaenoic acid (DHA) effects on proliferation and steroidogenesis of bovine granulosa cells. Reprod Biol Endocrinol. 2018;16(1):40.

311. Aguinaga Casanas MA, Schaff CT, Albrecht E, Hammon HM, Kuhla B, Rontgen $\mathrm{M}$, et al. Short communication: Free fatty acid receptors FFAR1 and FFAR2 during the peripartal period in liver of dairy cows grouped by their postpartum plasma beta-hydroxybutyrate concentrations. J Dairy Sci. 2017; 100(4):3287-92.

312. Månsson HL. Fatty acids in bovine milk fat. Food Nutr Res. 2008:52.

313. Liu N, Pustjens AM, Erasmus SW, Yang Y, Hettinga K, van Ruth SM. Dairy farming system markers: The correlation of forage and milk fatty acid profiles from organic, pasture and conventional systems in the Netherlands. Food Chem. 2020;314:126153.

314. Walter L, Shrestha P, Fry R, Leury BJ, Logan A. Lipid metabolic differences in cows producing small or large milk fat globules: Fatty acid origin and degree of saturation. J Dairy Sci. 2020;103(2):1920-30.

315. Moate PJ, Chalupa W, Boston RC, Lean IJ. Milk fatty acids. I. Variation in the concentration of individual fatty acids in bovine milk. J Dairy Sci. 2007; 90(10):4730-9.

316. Vargas-Bello-Pérez E, Toro-Mujica P, Enriquez-Hidalgo D, Fellenberg MA, Gómez-Cortés P. Discrimination between retail bovine milks with different fat contents using chemometrics and fatty acid profiling. J Dairy Sci. 2017; 100(6):4253-7.

317. Weisbjerg MR, Wiking L, Kristensen NB, Lund P. Effects of supplemental dietary fatty acids on milk yield and fatty acid composition in high and medium yielding cows. J Dairy Res. 2008;75(2):142-52.

318. Rego OA, Rosa HJD, Portugal P, Cordeiro R, Borba AES, Vouzela CM, et al. Influence of dietary fish oil on conjugated linoleic acid, omega-3 and other fatty acids in milk fat from grazing dairy cows. Livestock Prod Sci. 2005; 95(1-2):27-33.

319. Vargas-Bello-Perez E, Cancino-Padilla N, Geldsetzer-Mendoza C, Vyhmeister $\mathrm{S}$, Morales MS, Leskinen $\mathrm{H}$, et al. Effect of feeding cows with unsaturated fatty acid sources on milk production, milk composition, milk fatty acid profile, and physicochemical and sensory characteristics of ice cream. Animals. 2019;9(8):568.

320. Vargas-Bello-Pérez E, Geldsetzer-Mendoza C, Morales MS, Toro-Mujica P, Fellenberg MA, Ibáñez RA, et al. Effect of olive oil in dairy cow diets on the fatty acid profile and sensory characteristics of cheese. Int Dairy J. 2018;85: 8-15.

321. Vargas-Bello-Perez E, Fehrmann-Cartes K, Iniguez-Gonzalez G, Toro-Mujica P, Garnsworthy PC. Short communication: Chemical composition, fatty acid composition, and sensory characteristics of Chanco cheese from dairy cows supplemented with soybean and hydrogenated vegetable oils. J Dairy Sci. 2015;98(1):111-7.

322. Vargas-Bello-Pérez E, Îniguez-González G, Fehrmann-Cartes K, Toro-Mujica P, Garnsworthy PC. Influence of fish oil alone or in combination with hydrogenated palm oil on sensory characteristics and fatty acid composition of bovine cheese. Anim Feed Sci Technol. 2015;205:60-8

323. Kliem KE, Humphries DJ, Kirton P, Givens DI, Reynolds CK. Differential effects of oilseed supplements on methane production and milk fatty acid concentrations in dairy cows. Animal. 2019;13(2):309-17.

324. Muñoz C, Sánchez R, Peralta AMT, Espíndola S, Yan T, Morales R, et al. Effects of feeding unprocessed oilseeds on methane emission, nitrogen utilization efficiency and milk fatty acid profile of lactating dairy cows. Anim Feed Sci Technol. 2019;249:18-30.

325. Marques JA, Del Valle TA, Ghizzi LG, Zilio EMC, Gheller LS, Nunes AT, et al. Increasing dietary levels of docosahexaenoic acid-rich microalgae: Ruminal fermentation, animal performance, and milk fatty acid profile of midlactating dairy cows. J Dairy Sci. 2019;102(6):5054-65.

326. Pi Y, Ma L, Pierce KM, Wang HR, Xu JC, Bu DP. Rubber seed oil and flaxseed oil supplementation alter digestion, ruminal fermentation and rumen fatty acid profile of dairy cows. Animal. 2019;13(12):2811-20.

327. de Souza J, Lock AL. Effects of timing of palmitic acid supplementation on production responses of early-lactation dairy cows. J Dairy Sci. 2019;102(1):260-73.

328. Bougouin A, Martin C, Doreau M, Ferlay A. Effects of starch-rich or lipidsupplemented diets that induce milk fat depression on rumen biohydrogenation of fatty acids and methanogenesis in lactating dairy cows. Animal. 2019;13(7):1421-31.

329. Western MM, de Souza J, Lock AL. Effects of commercially available palmitic and stearic acid supplements on nutrient digestibility and production responses of lactating dairy cows. J Dairy Sci. 2020;103(6):5131-42.

330. Rico DE, Ying Y, Harvatine KJ. Effect of a high-palmitic acid fat supplement on milk production and apparent total-tract digestibility in high- and lowmilk yield dairy cows. J Dairy Sci. 2014;97(6):3739-51.

331. Chamberlain MB, DePeters EJ. Impacts of feeding lipid supplements high in palmitic acid or stearic acid on performance of lactating dairy cows. J Appl Anim Res. 2017;45(1):126-35.

332. Bu DP, Wang JQ, Dhiman TR, Liu SJ. Effectiveness of oils rich in linoleic and linolenic acids to enhance conjugated linoleic acid in milk from dairy cows. J Dairy Sci. 2007;90(2):998-1007.

333. Huang Y, Schoonmaker JP, Bradford BJ, Beitz DC. Response of milk fatty acid composition to dietary supplementation of soy oil, conjugated linoleic acid, or both. J Dairy Sci. 2008;91(1):260-70.

334. Flowers G, Ibrahim SA, AbuGhazaleh AA. Milk fatty acid composition of grazing dairy cows when supplemented with linseed oil. J Dairy Sci. 2008; 91(2):722-30.

335. Ueda K, Ferlay A, Chabrot J, Loor JJ, Chilliard Y, Doreau M. Effect of linseed oil supplementation on ruminal digestion in dairy cows fed diets with different forage:concentrate ratios. J Dairy Sci. 2003;86(12):3999-4007.

336. Jenkins TC, Harvatine KJ. Lipid feeding and milk fat depression. Vet Clin North Am Food Anim Pract. 2014;30(3):623-42.

337. Vargas-Bello-Pérez E, Garnsworthy PC. Trans fatty acids and their role in the milk of dairy cows. Cien Invest Agraria. 2013;40:449-73.

338. Allen MS. Effects of diet on short-term regulation of feed intake by lactating dairy cattle. J Dairy Sci. 2000;83(7):1598-624.

339. Mozaffarian D. Dietary and policy priorities to reduce the global crises of obesity and diabetes. Nat Food. 2020;1(1):38-50.

340. Chowdhury R, Warnakula S, Kunutsor S, Crowe F, Ward HA, Johnson L, et al. Association of dietary, circulating, and supplement fatty acids with coronary risk: a systematic review and meta-analysis. Ann Intern Med. 2014;160(6):398.

341. Glasser F, Ferlay A, Chilliard Y. Oilseed lipid supplements and fatty acid composition of cow milk: a meta-analysis. J Dairy Sci. 2008;91(12):4687-703.

342. Vargas-Bello-Pérez E, Cancino-Padilla N, Romero J, Garnsworthy PC. Quantitative analysis of ruminal bacterial populations involved in lipid metabolism in dairy cows fed different vegetable oils. Animal. 2016;10(11):1821-8.

343. Buccioni A, Decandia M, Minieri S, Molle G, Cabiddu A. Lipid metabolism in the rumen: New insights on lipolysis and biohydrogenation with an emphasis on the role of endogenous plant factors. Anim Feed Sci Technol. 2012;174:1-2 1-25.

344. Rivero MJ, Anrique R. Milk fat depression syndrome and the particular case of grazing cows: A review. Acta Agricult Scand Sect A. 2015;65(1):42-54.

345. Lee $M$, Tweed J, Minchin F, Winters A. Red clover polyphenol oxidase: Activation, activity and efficacy under grazing. Anim feed Sci Technol. 2009;149(3-4):250-64.

346. Thatcher WW, Bilby TR, Bartolome JA, Silvestre F, Staples CR, Santos JEP. Strategies for improving fertility in the modern dairy cow. Theriogenology. 2006;65(1):30-44.

347. Fahey J, Mee JF, O'Callaghan D, Murphy JJ. Effect of calcium salts of fatty acids and calcium salt of methionine hydroxy analogue on reproductive responses and milk production in Holstein-Friesian cows. Anim Sci. 2002;74:145-54.

348. Thomas MG, Bao B, Williams GL. Dietary fats varying in their fatty acid composition differentially influence follicular growth in cows fed isoenergetic diets. J Anim Sci. 1997;75(9):2512-9.

349. Staples CR, Burke JM, Thatcher $\mathrm{WW}$. Influence of supplemental fats on reproductive tissues and performance of lactating cows. J Dairy Sci. 1998;81(3):856-71. 
350. Cerri RLA, Santos JEP, Juchem SO, Galvão KN, Chebel RC. Timed artificial insemination with estradiol cypionate or insemination at estrus in highproducing dairy cows. J Dairy Sci. 2004;87(11):3704-15.

351. Santos JEP, Bilby TR, Thatcher WW, Staples CR, Silvestre FT. Long chain fatty acids of diet as factors influencing reproduction in cattle. Reprod Dom Anim. 2008:43:23-30

352. Milojevic V, Sinz S, Kreuzer M, Chiumia D, Marquardt S, Giller K. Partitioning of fatty acids into tissues and fluids from reproductive organs of ewes as affected by dietary phenolic extracts. Theriogenology. 2020;144:174-84.

353. Fouladi-Nashta AA, Gutierrez CG, Gong JG, Garnsworthy PC, Webb R. Impact of dietary fatty acids on oocyte quality and development in lactating dairy cows. Biol Reprod. 2007;77(1):9-17.

354. Calder PC. Marine omega-3 fatty acids and inflammatory processes: Effects, mechanisms and clinical relevance. Biochim Biophys Acta. 2015; 1851(4):469-84

355. Wonnacott KE, Kwong WY, Hughes J, Salter AM, Lea RG, Garnsworthy PC, et al. Dietary omega-3 and -6 polyunsaturated fatty acids affect the composition and development of sheep granulosa cells, oocytes and embryos. Reproduction (Cambridge, England). 2010;139(1):57-69.

356. Silvestre FT, Carvalho TS, Francisco N, Santos JE, Staples CR, Jenkins TC, et al. Effects of differential supplementation of fatty acids during the peripartum and breeding periods of Holstein cows: I. Uterine and metabolic responses, reproduction, and lactation. J Dairy Sci. 2011;94(1):189-204.

357. Sinedino LD, Honda PM, Souza LR, Lock AL, Boland MP, Staples CR, et al. Effects of supplementation with docosahexaenoic acid on reproduction of dairy cows. Reproduction (Cambridge, England). 2017;153(5):707-23.

358. Zachut M, Arieli A, Moallem U. Incorporation of dietary n-3 fatty acids into ovarian compartments in dairy cows and the effects on hormonal and behavioral patterns around estrus. Reproduction (Cambridge, England). 2011;141(6):833-40.

359. Froment P. PPARs and RXRs in Male and Female Fertility and Reproduction. PPAR Res. 2008;2008:637490.

360. Minge CE, Robker RL, Norman RJ. PPAR gamma: coordinating metabolic and immune contributions to female fertility. PPAR Res. 2008;2008:243791.

361. Ribeiro ES. Symposium review: Lipids as regulators of conceptus development: Implications for metabolic regulation of reproduction in dairy cattle. J Dairy Sci. 2018;101(4):3630-41.

362. D'Occhio MJ, Baruselli PS, Campanile G. Influence of nutrition, body condition, and metabolic status on reproduction in female beef cattle: A review. Theriogenology. 2019;125:277-84.

363. Lolicato F, Brouwers JF, de Lest $\mathrm{CH}$, Wubbolts $\mathrm{R}$, Aardema $\mathrm{H}$, Priore $\mathrm{P}$, et al The cumulus cell layer protects the bovine maturing oocyte against fatty acid-induced lipotoxicity. Biol Reprod. 2015;92(1):16.

364. Yang $Y$, Pei $X$, Jin $Y$, Wang $Y$, Zhang $C$. The roles of endoplasmic reticulum stress response in female mammalian reproduction. Cell Tissue Res. 2016; 363(3):589-97.

365. Gentile CL, Frye MA, Pagliassotti MJ. Fatty acids and the endoplasmic reticulum in nonalcoholic fatty liver disease. Biofactors. 2011;37(1):8-16.

366. Zhu Y, Guan Y, Loor JJ, Sha X, Coleman DN, Zhang C, et al. Fatty acidinduced endoplasmic reticulum stress promoted lipid accumulation in calf hepatocytes, and endoplasmic reticulum stress existed in the liver of severe fatty liver cows. J Dairy Sci. 2019;102(8):7359-70.

367. Mattos R, Staples CR, Arteche A, Wiltbank MC, Diaz FJ, Jenkins TC, et al. The effects of feeding fish oil on uterine secretion of PGF2alpha, milk composition, and metabolic status of periparturient Holstein cows. J Dairy Sci. 2004;87(4):921-32.

368. Gulliver CE, Friend MA, King BJ, Clayton EH. The role of omega-3 polyunsaturated fatty acids in reproduction of sheep and cattle. Anim Reprod Sci. 2012;131(1-2):9-22

369. Mattos R, Staples CR, Williams J, Amorocho A, McGuire MA, Thatcher WW. Uterine, ovarian, and production responses of lactating dairy cows to increasing dietary concentrations of menhaden fish meal. J Dairy Sci. 2002:85(4):755-64.

370. Fuentes MC, Calsamiglia S, Sánchez C, González A, Newbold JR, Santos JEP, et al. Effect of extruded linseed on productive and reproductive performance of lactating dairy cows. Livestock Sci. 2008;113(2-3):144-54.

371. Petit HV, Germiquet C, Lebel D. Effect of feeding whole, unprocessed sunflower seeds and flaxseed on milk production, milk composition, and prostaglandin secretion in dairy cows. J Dairy Sci. 2004;87(11):3889-98.

372. Heravi Moussavi AR, Gilbert RO, Overton TR, Bauman DE, Butler WR. Effects of feeding fish meal and n-3 fatty acids on milk yield and metabolic responses in early lactating dairy cows. J Dairy Sci. 2007;90(1):136-44.
373. Petit HV, Twagiramungu $\mathrm{H}$. Conception rate and reproductive function of dairy cows fed different fat sources. Theriogenology. 2006;66(5):1316-24.

374. Mattos R, Staples CR, Thatcher WW. Effects of dietary fatty acids on reproduction in ruminants. Rev Reprod. 2000;5(1):38-45.

375. Ashworth CJ, Toma LM, Hunter MG. Nutritional effects on oocyte and embryo development in mammals: implications for reproductive efficiency and environmental sustainability. Phil Transact Royal Soc London B Biol Sci. 2009;364(1534):3351-61.

376. Oseikria M, Elis S, Maillard V, Corbin E, Uzbekova S. N-3 polyunsaturated fatty acid DHA during IVM affected oocyte developmental competence in cattle. Theriogenology. 2016;85(9):1625-34.

377. Vasconcelos JL, Sartori R, Oliveira HN, Guenther JG, Wiltbank MC. Reduction in size of the ovulatory follicle reduces subsequent luteal size and pregnancy rate. Theriogenology. 2001;56(2):307-14.

378. Ambrose DJ, Kastelic JP, Corbett R, Pitney PA, Petit HV, Small JA, et al. Lower pregnancy losses in lactating dairy cows fed a diet enriched in alphalinolenic acid. J Dairy Sci. 2006;89(8):3066-74.

379. Castaneda-Gutierrez E, Benefield BC, de Veth MJ, Santos NR, Gilbert RO, Butler WR, et al. Evaluation of the mechanism of action of conjugated linoleic acid isomers on reproduction in dairy cows. J Dairy Sci. 2007;90(9):4253-64.

380. Sharma A, Baddela VS, Roettgen V, Vernunft A, Viergutz T, Dannenberger D, et al. Effects of dietary fatty acids on bovine oocyte competence and granulosa cells. Front Endocrinol (Lausanne). 2020;11(87):87.

381. Roche JR, Bell AW, Overton TR, Loor JJ. Nutritional management of the transition cow in the 21 st century - a paradigm shift in thinking. Anim Prod Sci. 2013;53(9):1000-23.

382. Overton TR, Waldron MR. Nutritional management of transition dairy cows: strategies to optimize metabolic health. J Dairy Sci. 2004;87:E105-19.

383. Selberg KT, Lowe AC, Staples CR, Luchini ND, Badinga L. Production and metabolic responses of periparturient Holstein cows to dietary conjugated linoleic acid and trans-octadecenoic acids. J Dairy Sci. 2004;87(1):158-68.

384. Bernal-Santos G, Perfield JW, Barbano DM, Bauman DE, Overton TR. Production responses of dairy cows to dietary supplementation with conjugated linoleic acid (CLA) during the transition period and early lactation. J Dairy Sci. 2003;86(10):3218-28.

385. Bauman DE, Griinari JM. Nutritional regulation of milk fat synthesis. Annu Rev Nutr. 2003:23:203-27.

386. Kay JK, Roche JR, Moore CE, Baumgard LH. Effects of dietary conjugated linoleic acid on production and metabolic parameters in transition dairy cows grazing fresh pasture. J Dairy Res. 2006;73(3):367-77.

387. Petit HV, Benchaar C. Milk production, milk composition, blood composition, and conception rate of transition dairy cows fed different profiles of fatty acids. Can J Anim Sci. 2007;87(4):591-600.

388. Santschi DE, Wettstein HR, Leiber F, Witschi AKM, Kreuzer M. Colostrum and milk fatty acids of dairy cows as influenced by extruded linseed supplementation during the transition period. Can J Anim Sci. 2009:89(3):383-92.

389. Mashek DG, Grummer RR. Effects of long chain fatty acids on lipid and glucose metabolism in monolayer cultures of bovine hepatocytes. J Dairy Sci. 2003;86(7):2390-6.

390. Leiber F, Hochstrasser R, Wettstein HR, Kreuzer M. Feeding transition cows with oilseeds: Effects on fatty acid composition of adipose tissue, colostrum and milk. Livestock Sci. 2011;138:1-3):1-12.

391. Lessard M, Gagnon N, Godson DL, Petit HV. Influence of parturition and diets enriched in n-3 or n-6 polyunsaturated fatty acids on immune response of dairy cows during the transition period. J Dairy Sci. 2004;87(7):2197-210.

392. Calder PC, Yaqoob P, Thies F, Wallace FA, Miles EA. Fatty acids and lymphocyte functions. Br J Nutr. 2007:87(S1):S31-48.

Ready to submit your research? Choose BMC and benefit from:

- fast, convenient online submission

- thorough peer review by experienced researchers in your field

- rapid publication on acceptance

- support for research data, including large and complex data types

- gold Open Access which fosters wider collaboration and increased citations

- maximum visibility for your research: over $100 \mathrm{M}$ website views per year

At $\mathrm{BMC}$, research is always in progress.

Learn more biomedcentral.com/submissions 